\title{
Thermal Degradation of Cellulose Filaments and Nanocrystals
}

Francesco D’Acierno ${ }^{1,2}$, Wadood Y. Hamad ${ }^{3}$, Carl A. Michal*2,1, and Mark J. MacLachlan*1

${ }^{1}$ Department of Chemistry, The University of British Columbia, 2036 Main Mall, Vancouver, BC, V6T

1Z1, Canada ${ }^{2}$ Department of Physics and Astronomy, The University of British Columbia, 6224 Agricul-

tural Rd., Vancouver, BC, V6T 1Z1, Canada ${ }^{3}$ Transformation and Interfaces Group, Bioproducts Innovation Centre of Excellence, FPInnovations, 2665 East Mall, Vancouver, BC, V6T 1Z4, Canada.

\section{SUPPORTING INFORMATION}




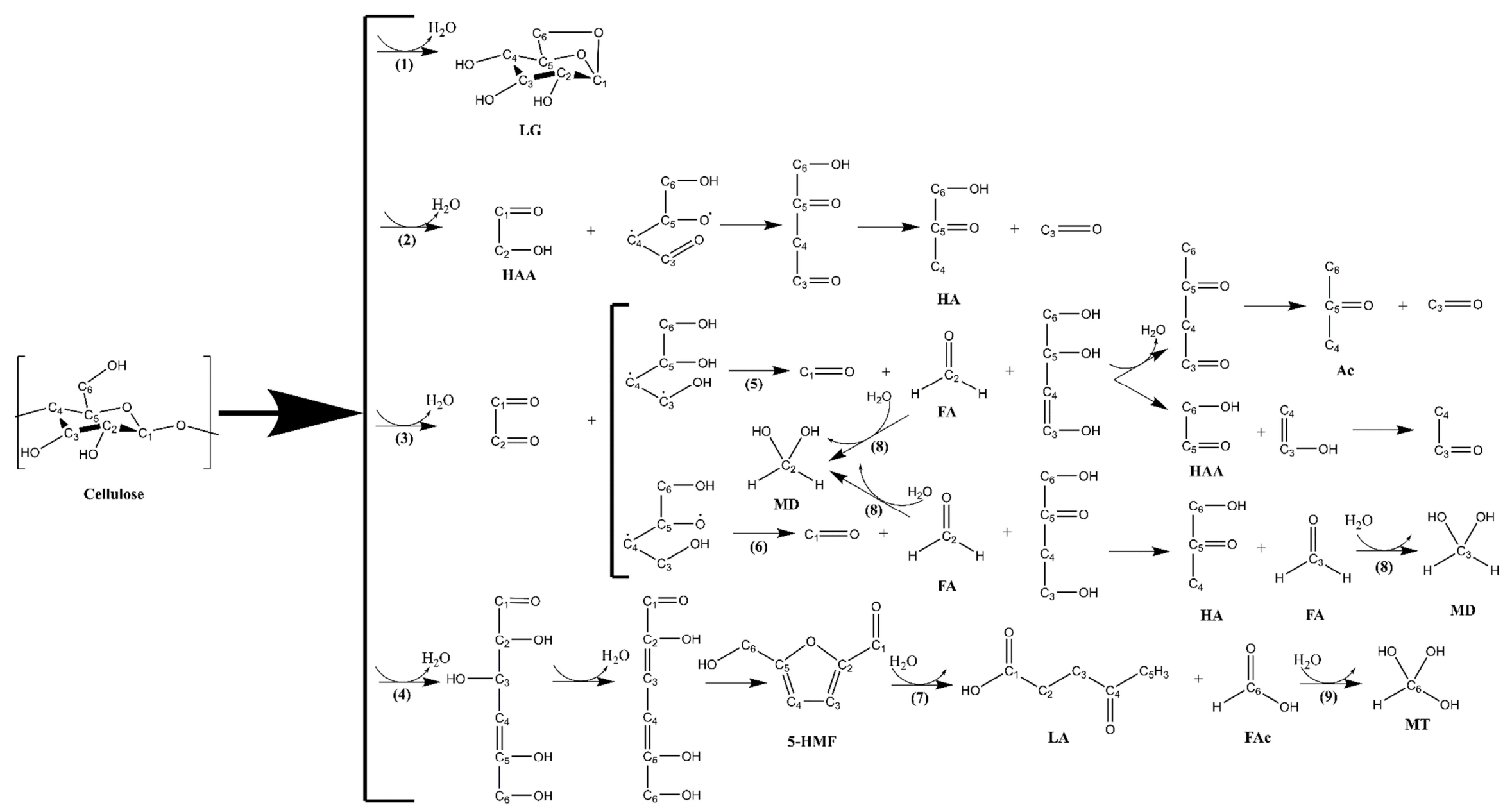

Scheme S1. Tar- and gas-forming reaction scheme of CF, CNC-H, and CNC-Na (direct conversion). 


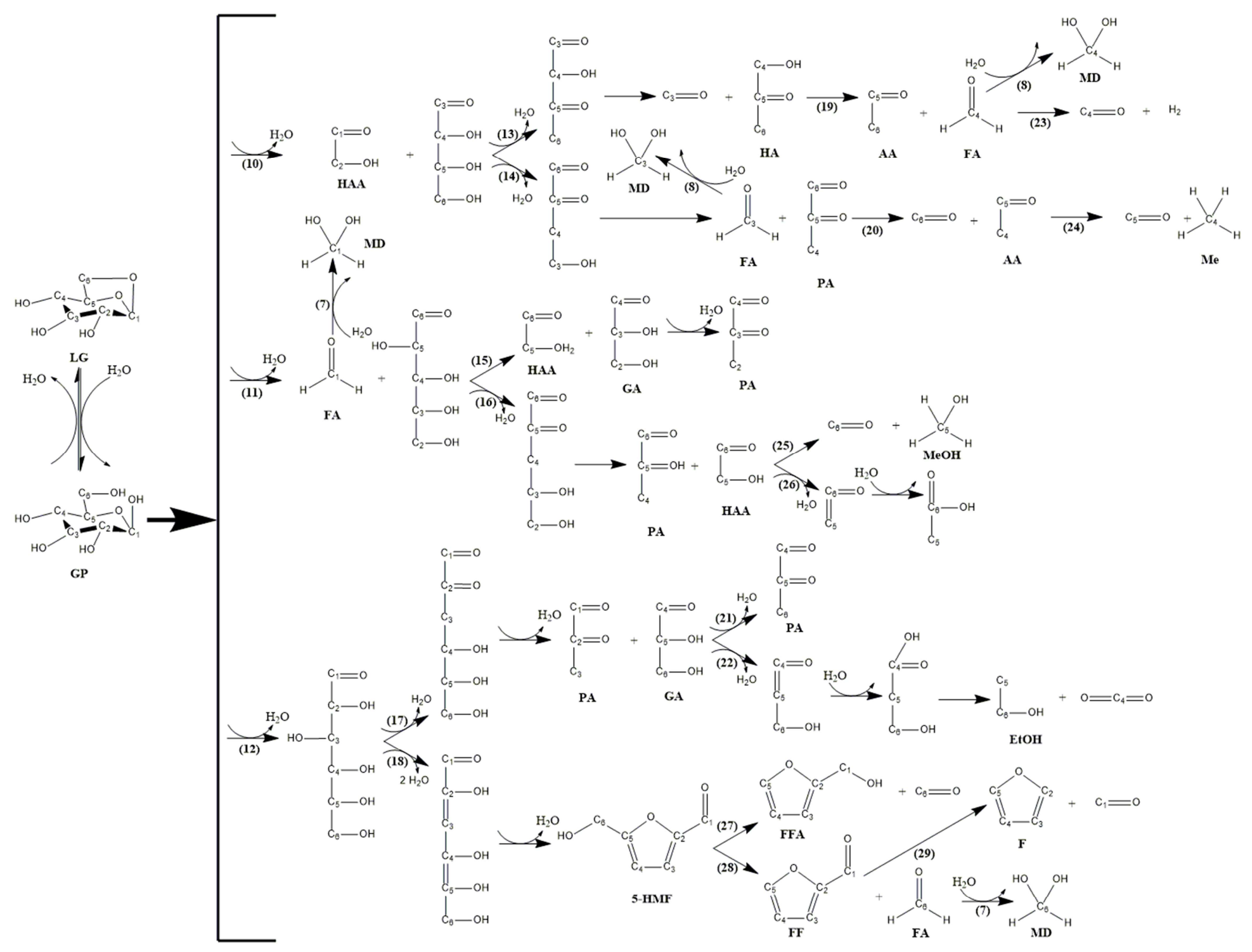

Scheme S2. Tar- and gas-forming reaction scheme of CF, CNC-H, and CNC-Na (secondary decomposition of levoglucosan). 


\section{Materials S1: Details of Preparations of CFs and CNCs}

Both CFs and CNCs were produced from bleached softwood pulp. CFs are extracted via mechanical refining (refining energy $=3500 \mathrm{kWhr}$ tonne $\mathrm{e}^{-1}$ ) and have a total surface carboxylate content of $0.035 \mathrm{mmol}$ $\mathrm{g}^{-1}$, measured via conductometric titration. CNCs are produced via sulfuric acid hydrolysis $\left(62 \mathrm{wt}^{\%} \%\right.$ $\left.\mathrm{H}_{2} \mathrm{SO}_{4}, 5^{\circ} \mathrm{C}, 20 \mathrm{~min}\right)$.

Table S1. Concentration, $\mathrm{pH}$, conductivity $(\sigma)$, and $\zeta$-potential of CNC suspensions prior to freeze drying.

\begin{tabular}{|l|l|l|l|l|}
\hline Samples & $\begin{array}{l}\text { Concentration } \\
(\mathrm{wt} \%)\end{array}$ & $\mathrm{pH}$ & $\sigma\left(\mu \mathrm{S} \mathrm{cm}^{-1}\right)$ & $\zeta$-potential $(\mathrm{mV})$ \\
\hline CNCs & 4.06 & $4.518^{\mathrm{a}}$ & 345.1 & $-33.8 \pm 0.3$ \\
\hline
\end{tabular}

${ }^{\mathrm{a}} \mathrm{pH}$ of CNC-H.

\section{Methods S1: Experimental details of activation energy calculations}

The conversion factor, $\alpha$, is defined as the ratio between the difference of initial mass and mass at time $t$ and the initial and final masses. The mean value from 61 conversion factors $(0.14-0.74)$ at a spacing of 0.01 for $\mathrm{CF}$, the mean value from 25 conversion factors $(0.09-0.33)$ at a spacing of 0.01 was used for $\mathrm{CNC}-\mathrm{H}$, and the mean value from 35 conversion factors $(0.10-0.44)$ at a spacing of 0.01 for $\mathrm{CNC}-\mathrm{Na}$. The activation energy was calculated as a function of $\alpha$, the heating rate, and the inverse of temperature, as described by Rowe et al. ${ }^{1}$

\section{Methods S2: Experimental details of degree of crystallinity calculations}

Degree of crystallinity values $\left(\mathrm{X}_{\mathrm{r}}\right)$ were determined from the diffractograms, using the Rietveld-Ruland method. The Rietveld refinement consists of a least-squares fitting procedure of the full diffraction pattern to simultaneously fit unit cell, crystal structure, peak profile parameters, background, and other parameters. ${ }^{2,3}$ The refinement was carried out in FullProf Suite ${ }^{4}$ using a modified LHMP1 Rietveld program with 
the cellulose I $\beta$ crystal structure including thermal parameters from Nishiyama et al. ${ }^{5}$ as input. The function used to represent the peak shape was the pseudo-Voigt function. The parameters refined to obtain the best fit for all samples were one scale factor, 10 Chebyshev background parameters, 2 pseudo-Voigt peak profile parameters, and 2 cell dimensions ( $\mathrm{a}$ and $\mathrm{b}$ ). The $2 \theta$ zero-shift was fixed to zero, the c-axis parameter to $10.35 \AA$ and the $\gamma$-angle to $96.5^{\circ}$. After the refinement, the sample crystallinity was retrieved using the Ruland method. ${ }^{6}$ Assuming that the intensity $\mathrm{I}(\mathrm{s})$ at a given angle $\theta$ is the sum of the crystalline $\mathrm{I}_{\mathrm{CR}}(\mathrm{s})$ contribution and the amorphous contribution $\mathrm{I}_{\mathrm{AM}}(\mathrm{s})$, represented by the fitted background, the degree of crystallinity $\left(\mathrm{X}_{\mathrm{r}}\right)$ was calculated from:

$$
\mathrm{Xr}=\frac{\int_{\mathrm{s}_{0}}^{\mathrm{s}_{\mathrm{p}}} \mathrm{I}_{\mathrm{CR}}(\mathrm{s}) \cdot \mathrm{s}^{2} \mathrm{ds}}{\int_{\mathrm{s}_{0}}^{\mathrm{s}_{\mathrm{p}}} \mathrm{I}(\mathrm{s}) \cdot \mathrm{s}^{2} \mathrm{ds}}
$$

where $s=2 \sin \theta / \lambda$ and the integration limits chosen in this work consider the part of the diffractogram containing visible crystalline intensity, i.e. $\mathrm{s}_{0}=0.11 \AA\left(2 \theta=10^{\circ}\right)$ and $\mathrm{s}_{\mathrm{p}}=0.99 \AA\left(2 \theta=50^{\circ}\right)$.

\section{Discussion S1: Interpretation of degradation stages in derivative thermogravimetric analysis (DTGA) curves of CF, CNC-H, and CNC-Na}

The first peak at low temperatures $\left(25-150^{\circ} \mathrm{C}\right)$ is unambiguously attributed to the evaporation of moisture. ${ }^{7,8}$ CNCs have a larger surface area than CFs, but the freeze-drying method, applied to CNCs, yields a reduced water adsorption in cellulose materials than air-drying, used for CFs. ${ }^{9}$ The combination of these effects results in approximately the same amount of moisture (3-4\%). The absence of any kind of acidic groups and the larger dimensions of CFs lead to a primary pyrolysis stage at high temperatures (325-400 $\left.{ }^{\circ} \mathrm{C}\right)$.

The second small peak at low $\mathrm{T}$ in $\mathrm{CNC}-\mathrm{H}\left(150-200^{\circ} \mathrm{C}\right)$ is attributed to acid-catalyzed dehydration, caused by the high concentration of unscreened sulfate half-ester groups on the surface. ${ }^{7,10}$ For clarity, it will be defined as the pre-pyrolysis stage. 
The third peak of CNC-H $\left(200-260{ }^{\circ} \mathrm{C}\right)$ and the second of $\mathrm{CNC}-\mathrm{Na}\left(300-350{ }^{\circ} \mathrm{C}\right)$ degradations represent the pyrolysis of sulfated and amorphous/surface regions catalyzed by the presence of sulfuric acid and accelerated by the nanoscopic dimensions of the material (primary pyrolysis). ${ }^{7}$ This degradation stage may also affect crystalline chains closer to the surface. The presence of $\mathrm{Na}^{+}$as counterion in $\mathrm{CNC}$ $\mathrm{Na}$ has the effect of preventing desulfation and limiting acid-catalyzed dehydration and depolymerization. Therefore, sodium ions simplify the degradation pattern of CNC-Na and leads to the disappearance of the pre-pyrolysis step. $^{11}$

In CNCs, a significant mass-loss stage is observed after the first pyrolysis process, at comparable temperatures for $\mathrm{CNC}-\mathrm{H}$ and $\mathrm{CNC}-\mathrm{Na}\left(300-375^{\circ} \mathrm{C}\right)$ and denoted as secondary pyrolysis. It can be assigned to the transglycosylation, and depolymerization of cellulose chains, contributing to the volatilization of a large fraction of by-products and the decomposition of the bulky crystalline regions of the nanomaterials. ${ }^{7}$ This process is not directly visible in the TGA/DTGA curves for the thermal degradation of CF because of the higher thermal stability of untreated cellulose chains. However, from the wider linewidth it can be inferred that this stage is occurring simultaneously with the first process, merging into a single pyrolysis step.

The final independent peak is attributed to the thermal auto-oxidation of cellulose, a flameless combustion of materials by reaction with oxygen, particularly evident under air atmosphere. ${ }^{12}$ Thus, this stage is denoted as a thermo-oxidative stage. The complex structure of the micro/nanomaterials induces most of the described reactions to onset before the previous stage is complete, making the profile analysis of overlapping DTGA peaks more convoluted. 


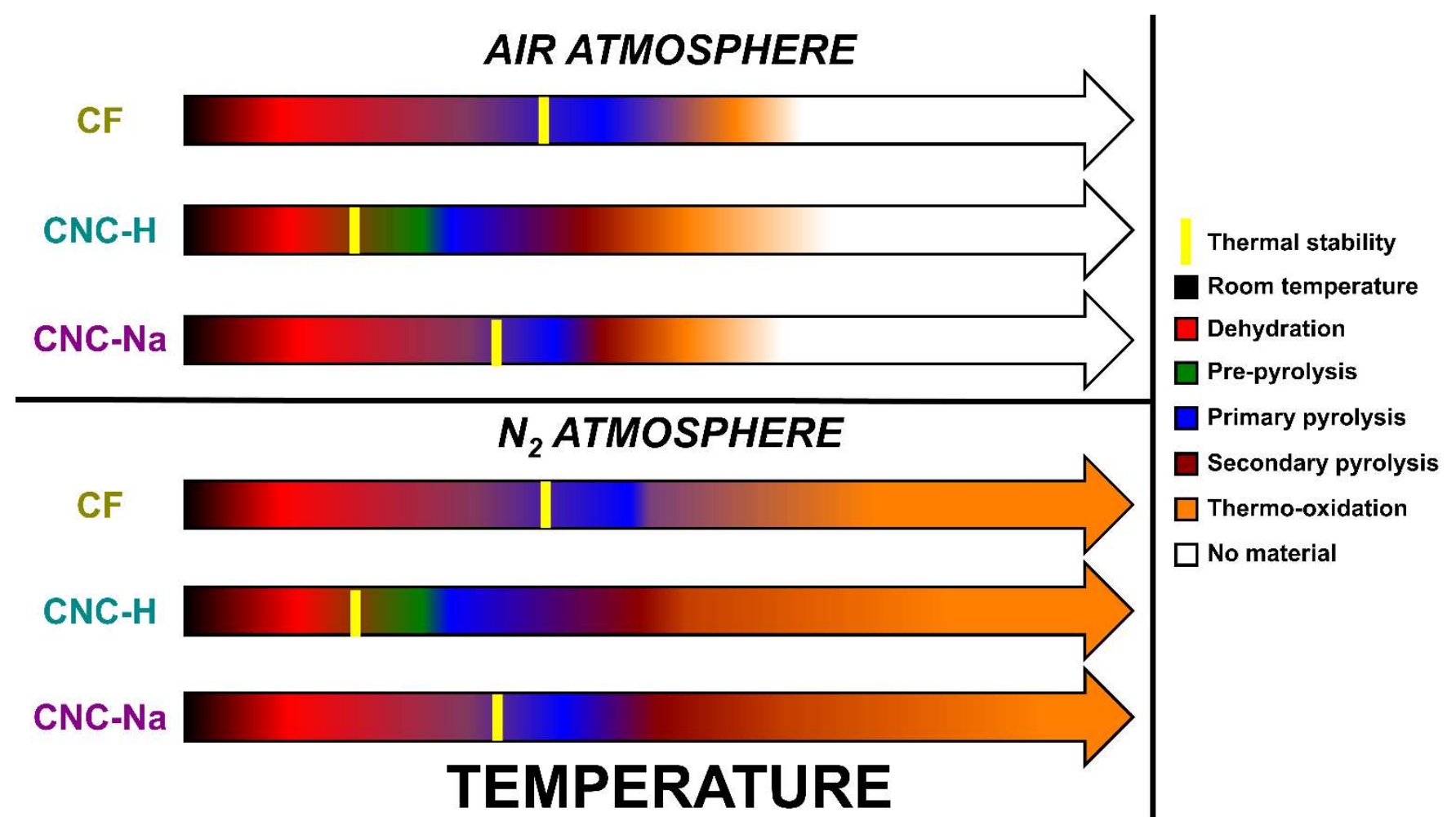

Figure S1. Structural degradation of $\mathrm{CF}, \mathrm{CNC}-\mathrm{H}$, and $\mathrm{CNC}-\mathrm{Na}$, under air and $\mathrm{N}_{2}$ atmospheres with increasing temperature. Colors indicate the range of thermal degradation processes indicated by the legend on the right. Yellow bars indicate the thermal stability, defined as the onset temperature of the pyrolytic stage at lower temperatures.

Discussion S2: Kinetic analysis and activation energies $\left(E_{a}\right)$ calculation of $\mathrm{CF}, \mathrm{CNC}-\mathrm{H}$, and $\mathrm{CNC}$ $\mathrm{Na}$

The thermal degradation of the cellulose materials was carried out by TGA as a function of the heating rate (Figure S2), in order to calculate the kinetic parameters. We achieved qualitative and quantitative analyses of all the stages through best fitting DTGA curves with an asymmetric beta-shape $\left(\mathrm{R}^{2}>0.999\right)$. The onset temperature $\left(\mathrm{T}_{\text {onset }}\right)$, the temperature at maximum weight loss rate ( $\left.\mathrm{T}_{\mathrm{MAX}}\right)$, and the maximum weight loss rate (WLR $\mathrm{WAX}_{\text {) }}$ of each stage increase monotonically with increasing heating rates (Figures S3, S4). The slopes depend on the structure of the materials and the reaction rate of each degradation stage. In Figure S3, we reported the parameters referring to the primary pyrolysis stage, since these can 
be considered as reliable indicators of the thermal stability of the materials. CFs display the highest onset temperatures $\mathrm{T}_{\text {onset, }}$ well above $300^{\circ} \mathrm{C}$ across most of the heating rates adopted (Figure S3A), emphasizing their suitability in composite processing, even when very low heating rates are used. In contrast, $\mathrm{CNC}-\mathrm{H}$ have $\mathrm{T}_{\text {onset }}$ down to $<150{ }^{\circ} \mathrm{C}$, making them unfit for composite manufacturing and highlighting the extremely harmful role that the acidic surface sulfate half-ester groups play in their thermal properties. This effect is partially prevented by the sodium counterions in CNC-Na, which show $\mathrm{T}_{\text {onset }}$ between $225{ }^{\circ} \mathrm{C}$ and $335^{\circ} \mathrm{C}$.

As expected from the qualitative analysis, the temperature at maximum weight loss rate, $\mathrm{T}_{\mathrm{MAX}}$, is highest for $\mathrm{CF}$ (Figure S3B, olive lines), $\sim 20-30{ }^{\circ} \mathrm{C}$ above $\mathrm{CNC}-\mathrm{Na}$ (Figure S3B, purple lines) and $~$ $100-110^{\circ} \mathrm{C}$ above $\mathrm{CNC}-\mathrm{H}$ (Figure $\mathrm{S} 3 \mathrm{~B}$, teal lines). The trend of $\mathrm{T}_{\text {onset }}$ and $\mathrm{T}_{\mathrm{MAx}}$ curves as functions of the heating rate are almost identical in all cellulose materials due to the common reactions taking place with a first-order kinetics.

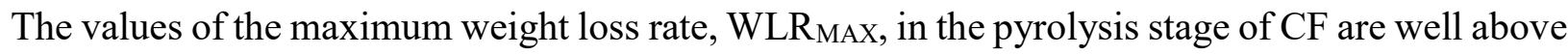
that of $\mathrm{CNC}-\mathrm{H}$, as the weight loss is not hindered by the presence of surface acidic groups. In fact, sulfate half-ester groups of $\mathrm{CNC}-\mathrm{H}$ have flame-retardant properties, catalyzing dehydration and reducing the fraction of syn-gases and volatile bio-oil products. ${ }^{7}$ Conversely, in $\mathrm{CNC}-\mathrm{Na}$ the volatilization kinetics is promoted by hard alkaline cations, such as $\mathrm{Na}^{+}$, yielding complete decomposition of glycosidic units due to the Lewis acidity of the cation. ${ }^{11,13,14}$ This leads to a higher weight loss rate and a decreased char residue yield. In fact, CNC-Na show comparable WLR $\mathrm{MAX}$ with $\mathrm{CF}$, despite the latter have a higher weight loss, calculated as normalized integral area below the DTGA curves (Table S2). The reason is that pyrolysis in CF takes place over a wider temperature range, represented by the fitted peak width of the DTGA curves (Figure S5). The degradation kinetics of the mechanically treated filaments is influenced by the larger abundance of amorphous regions and/or the presence of residual hemicellulose in the structure. The poor thermal stability of the amorphous regions triggers their conversion into bio-oil and syn-gases at lower 
temperatures than crystalline regions. Furthermore, decomposition of crystalline regions adjacent to amorphous domains is catalyzed, as the activation energy required for the thermal degradation of heterogeneous interfaces is lower than for homogeneous regions. ${ }^{15}$

The weight losses associated with the other stages are reported in Table S3. The first and the last stages, i.e., moisture dehydration and the thermo-oxidation step, have very similar weight loss among the studied cellulose materials. In fact, the reactions affecting cellulose at low and high temperatures target the same areas, independent of size and surface chemistry. However, remarkable differences are visible for the secondary pyrolysis of CNCs: in $\mathrm{CNC}-\mathrm{H}$ mass volatilization is consistent and comparable to the primary pyrolysis, while in $\mathrm{CNC}-\mathrm{Na}$ this phenomenon is contained due to the different surface chemistry.

To accurately obtain kinetic parameters and identify the best-fitting model, we used several different methods to calculate activation energies and pre-exponential factor values. We employed FlynnWall-Ozawa (FWO, Table S4), ${ }^{16}$ Friedman, ${ }^{17}$ and Broido (Table S5). ${ }^{18}$ The overall best-fitting model was found to be that of the FWO method, with a spacing of 0.01 for conversion factor $\alpha$ (Figure S6). We carried out the calculations assuming first-order reaction kinetics, typical of cellulose degradation reactions. ${ }^{19}$ We found that the activation energies of all the materials analyzed are similar. Table S4 shows that under air atmosphere CNC-Na and CF have the highest activation energy $(\sim 110 \mathrm{~kJ} / \mathrm{mol})$ for all the methods used, while CNC-H have the lowest ( $\sim 85 \mathrm{~kJ} / \mathrm{mol})$. Similar results are found for the activation energies determined for the same materials degraded under inert conditions. The activation energies found for CNCs are in agreement with some of the previous studies, ${ }^{7,20}$ while other publications display larger values. $^{1,21}$ 


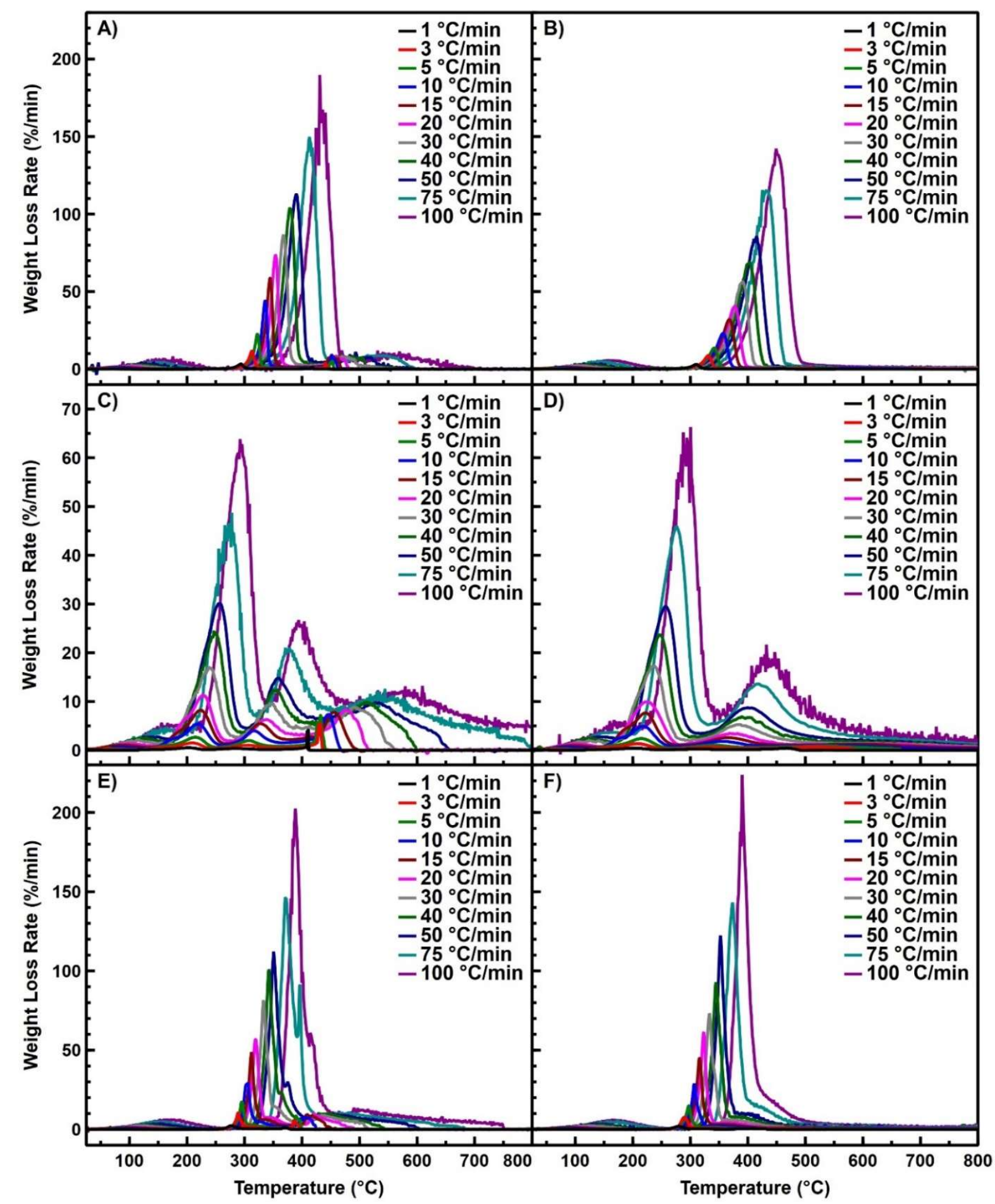

Figure S2. DTGA curves of (A,B) CF, (C,D) CNC-H, and (E,F) CNC-Na at different heating rates under air (left) and $\mathrm{N}_{2}$ (right) atmospheres. 


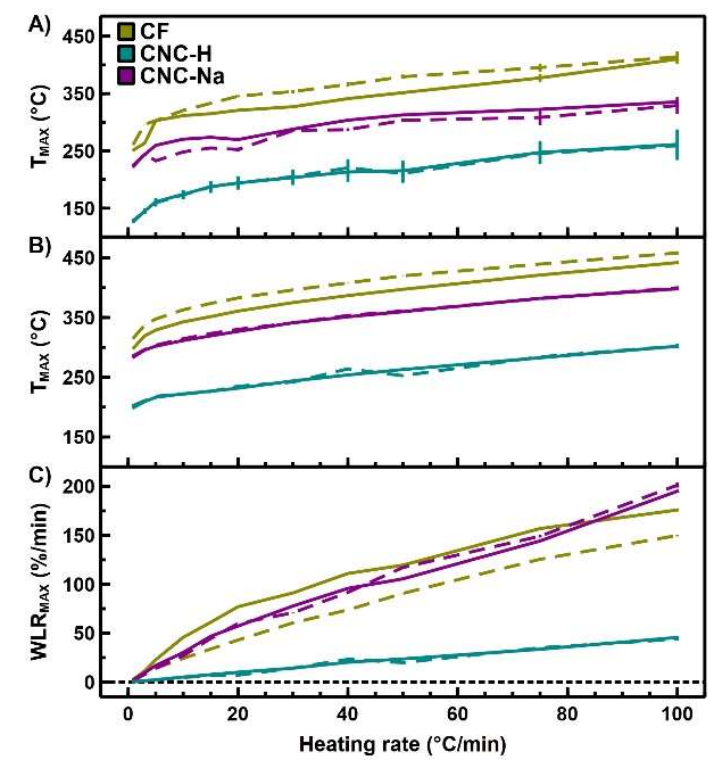

Figure S3. Plots representing (A) $\mathrm{T}_{\text {onset, }}$ (B) $\mathrm{T}_{\mathrm{MAX}}$, and (C) WLR $\mathrm{MAX}$, of the primary pyrolysis stage from DTGA curves of CF, CNC-H, and CNC-Na under air (solid) and $\mathrm{N}_{2}$ (dashed) atmospheres as functions of the heating rate.
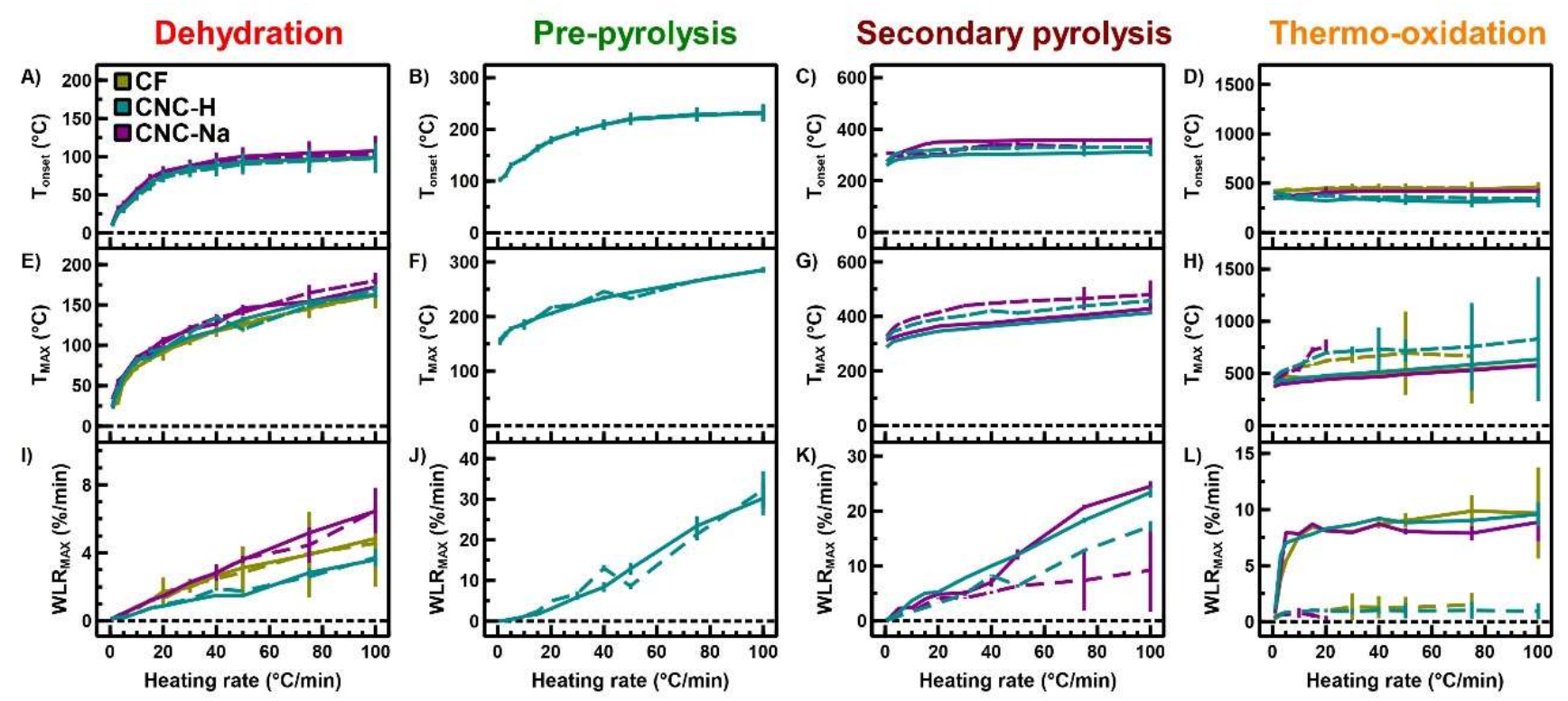

Figure S4. Plots representing (A,B,C,D) $T_{\text {onset, }}(\mathrm{E}, \mathrm{F}, \mathrm{G}, \mathrm{H}) \mathrm{T}_{\mathrm{MAX}}$, and (I,J,K,L) WLR $\mathrm{MAX}$, of the dehydration, pre-pyrolysis, secondary pyrolysis, and thermo-oxidation stages, respectively, from DTGA 
curves of $\mathrm{CF}, \mathrm{CNC}-\mathrm{H}, \mathrm{CNC}-\mathrm{Na}$ under air (solid) and $\mathrm{N}_{2}$ (dashed) atmospheres as functions of the heating rate. Solid lines of plot L) display a plateau due to complete volatilization.

Table S2. Heating-rate-averaged weight loss of the primary pyrolysis from DTGA curves of CF, CNC-H, and $\mathrm{CNC}-\mathrm{Na}$ under air and $\mathrm{N}_{2}$ atmospheres.

\begin{tabular}{|c|c|c|}
\hline Material & Atm. & Weight loss (\%) \\
\hline \multirow{2}{*}{$\mathrm{CF}$} & Air & $68.51(0.09)$ \\
\hline & $\mathrm{N}_{2}$ & $68.05(0.06)$ \\
\hline \multirow{2}{*}{$\mathrm{CNC}-\mathrm{H}$} & Air & $29.58(1.1)$ \\
\hline & $\mathrm{N}_{2}$ & $31.10(0.34)$ \\
\hline \multirow{2}{*}{$\mathrm{CNC}-\mathrm{Na}$} & Air & $60.51(0.16)$ \\
\hline & $\mathrm{N}_{2}$ & $52.70(0.12)$ \\
\hline
\end{tabular}




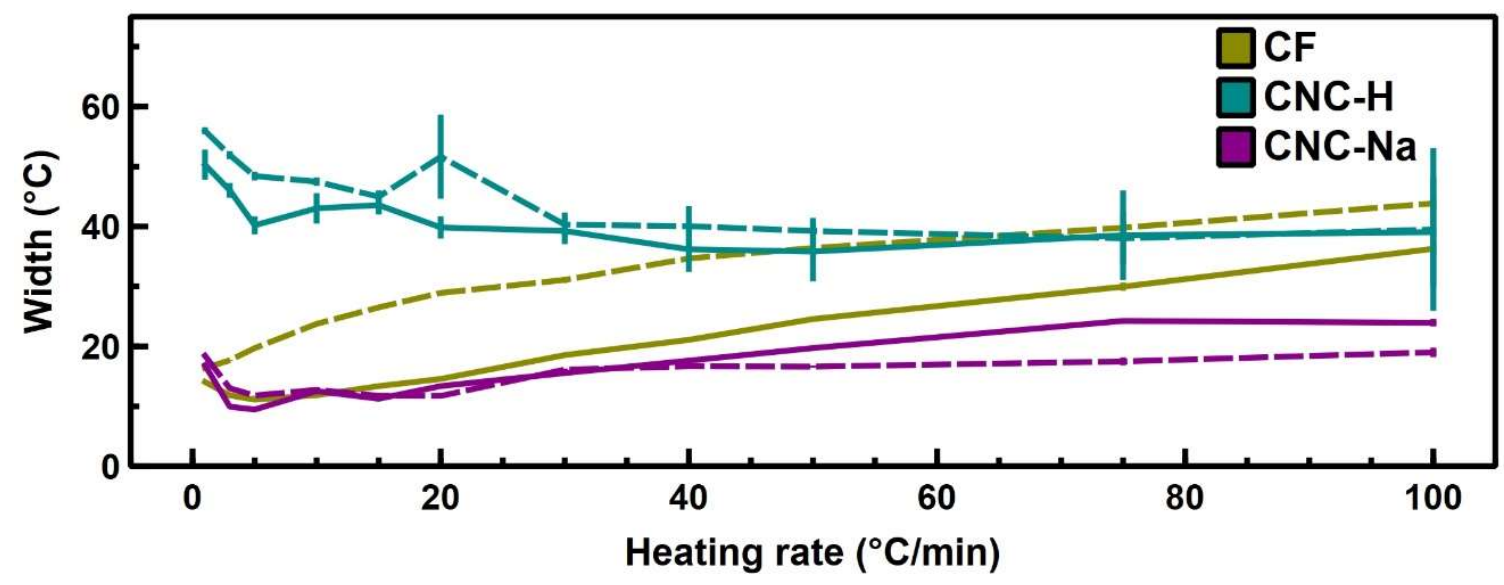

Figure S5. Plot representing width of the primary pyrolysis stage from DTGA curves of CF, CNC-H, and CNC-Na under air (solid) and $\mathrm{N}_{2}$ (dashed) atmospheres as a function of the heating rate.

Table S3. Weight loss of the the dehydration, pre-pyrolysis, secondary pyrolysis, and thermo-oxidation stages from DTGA curves of $\mathrm{CF}, \mathrm{CNC}-\mathrm{H}$, and $\mathrm{CNC}-\mathrm{Na}$ under air and $\mathrm{N}_{2}$ atmospheres. The values have been averaged over the heating rates.

\begin{tabular}{|c|c|c|c|}
\hline Material & Stage & Atm. & Weight loss (\%) \\
\hline \multirow{5}{*}{$\mathrm{CF}$} & \multirow{3}{*}{ Dehydration } & air & $3.97(0.08)$ \\
\hline & & & \\
\hline & & $\mathrm{N}_{2}$ & $3.72(0.99)$ \\
\hline & \multirow{2}{*}{$\begin{array}{c}\text { Thermo-oxi- } \\
\text { dation }\end{array}$} & air & $27.52(0.16)$ \\
\hline & & $\mathrm{N}_{2}$ & $28.23(0.13)$ \\
\hline \multirow{3}{*}{ CNC-H } & \multirow{2}{*}{ Dehydration } & Air & $3.14(1.58)$ \\
\hline & & $\mathrm{N}_{2}$ & $3.96(0.23)$ \\
\hline & Pre-pyrolysis & Air & $3.45(1.67)$ \\
\hline
\end{tabular}




\begin{tabular}{|c|c|c|c|}
\hline & & $\mathrm{N}_{2}$ & $7.05(0.77)$ \\
\hline & \multirow{2}{*}{$\begin{array}{c}\text { Secondary py- } \\
\text { rolysis }\end{array}$} & air & $32.72(0.90)$ \\
\hline & & $\mathrm{N}_{2}$ & $24.46(0.53)$ \\
\hline & \multirow{2}{*}{$\begin{array}{l}\text { Thermo-oxi- } \\
\text { dation }\end{array}$} & air & $29.11(0.27)$ \\
\hline & & $\mathrm{N}_{2}$ & $35.43(0.43)$ \\
\hline \multirow{6}{*}{$\mathrm{CNC}-\mathrm{Na}$} & \multirow{2}{*}{ Dehydration } & air & $3.89(0.30)$ \\
\hline & & $\mathrm{N}_{2}$ & $3.77(1.21)$ \\
\hline & Secondary py- & air & $14.04(0.24)$ \\
\hline & rolysis & $\mathrm{N}_{2}$ & $10.78(0.33)$ \\
\hline & Thermo-oxi- & air & $21.56(0.02)$ \\
\hline & dation & $\mathrm{N}_{2}$ & $32.75(0.29)$ \\
\hline
\end{tabular}

Table S4. Average activation energies $\left(E_{a}\right), \log$ of pre-exponential factor $(\log A)$, and $R^{2}$ value for $C F$, CNC-H, and CNC-Na pyrolysis using the FWO thermoanalytical method.

\begin{tabular}{|l|l|l|l|l|}
\hline Material & Atm. & $\mathrm{E}_{\mathrm{a}}(\mathrm{kJ} / \mathrm{mol})$ & $\log \mathrm{A}(\log / \mathrm{s})$ & $\mathrm{R}^{2}$ \\
\hline \multirow{3}{*}{$\mathrm{CF}$} & air & $103.3(1.3)$ & $6.92(0.04)$ & 0.9540 \\
\cline { 2 - 5 } & $\mathrm{N}_{2}$ & $109.0(1.5)$ & $7.12(0.27)$ & 0.9726 \\
\hline \multirow{2}{*}{$\mathrm{CNC}-\mathrm{H}$} & air & $85.8(3.3)$ & $7.06(0.25)$ & 0.9006 \\
\cline { 2 - 5 } & $\mathrm{N}_{2}$ & $84.2(4.9)$ & $7.02(0.43)$ & 0.8811 \\
\hline
\end{tabular}




\begin{tabular}{|l|l|l|l|l|}
\hline \multirow{2}{*}{ CNC-Na } & air & $110.5(0.3)$ & $7.64(0.01)$ & 0.9345 \\
\cline { 2 - 5 } & $\mathrm{N}_{2}$ & $112.4(0.3)$ & $7.72(0.06)$ & 0.9408 \\
\hline
\end{tabular}

Table S5. Average activation energies $\left(E_{a}\right), \log$ of pre-exponential factor $(\log A)$, and $R^{2}$ value for $C F$, CNC-H, and CNC-Na pyrolysis using Friedman (F), and Broido (B) thermoanalytical methods.

\begin{tabular}{|c|c|c|c|c|c|c|c|}
\hline Mate- & Atm. & \multicolumn{2}{|l|}{$\mathrm{E}_{\mathrm{a}}(\mathrm{kJ} / \mathrm{mol})$} & \multicolumn{2}{|l|}{$\log \mathrm{A}(\log / \mathrm{s})$} & \multicolumn{2}{|l|}{$\mathrm{R}^{2}$} \\
\hline Method & & $\mathrm{F}$ & B & $\mathrm{F}$ & B & $\mathrm{F}$ & B \\
\hline \multirow{2}{*}{$\mathrm{CF}$} & air & $103.2(6.1)$ & $105.5(6.6)$ & $7.97(0.19)$ & $6.33(0.65)$ & 0.8616 & 0.9102 \\
\hline & $\mathrm{N}_{2}$ & $113.7(4.0)$ & $107.3(8.9)$ & $8.94(0.70)$ & $7.91(0.99)$ & 0.9695 & 0.9555 \\
\hline \multirow{2}{*}{ CNC-H } & air & $101.7(5.9)$ & $95.42(6.31)$ & $10.2(0.4)$ & $7.22(1.04)$ & 0.9105 & 0.9009 \\
\hline & $\mathrm{N}_{2}$ & $123.8(11.3)$ & $97.39(10.03)$ & $13.2(1.1)$ & $8.13(2.11)$ & 0.8979 & 0.9034 \\
\hline \multirow[t]{2}{*}{ CNC- } & air & $107.1(2.1)$ & $105.4(4.3)$ & $8.84(0.07)$ & $10.02(0.88)$ & 0.9345 & 0.9289 \\
\hline & $\mathrm{N}_{2}$ & $118.8(2.1)$ & $108.0(8.1)$ & $9.60(0.44)$ & $12.47(1.21)$ & 0.9239 & 0.9255 \\
\hline
\end{tabular}




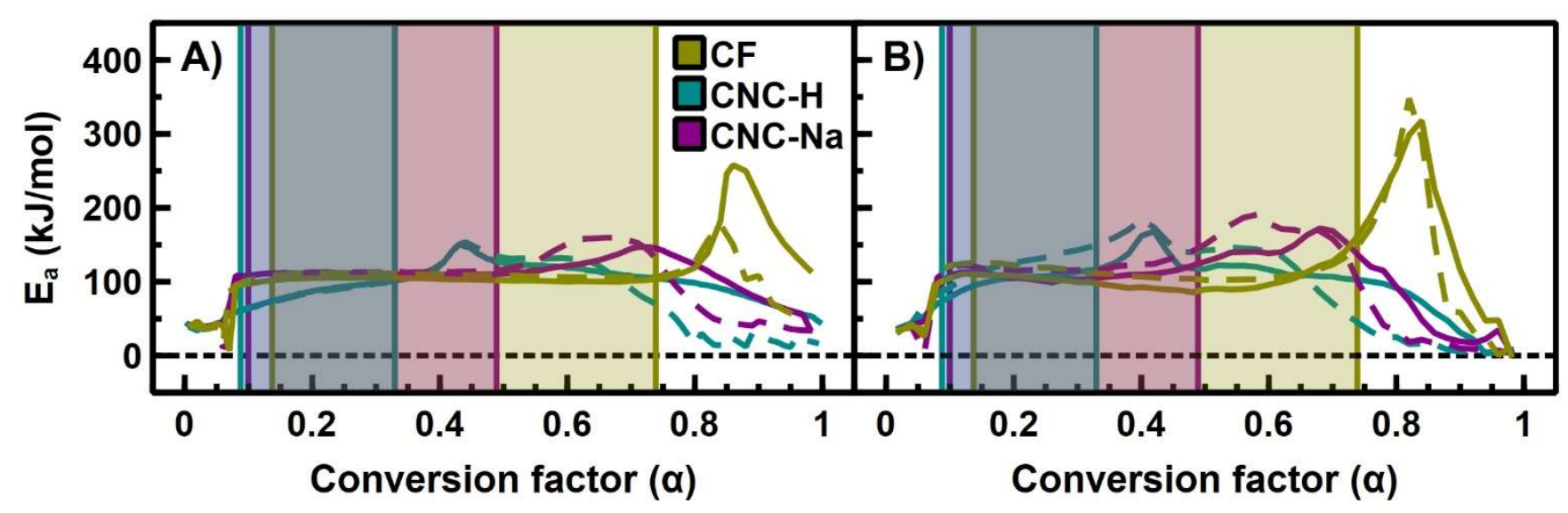

Figure S6. Activation energy $\left(E_{a}\right)$ versus conversion factor $(\alpha)$ at a spacing of 0.01 for pyrolysis of CF, CNC-H, and CNC-Na under air (solid) and $\mathrm{N}_{2}$ (dashed) atmospheres at heating rates of 1, 3, 5, 10, 15, 20, 30, 40, 50, 75, $100{ }^{\circ} \mathrm{C} / \mathrm{min}$, calculated using (A) FWO and (B) Friedman methods.

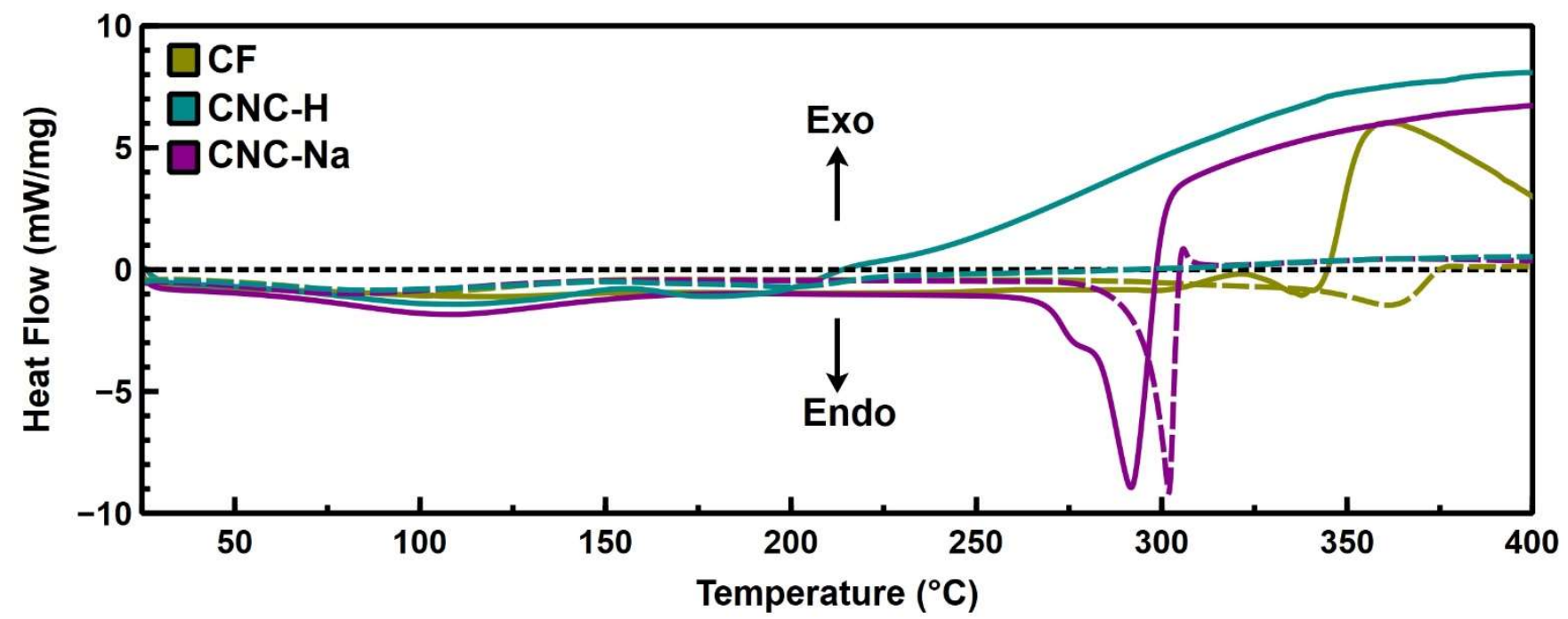

Figure S7. DSC curves of CF, CNC-H, and $\mathrm{CNC}-\mathrm{Na}$ obtained at a heating rate of $10{ }^{\circ} \mathrm{C} / \mathrm{min}$ under air (solid) and $\mathrm{N}_{2}$ (dashed) atmosphere. 


\section{Discussion S3: Analysis of differential scanning calorimetry (DSC) curves of CNC-H, CNC-Na, and CF}

The enthalpy for pyrolysis $\left(\Delta \mathrm{H}_{\mathrm{p}}\right)$ is calculated as the normalized area beneath the relative curve on the DSC curve (Table S6). These values have a semi-quantitative nature since the reactor used is partially sealed. ${ }^{22}$ The highest enthalpy was found for the primary pyrolysis stage of CNC-Na (Figure S7, purple lines, $300-340{ }^{\circ} \mathrm{C}$ ), up to 10 times greater than for the $\mathrm{CNC}-\mathrm{H}$ (Figure S7, teal lines, $200-260{ }^{\circ} \mathrm{C}$ ) and CF (Figure S7, olive lines, 325-400 ${ }^{\circ} \mathrm{C}$ ) enthalpies. In fact, the alkaline nature of $\mathrm{Na}^{+}$catalyzes the pyrolysis reactions, ${ }^{11,13,14}$ despite the improvement of thermal stability. This also explains the elevated weight loss in such a small temperature range.

In contrast to the rest of the plot, the tail of the DSC curves at high temperature show a defined exothermic character, related to the charring process occurring after the pyrolysis stages $\left(>400{ }^{\circ} \mathrm{C}\right) .{ }^{23}$ This phenomenon is more evident in CNCs due to the higher predisposition to charring caused by acidic surface groups. In fact, we showed that the char yields of CNCs are always larger than those of CF. A clear difference is observed between thermal degradation under air (solid lines) and nitrogen atmospheres (dashed lines). In fact, the exothermic region onsets at lower temperatures under air than under nitrogen. This is attributed to the strongly exothermic oxidation reactions taking place at high temperatures after pyrolysis. $^{24}$ 
Table S6. Enthalpies for pyrolysis $\left(\Delta \mathrm{H}_{\mathrm{p}}\right)$ from DTGA curves of $\mathrm{CF}, \mathrm{CNC}-\mathrm{H}$, and $\mathrm{CNC}-\mathrm{Na}$ at heating rate of $10^{\circ} \mathrm{C} / \mathrm{min}$ under air and $\mathrm{N}_{2}$ atmospheres.

\begin{tabular}{|c|c|c|}
\hline Material & Atm. & $\Delta H_{p}(J / g)$ \\
\hline \multirow{3}{*}{$\mathrm{CF}$} & air & $49.1(3.9)$ \\
\hline & & \\
\hline & $\mathrm{N}_{2}$ & $194.2(2.1)$ \\
\hline \multirow{2}{*}{$\mathrm{CNC}-\mathrm{H}$} & air & $150.1(2.4)$ \\
\hline & $\mathrm{N}_{2}$ & $82.37(2.1)$ \\
\hline \multirow{2}{*}{$\mathrm{CNC}-\mathrm{Na}$} & air & $476.7(1.0)$ \\
\hline & $\mathrm{N}_{2}$ & 300.7 (1.4) \\
\hline
\end{tabular}

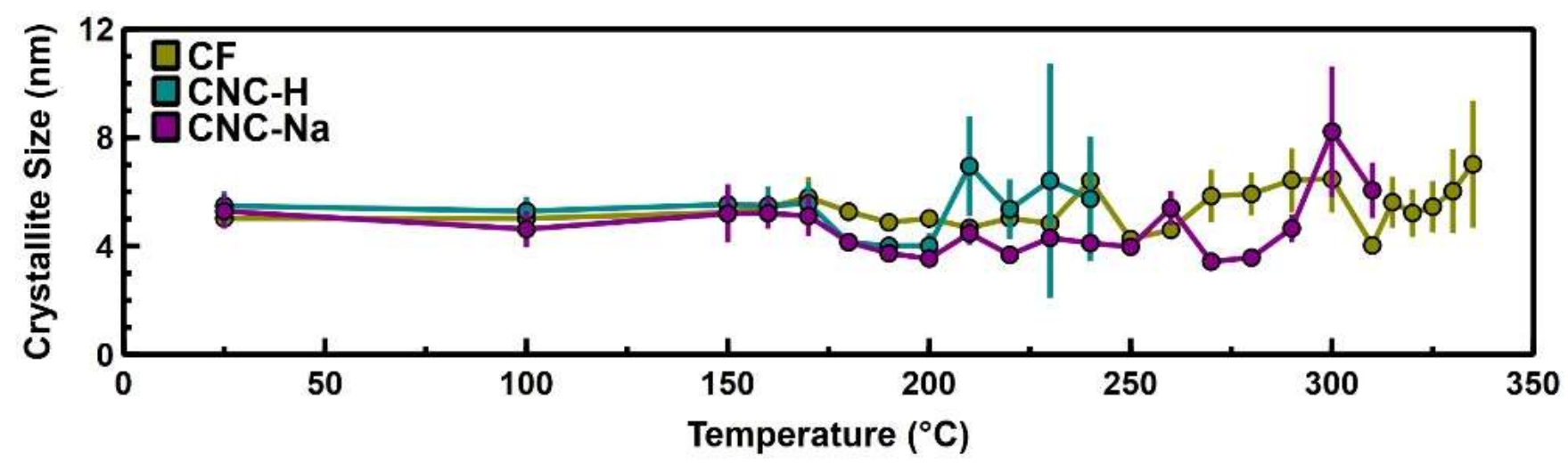

Figure S8. Plots of the crystallite size of CF, CNC-H, and $\mathrm{CNC}-\mathrm{Na}$ as a function of temperature. Temperatures where the structure is almost fully amorphous were not considered. Crystallite sizes were determined through the peak position and width by applying the corrected Scherrer equation. 


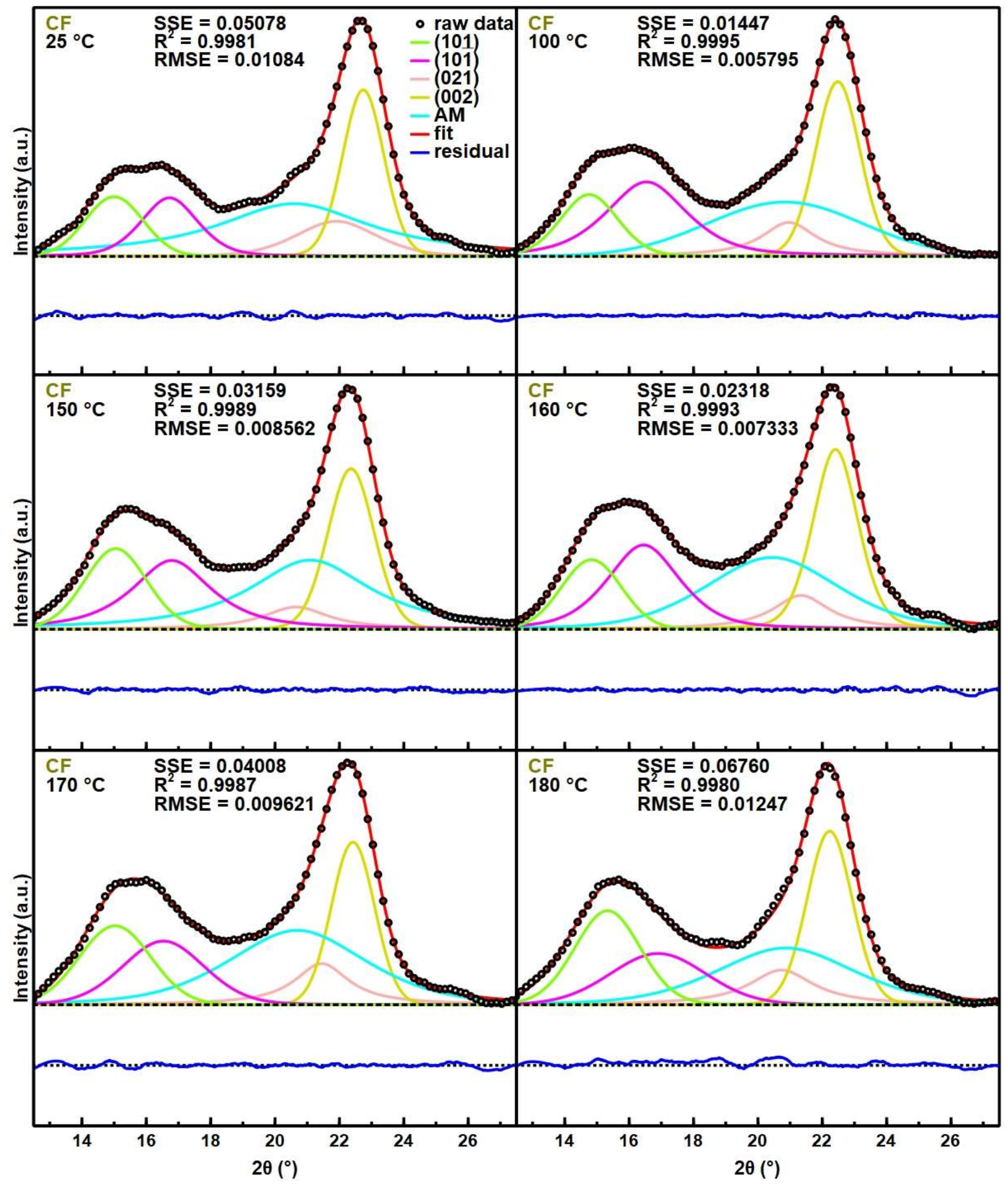

Figure S9. Rietveld fits of VT-PXRD patterns of CFs at $25^{\circ} \mathrm{C}, 100{ }^{\circ} \mathrm{C}, 150{ }^{\circ} \mathrm{C}, 160{ }^{\circ} \mathrm{C}, 170{ }^{\circ} \mathrm{C}$, and 180 ${ }^{\circ} \mathrm{C}$. 


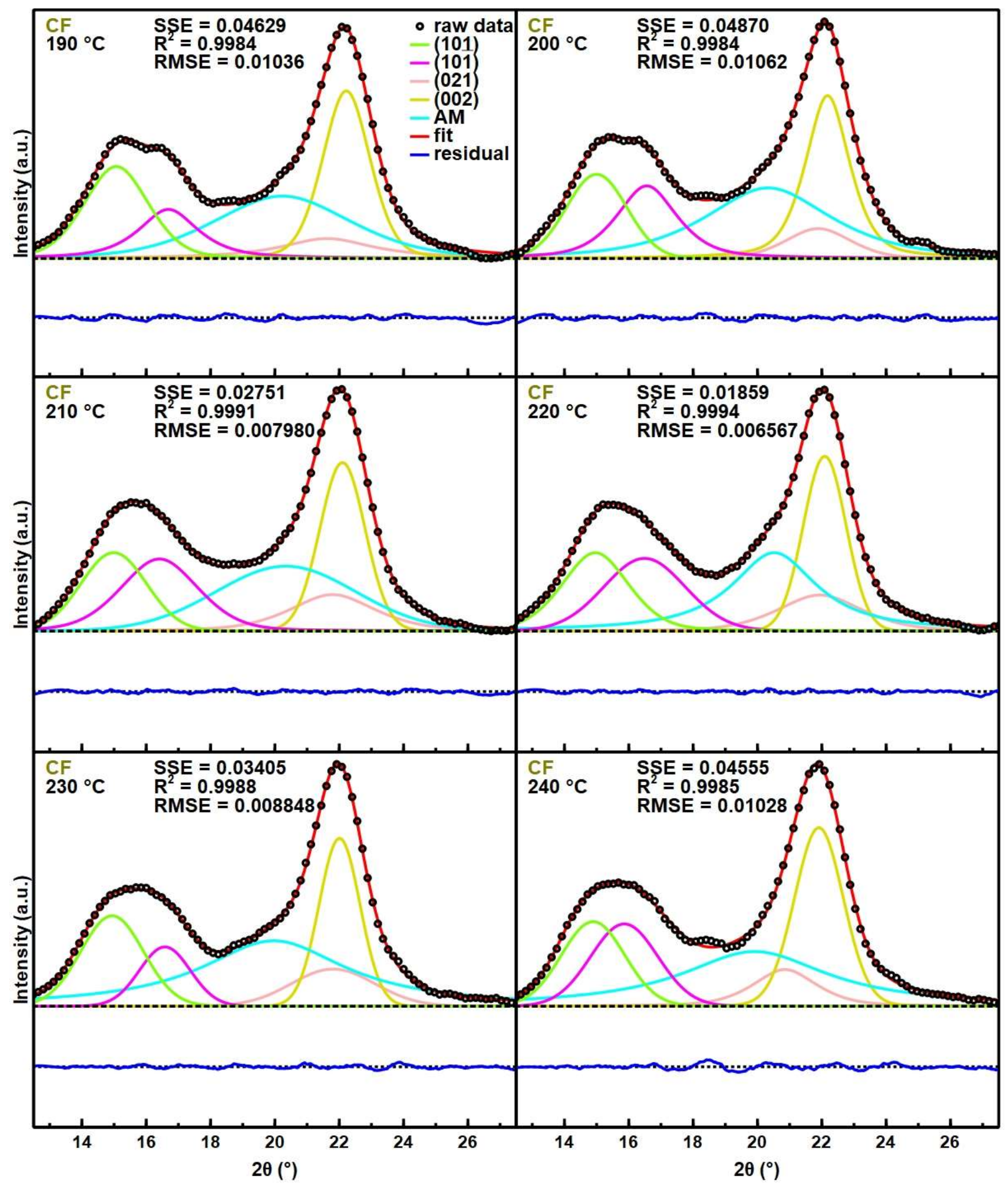

Figure S10. Rietveld fits of VT-PXRD patterns of CFs at $190{ }^{\circ} \mathrm{C}, 200{ }^{\circ} \mathrm{C}, 210{ }^{\circ} \mathrm{C}, 220{ }^{\circ} \mathrm{C}, 230{ }^{\circ} \mathrm{C}$, and $240^{\circ} \mathrm{C}$. 


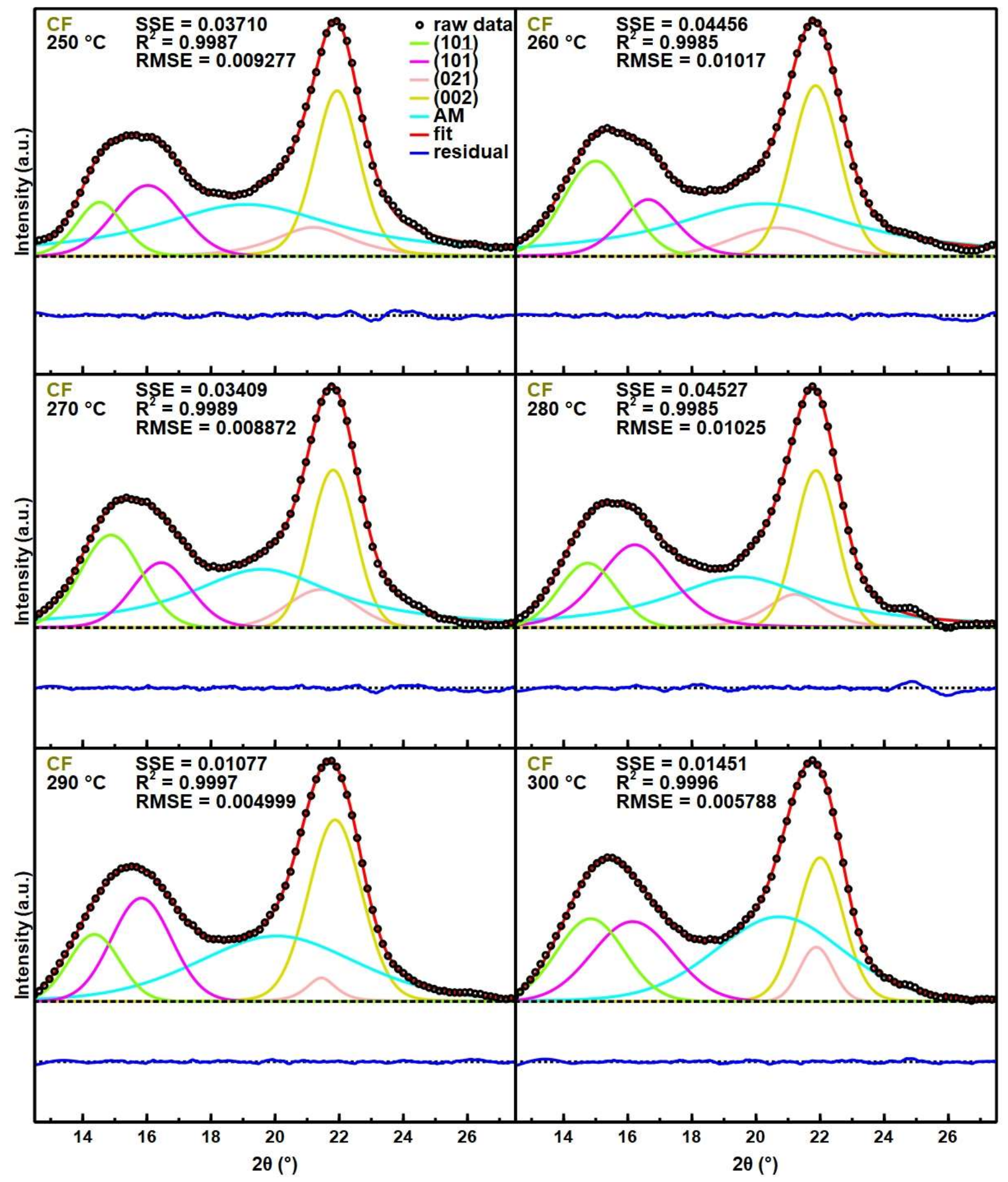

Figure S11. Rietveld fits of VT-PXRD patterns of CFs at $250{ }^{\circ} \mathrm{C}, 260{ }^{\circ} \mathrm{C}, 270{ }^{\circ} \mathrm{C}, 280{ }^{\circ} \mathrm{C}, 290{ }^{\circ} \mathrm{C}$, and $300^{\circ} \mathrm{C}$. 


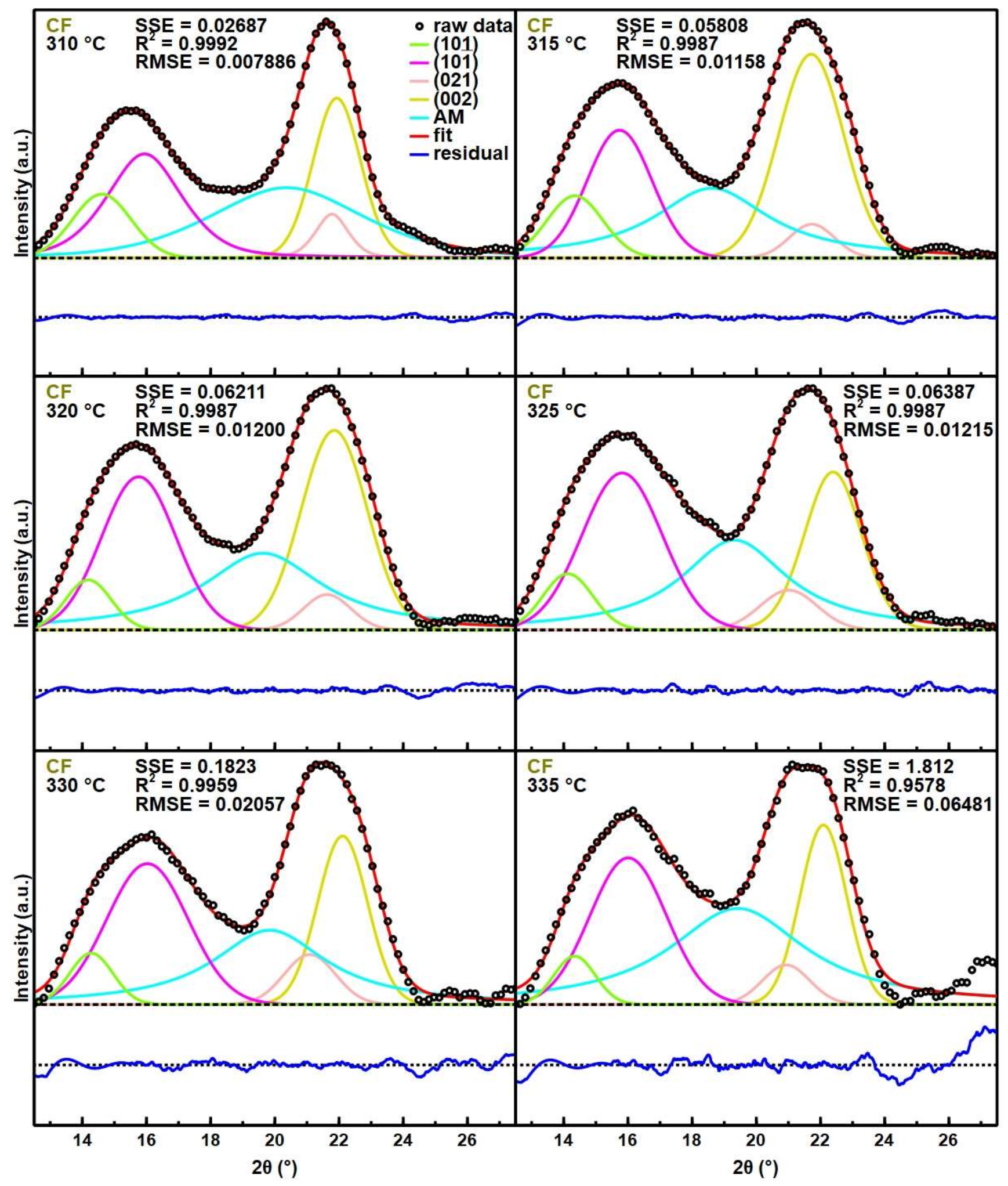

Figure S12. Rietveld fits of VT-PXRD patterns of CFs at $310{ }^{\circ} \mathrm{C}, 315{ }^{\circ} \mathrm{C}, 320{ }^{\circ} \mathrm{C}, 325{ }^{\circ} \mathrm{C}, 330{ }^{\circ} \mathrm{C}$, and $335^{\circ} \mathrm{C}$. 


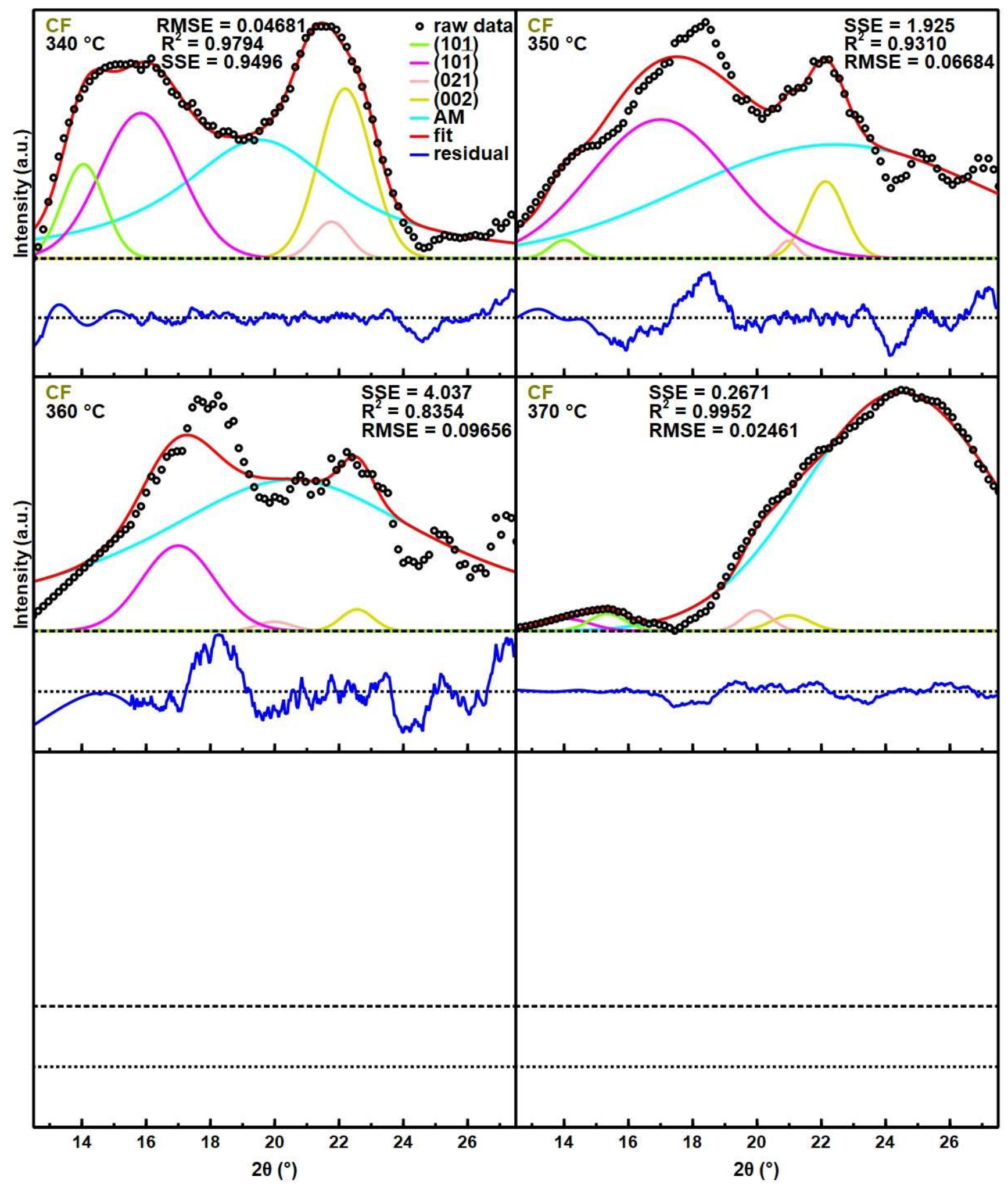

Figure S13. Rietveld fits of VT-PXRD patterns of CFs at $340{ }^{\circ} \mathrm{C}, 350{ }^{\circ} \mathrm{C}, 360^{\circ} \mathrm{C}$, and $370^{\circ} \mathrm{C}$. 


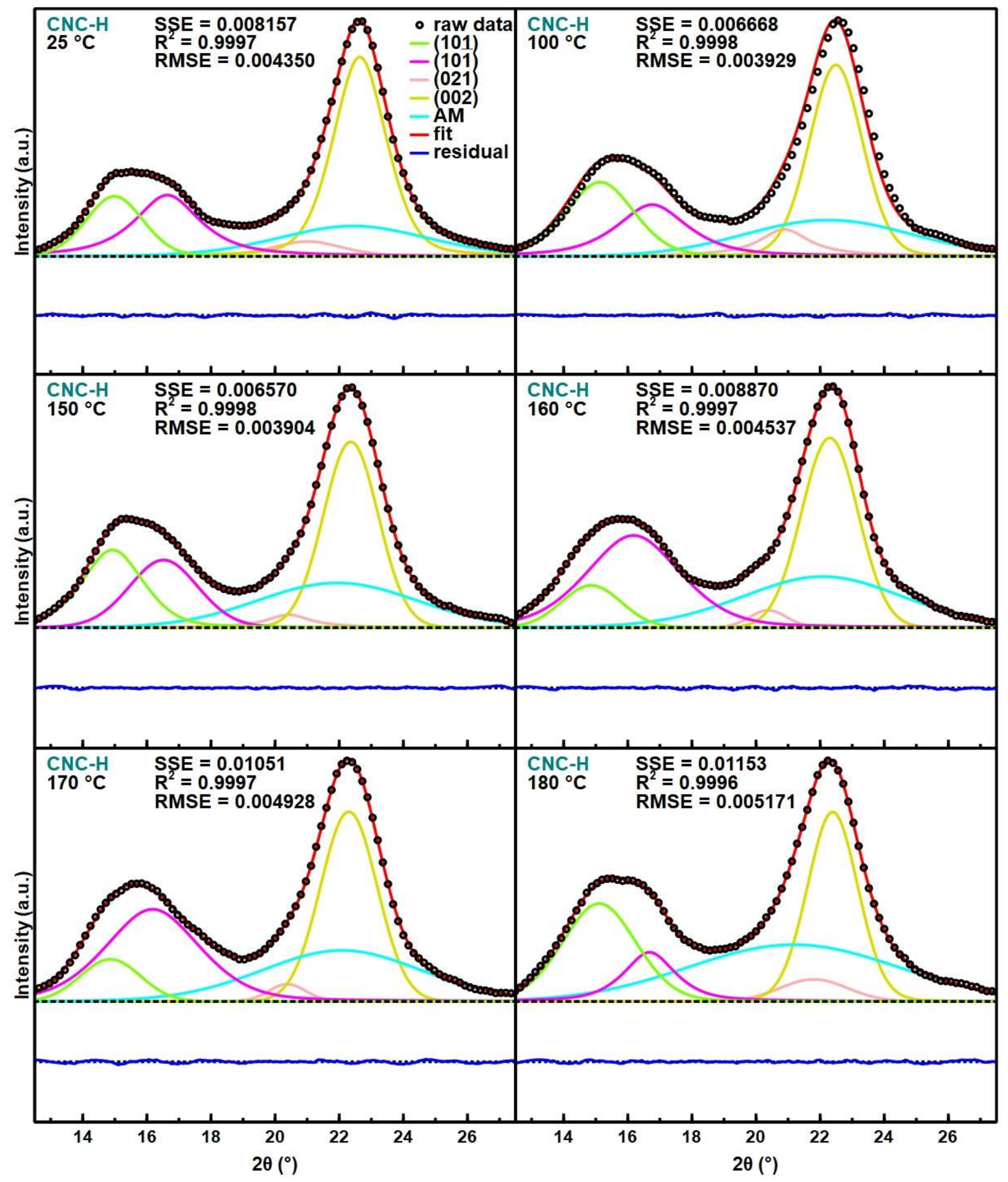

Figure S14. Rietveld fits of VT-PXRD patterns of CNC-H at $25^{\circ} \mathrm{C}, 100{ }^{\circ} \mathrm{C}, 150{ }^{\circ} \mathrm{C}, 160{ }^{\circ} \mathrm{C}, 170{ }^{\circ} \mathrm{C}$, and $180{ }^{\circ} \mathrm{C}$. 


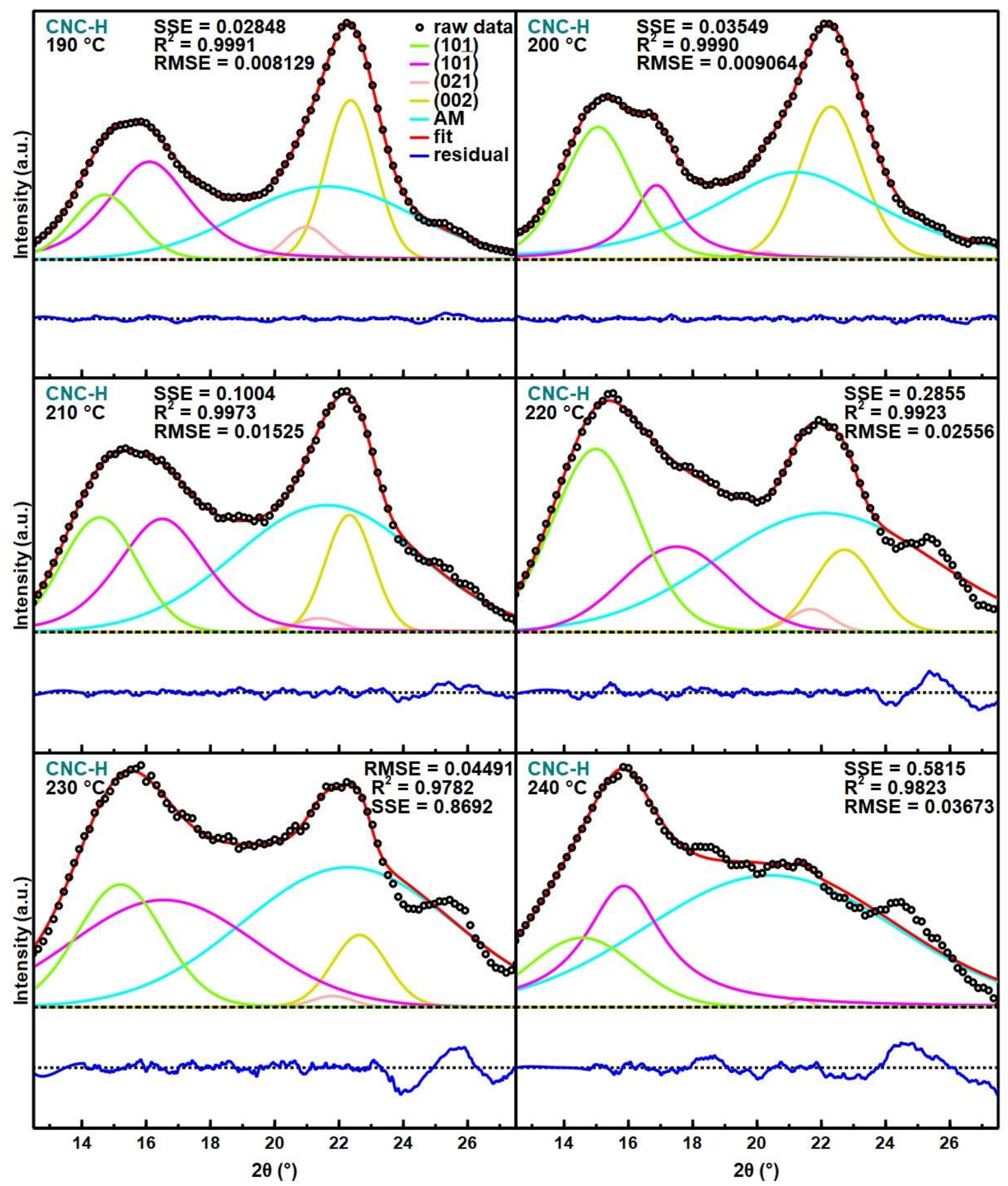

Figure S15. Rietveld fits of VT-PXRD patterns of CNC-H at $190{ }^{\circ} \mathrm{C}, 200{ }^{\circ} \mathrm{C}, 210{ }^{\circ} \mathrm{C}, 220{ }^{\circ} \mathrm{C}, 230{ }^{\circ} \mathrm{C}$, and $240{ }^{\circ} \mathrm{C}$. 


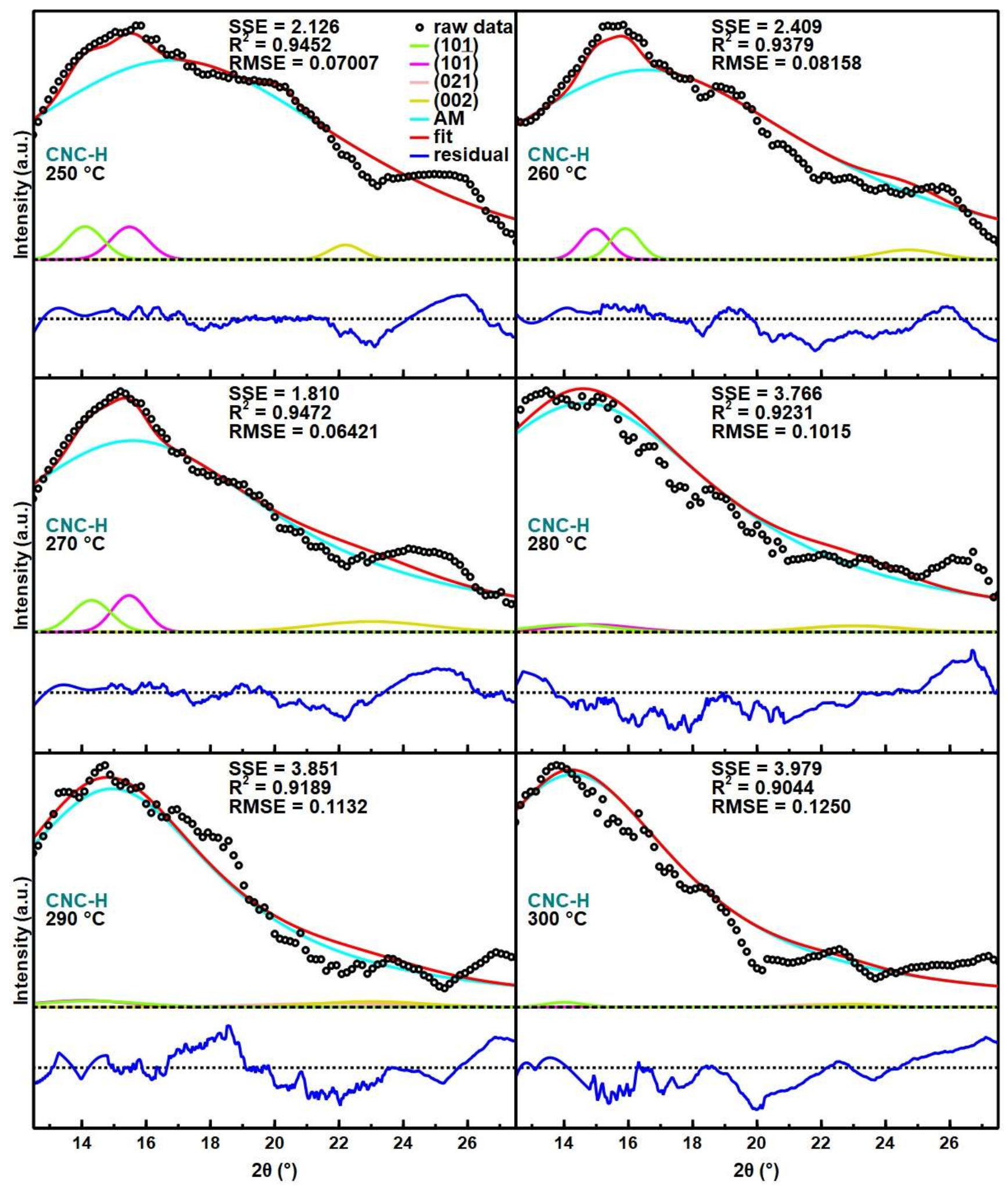

Figure S16. Rietveld fits of VT-PXRD patterns of $\mathrm{CNC}-\mathrm{H}$ at $250{ }^{\circ} \mathrm{C}, 260{ }^{\circ} \mathrm{C}, 270{ }^{\circ} \mathrm{C}, 280{ }^{\circ} \mathrm{C}, 290{ }^{\circ} \mathrm{C}$, and $300{ }^{\circ} \mathrm{C}$. 


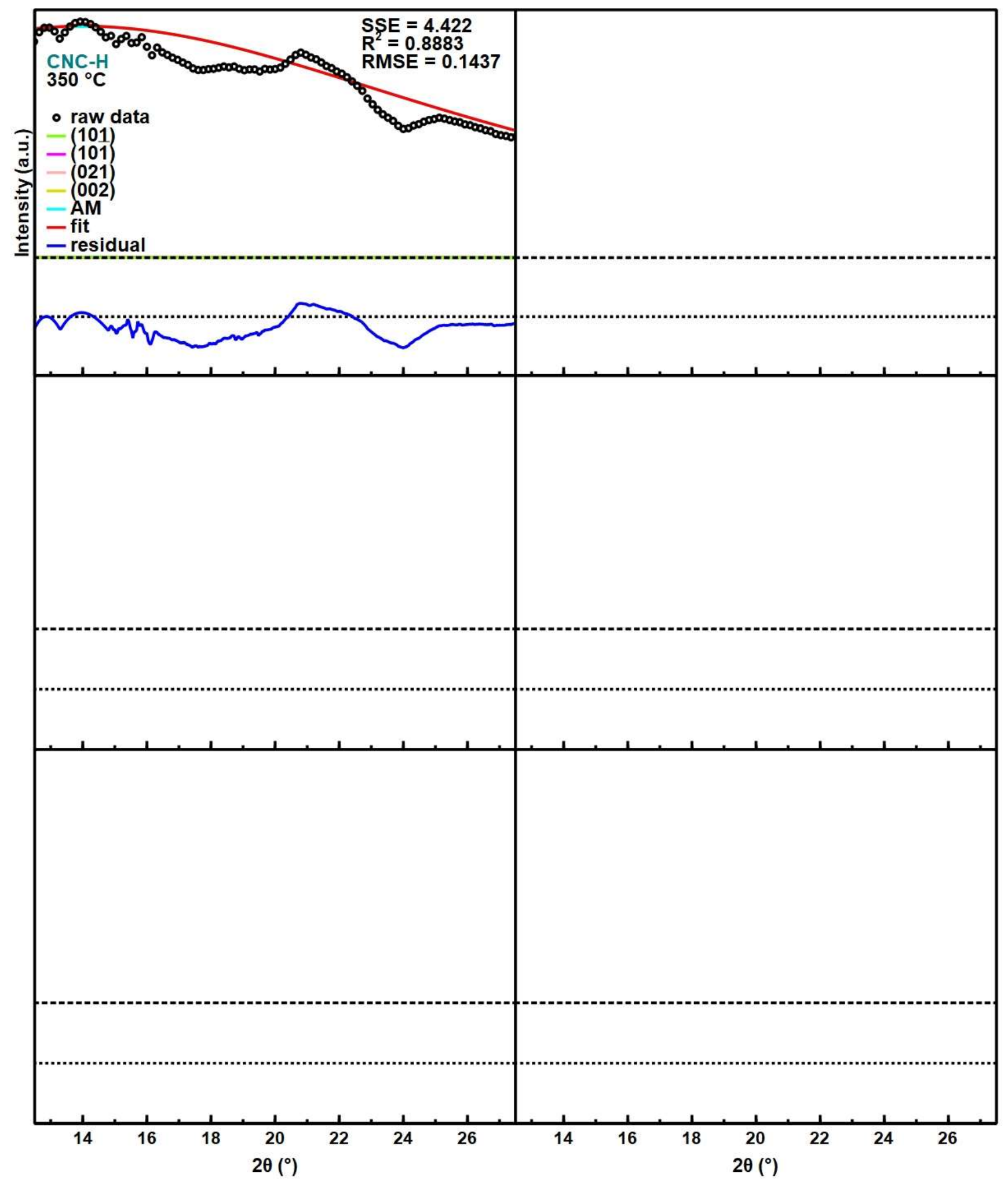

Figure S17. Rietveld fits of VT-PXRD patterns of $\mathrm{CNC}-\mathrm{H}$ at $350{ }^{\circ} \mathrm{C}$. 


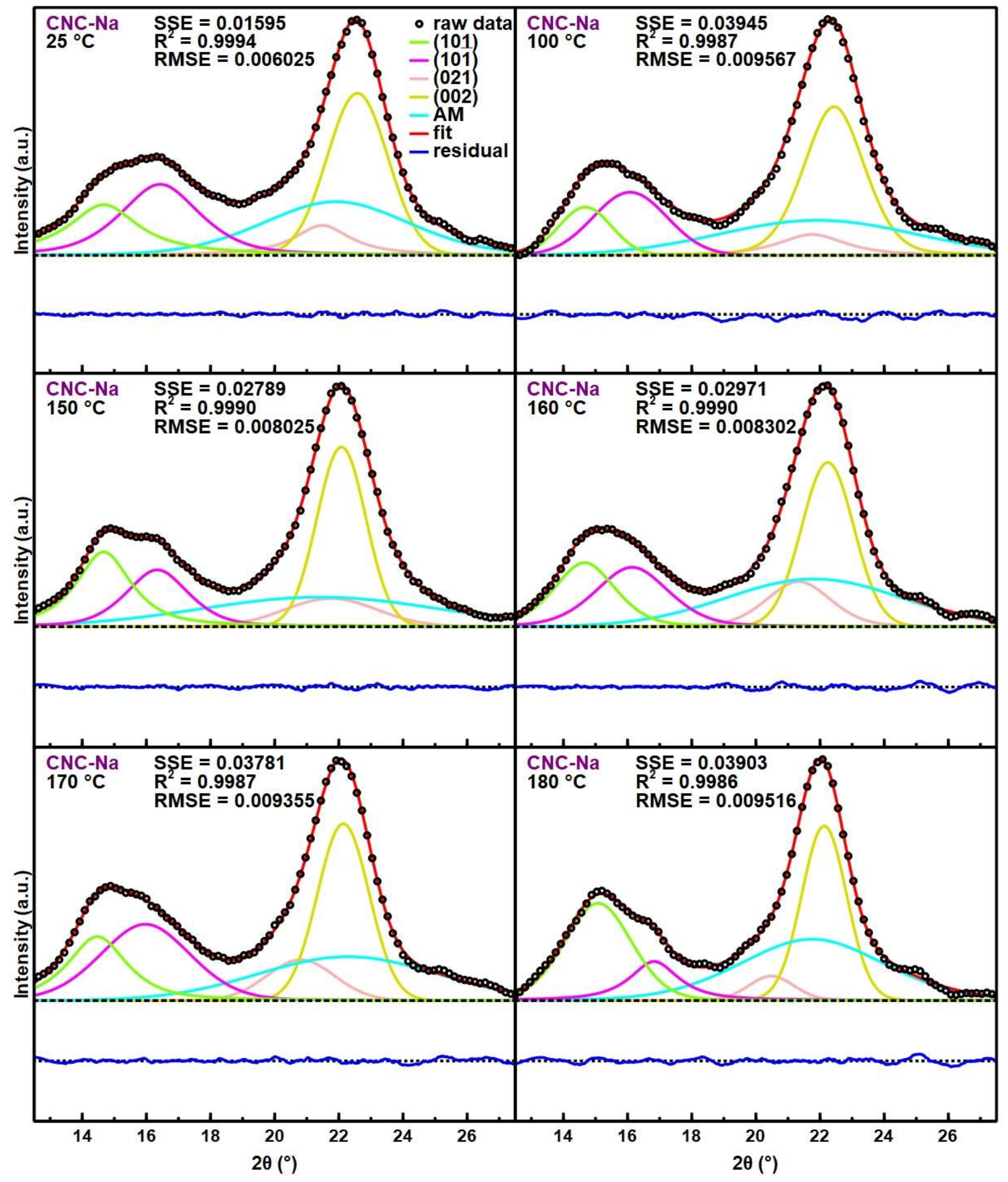

Figure S18. Rietveld fits of VT-PXRD patterns of CNC-Na at $25{ }^{\circ} \mathrm{C}, 100{ }^{\circ} \mathrm{C}, 150{ }^{\circ} \mathrm{C}, 160{ }^{\circ} \mathrm{C}, 170{ }^{\circ} \mathrm{C}$, and $180^{\circ} \mathrm{C}$. 


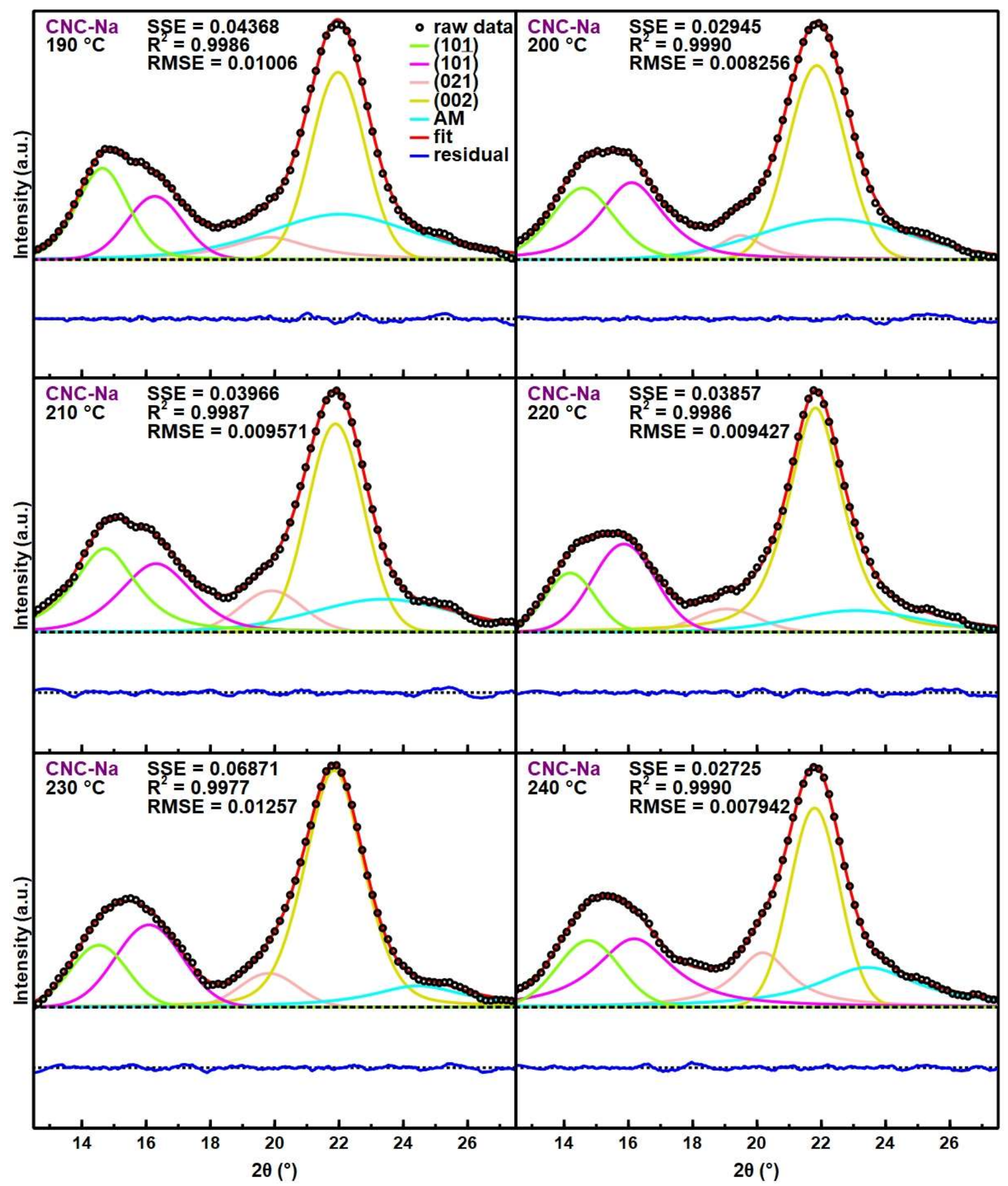

Figure S19. Rietveld fits of VT-PXRD patterns of CNC-Na at $190{ }^{\circ} \mathrm{C}, 200{ }^{\circ} \mathrm{C}, 210{ }^{\circ} \mathrm{C}, 220{ }^{\circ} \mathrm{C}, 230{ }^{\circ} \mathrm{C}$, and $240{ }^{\circ} \mathrm{C}$. 


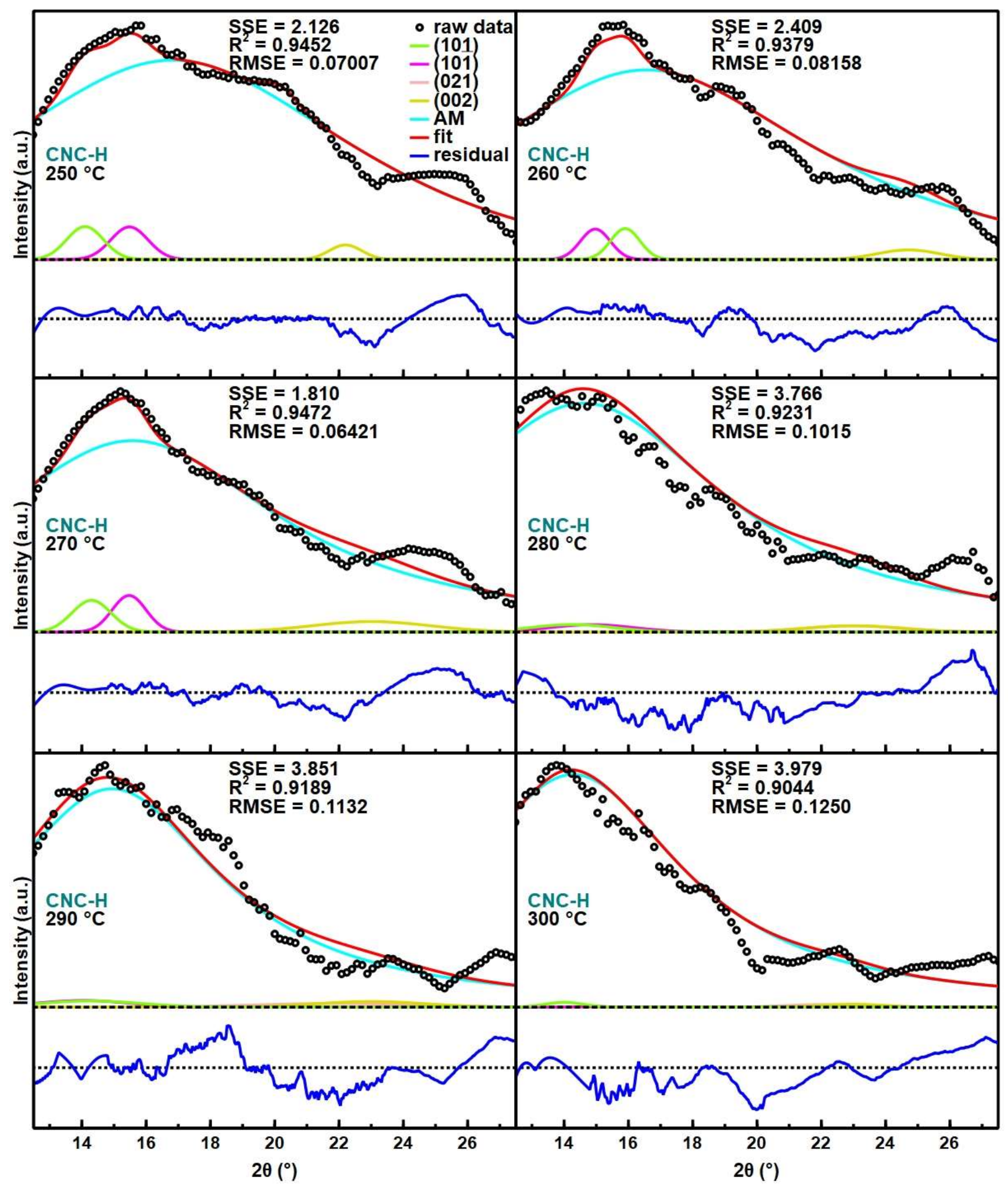

Figure S20. Rietveld fits of VT-PXRD patterns of CNC-Na at $250{ }^{\circ} \mathrm{C}, 260{ }^{\circ} \mathrm{C}, 270{ }^{\circ} \mathrm{C}, 280{ }^{\circ} \mathrm{C}, 290{ }^{\circ} \mathrm{C}$, and $300{ }^{\circ} \mathrm{C}$. 


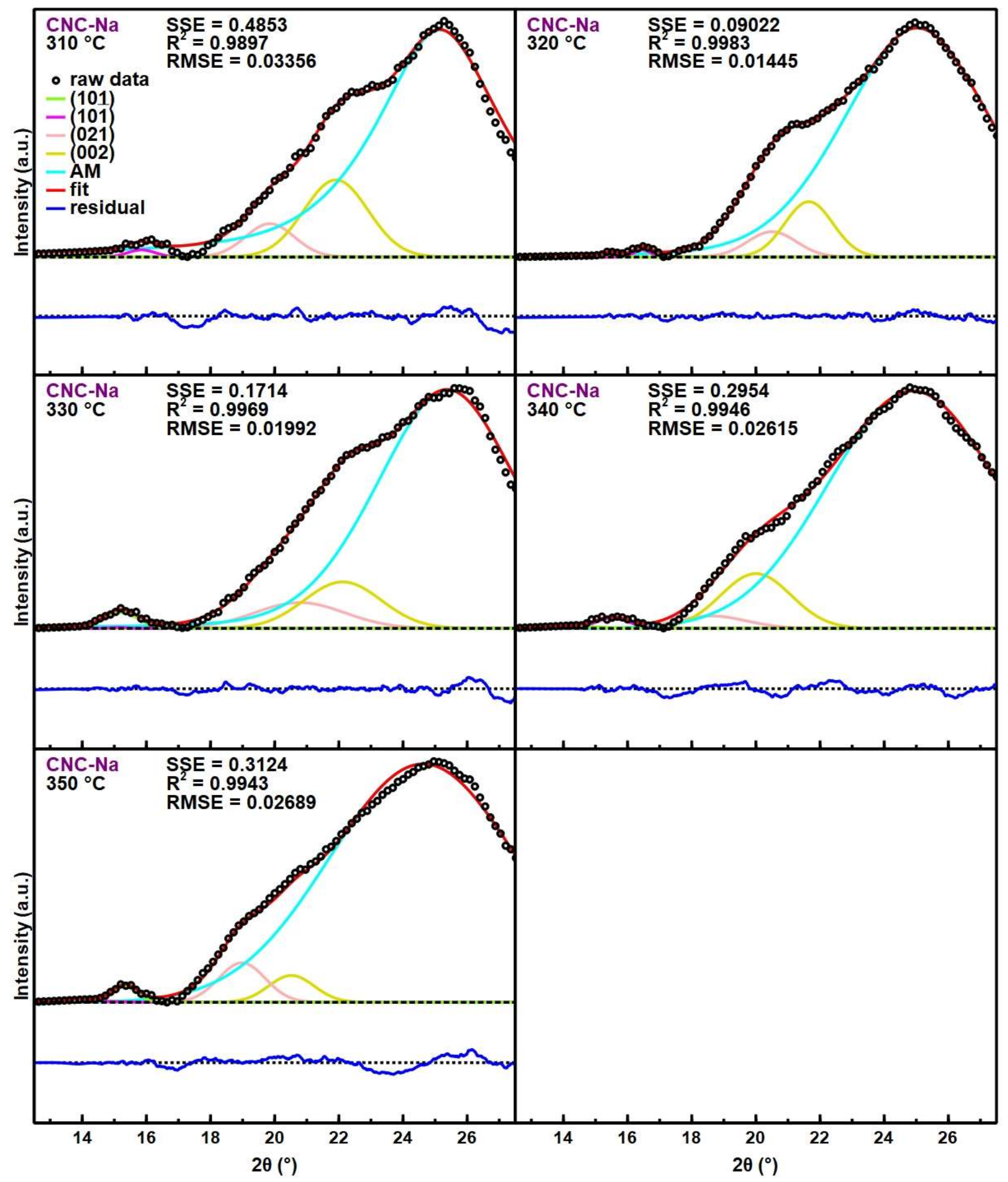

Figure S21. Rietveld fits of VT-PXRD patterns of CNC-Na at $310^{\circ} \mathrm{C}, 320^{\circ} \mathrm{C}, 330{ }^{\circ} \mathrm{C}, 340{ }^{\circ} \mathrm{C}$, and 350 ${ }^{\circ} \mathrm{C}$. 


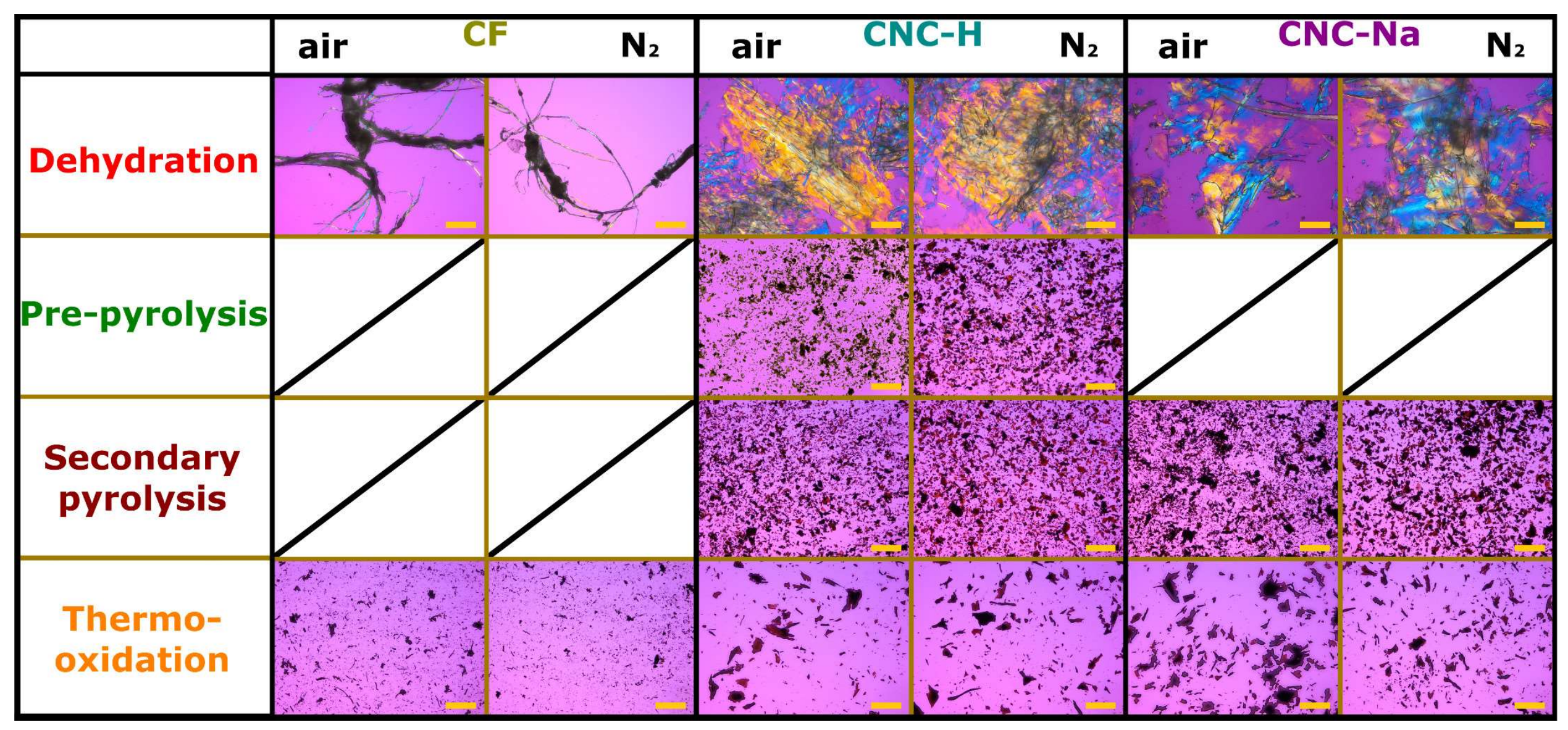

Figure S22. POM images (between crossed polarizers with a lambda plate) of the pristine birefringent surface of CF, CNC-H, and CNC-Na and debris of the same materials at dehydration, pre-pyrolysis, secondary pyrolysis, and thermo-oxidation stages using a heating rate of $10^{\circ} \mathrm{C} / \mathrm{min}$ under air and $\mathrm{N}_{2}$ atmospheres. Crossed boxes represent degradation stages that do not take place. Scale bar: $200 \mu \mathrm{m}$. 


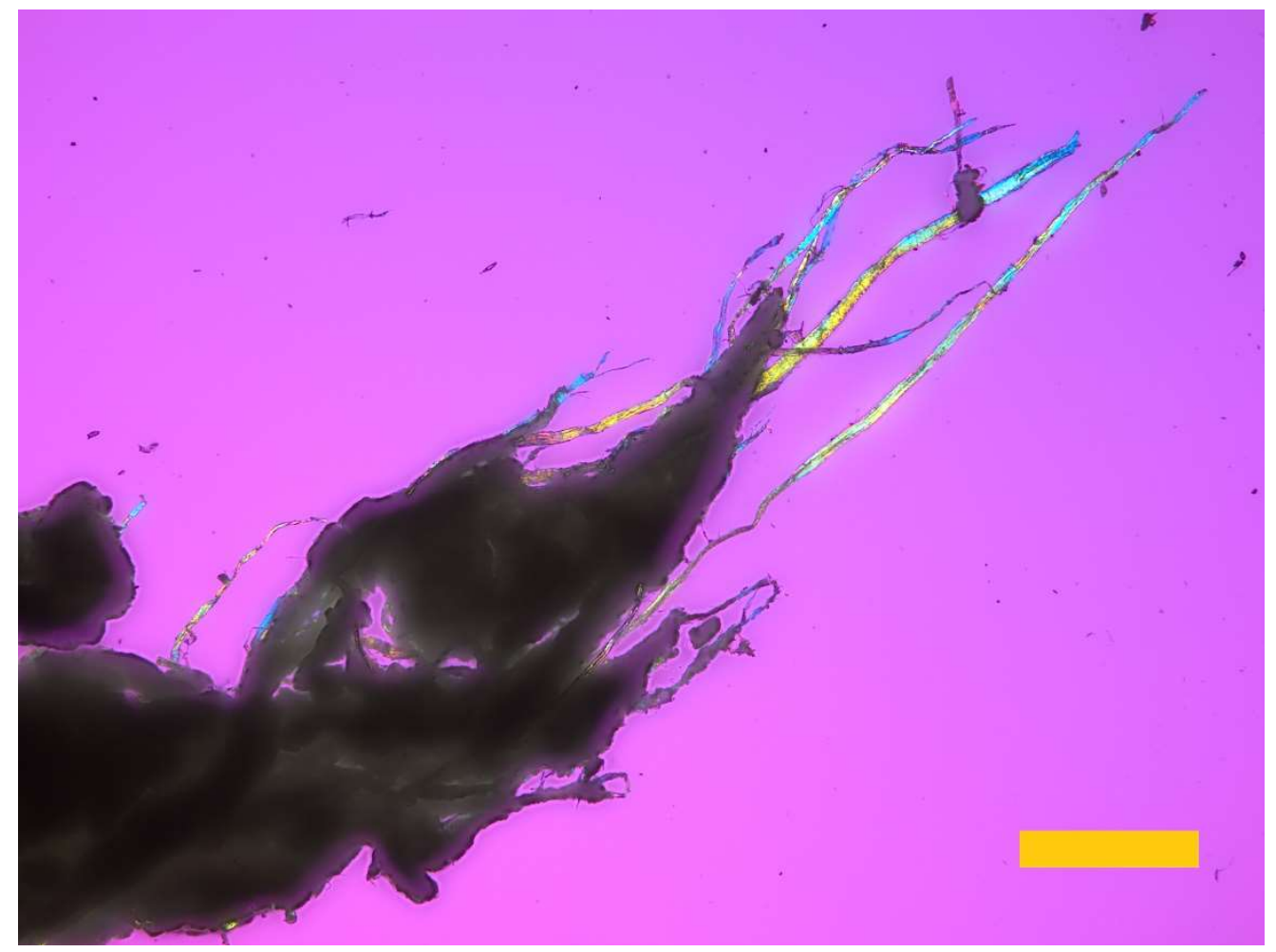

Figure S23. POM image of the pristine surface of CF. Scale bar: $200 \mu \mathrm{m}$.

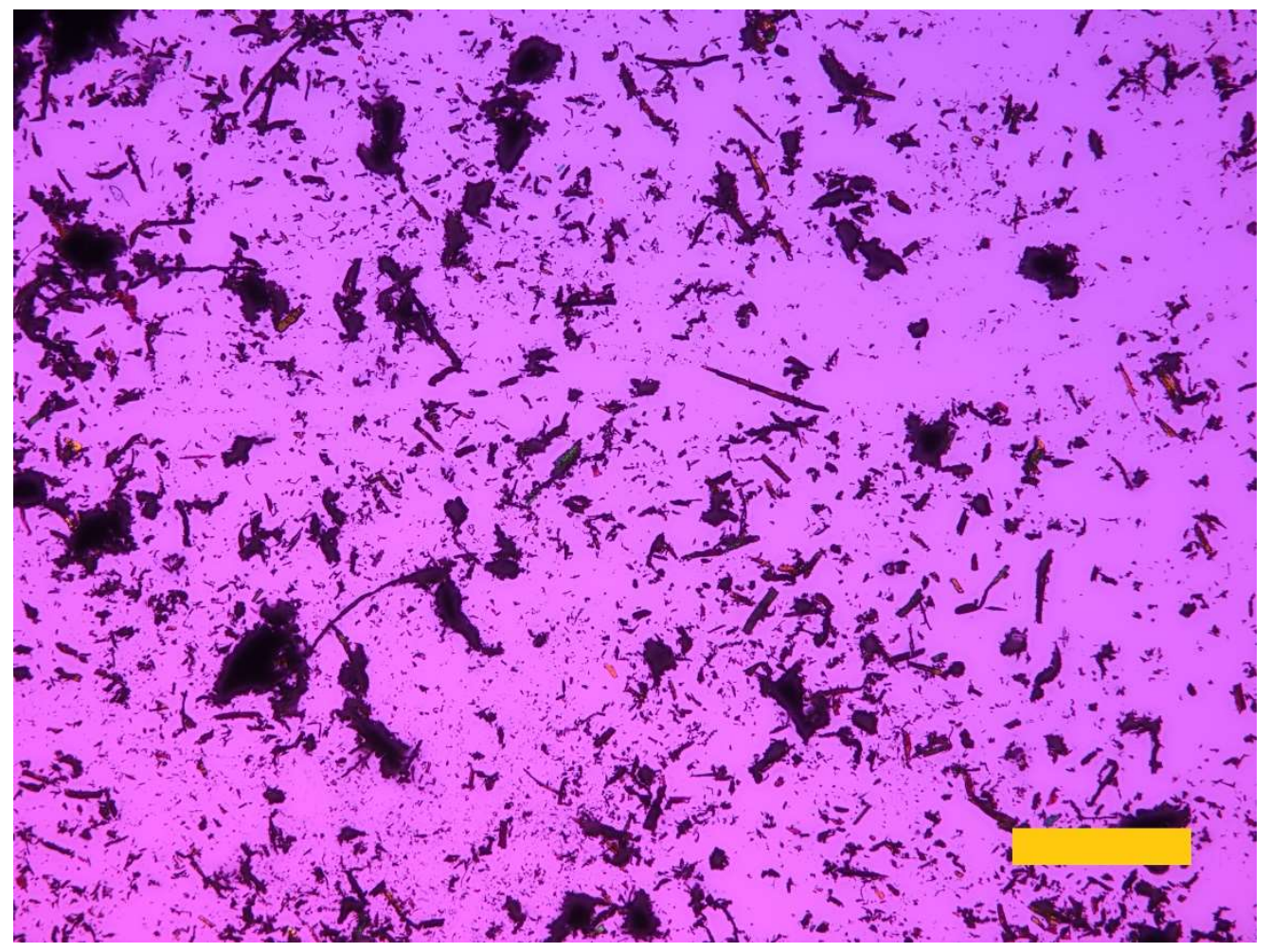

Figure S24. POM image of the surface of CF at the pyrolysis stage under air atmosphere. Scale bar: 200 $\mu \mathrm{m}$. 


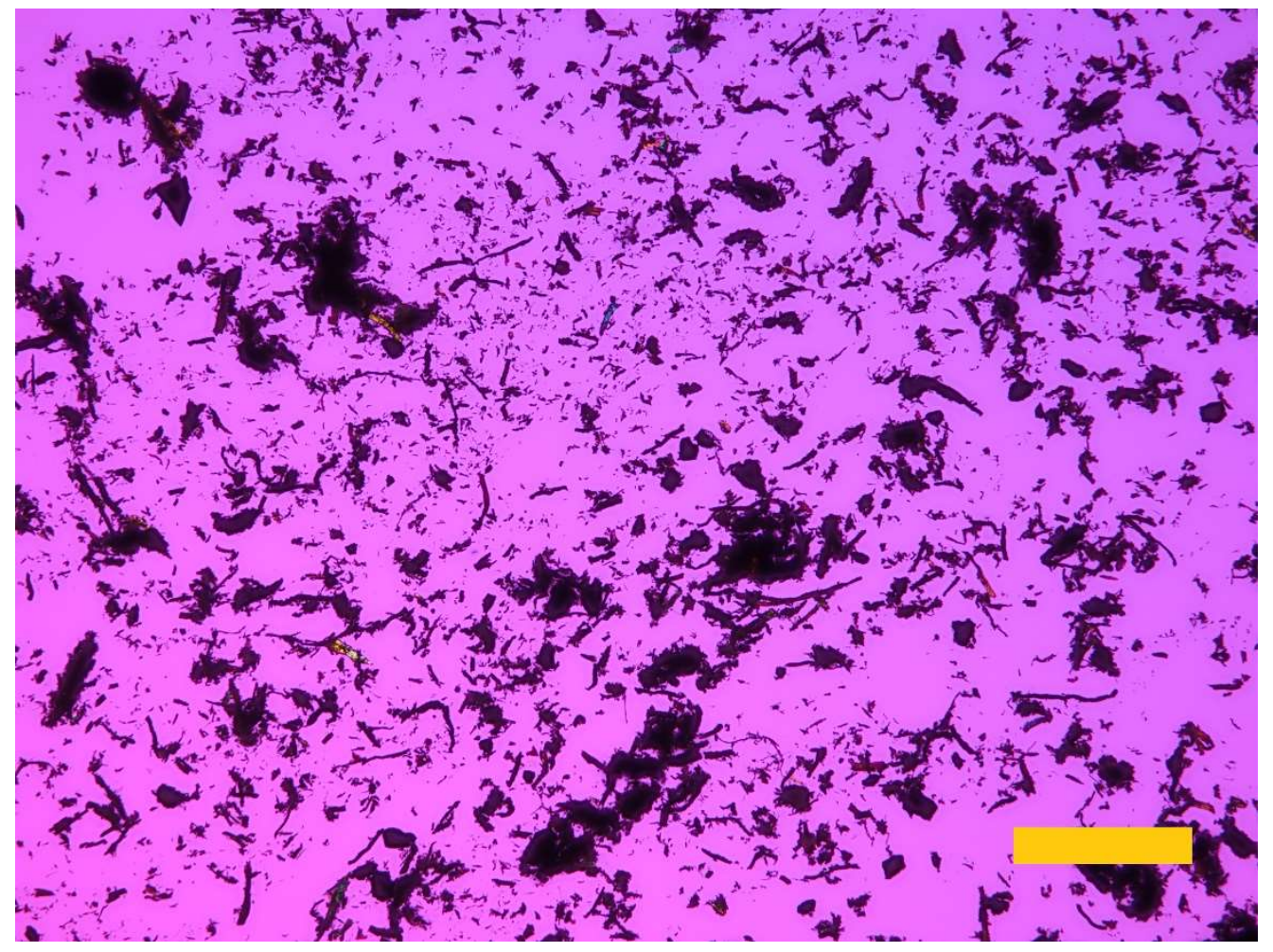

Figure S25. POM image of the surface of $\mathrm{CF}$ at the pyrolysis stage under $\mathrm{N}_{2}$ atmosphere. Scale bar: 200 $\mu \mathrm{m}$.

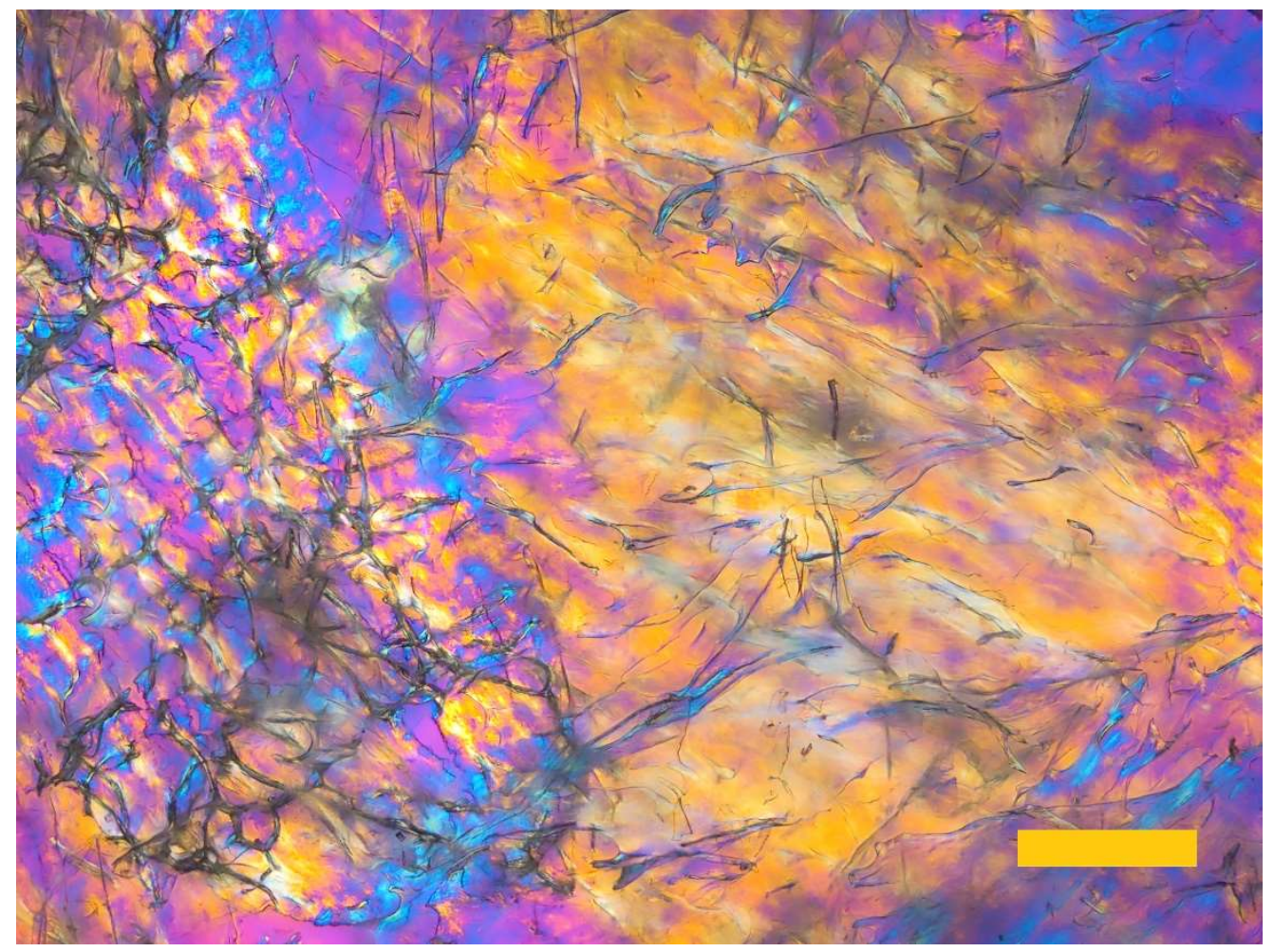

Figure S26. POM image of the surface of CNC-H. Scale bar: $200 \mu \mathrm{m}$. 


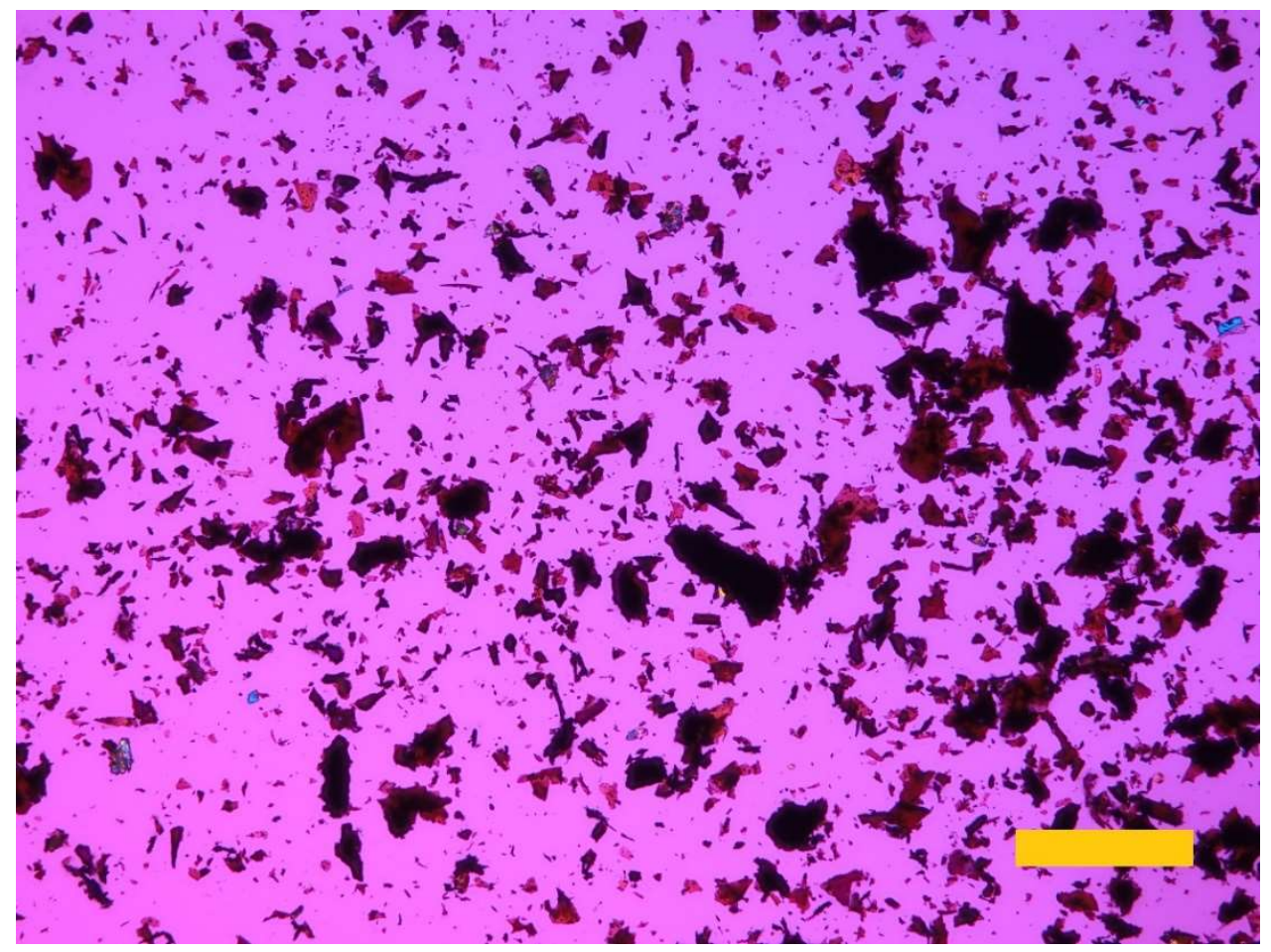

Figure S27. POM image of the surface of CNC-H at the primary pyrolysis stage under air atmosphere.

Scale bar: $200 \mu \mathrm{m}$.

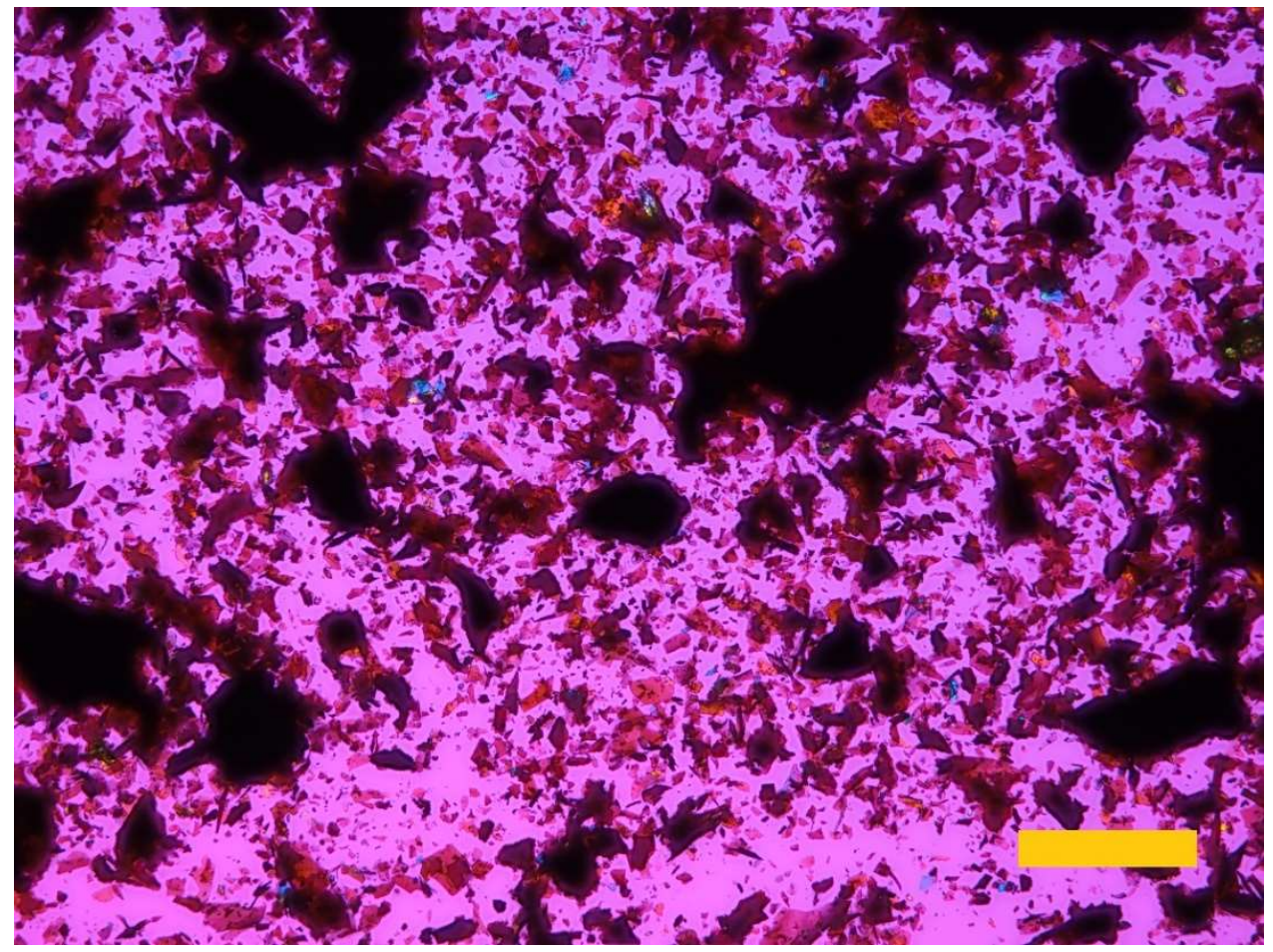

Figure S28. POM image of the surface of $\mathrm{CNC}-\mathrm{H}$ at the primary pyrolysis stage under $\mathrm{N}_{2}$ atmosphere.

Scale bar: $200 \mu \mathrm{m}$. 


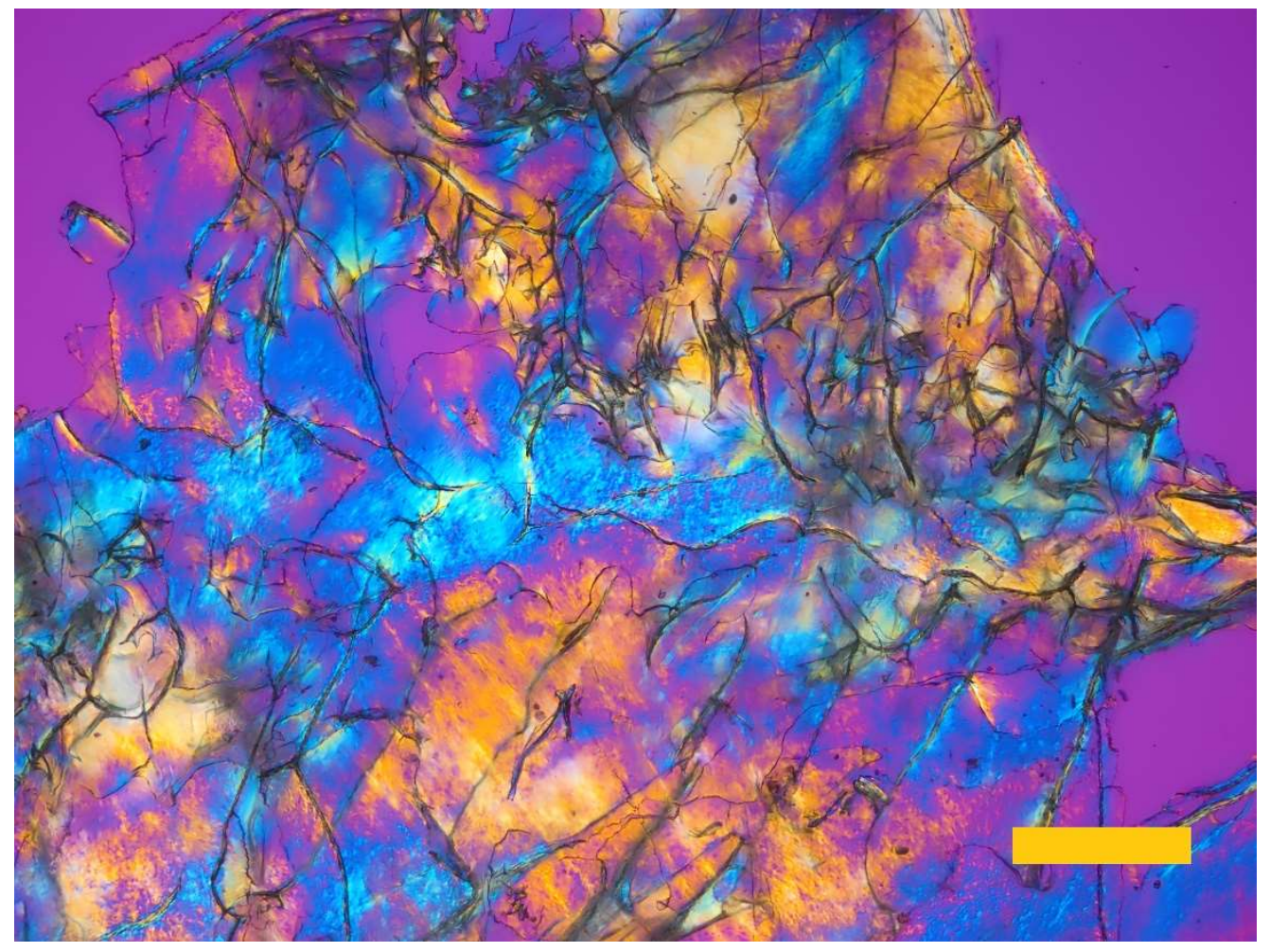

Figure S29. POM image of the surface of CNC-Na. Scale bar: $200 \mu \mathrm{m}$.

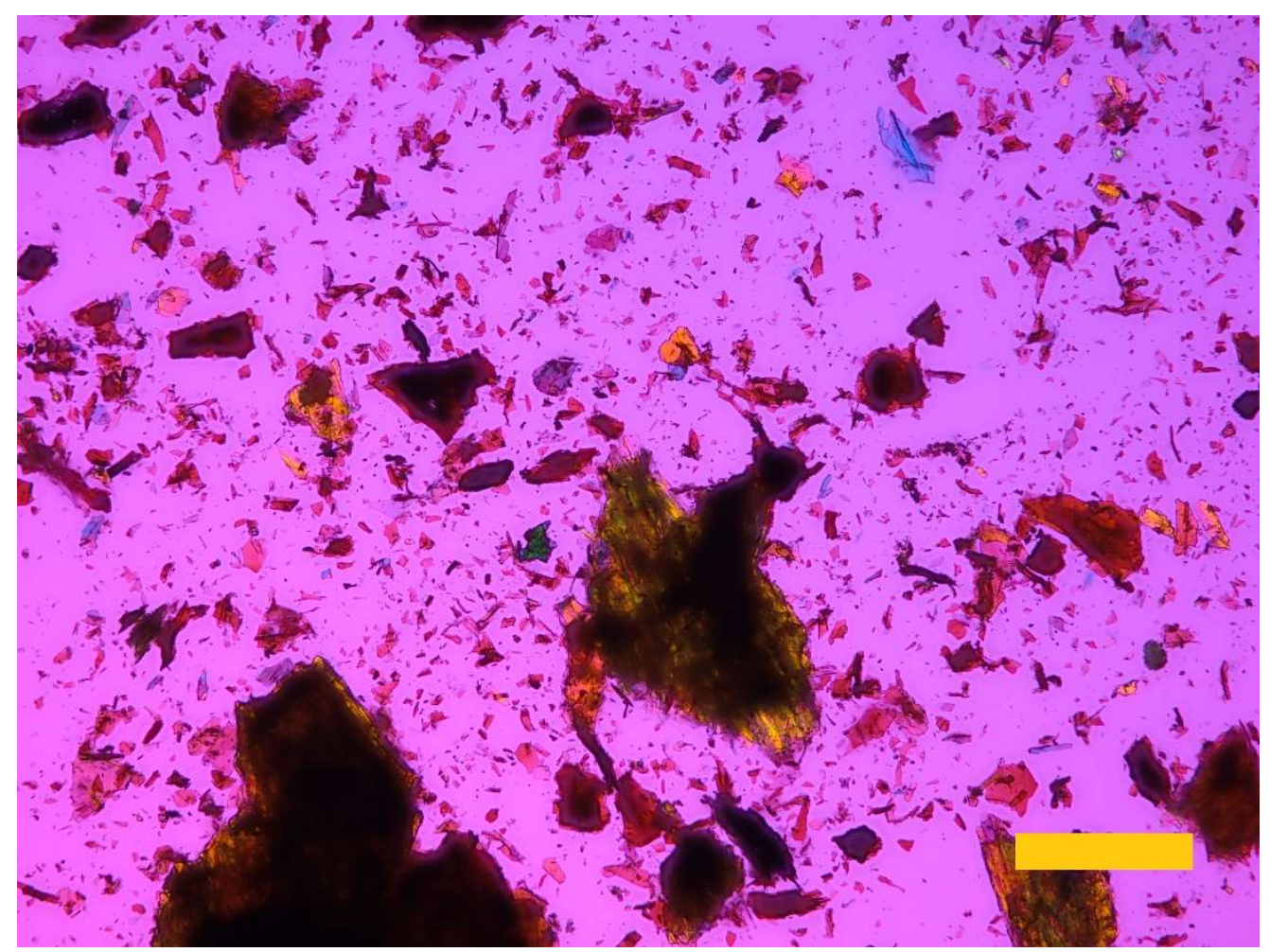

Figure S30. POM image of the surface of CNC-Na at the primary pyrolysis stage under air atmosphere.

Scale bar: $200 \mu \mathrm{m}$. 


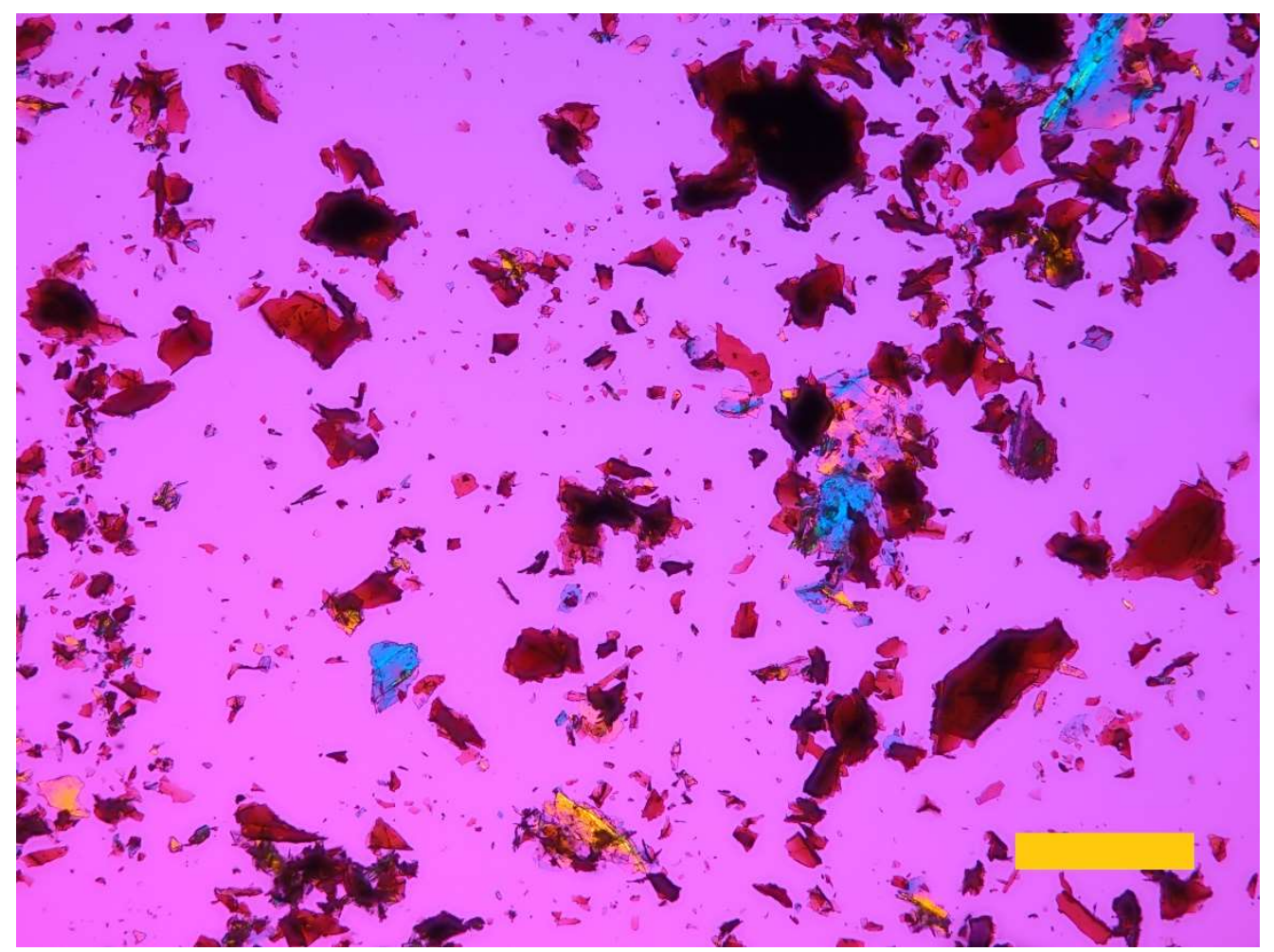

Figure S31. POM image of the surface of $\mathrm{CNC}-\mathrm{Na}$ at the primary pyrolysis stage under $\mathrm{N}_{2}$ atmosphere. Scale bar: $200 \mu \mathrm{m}$. 


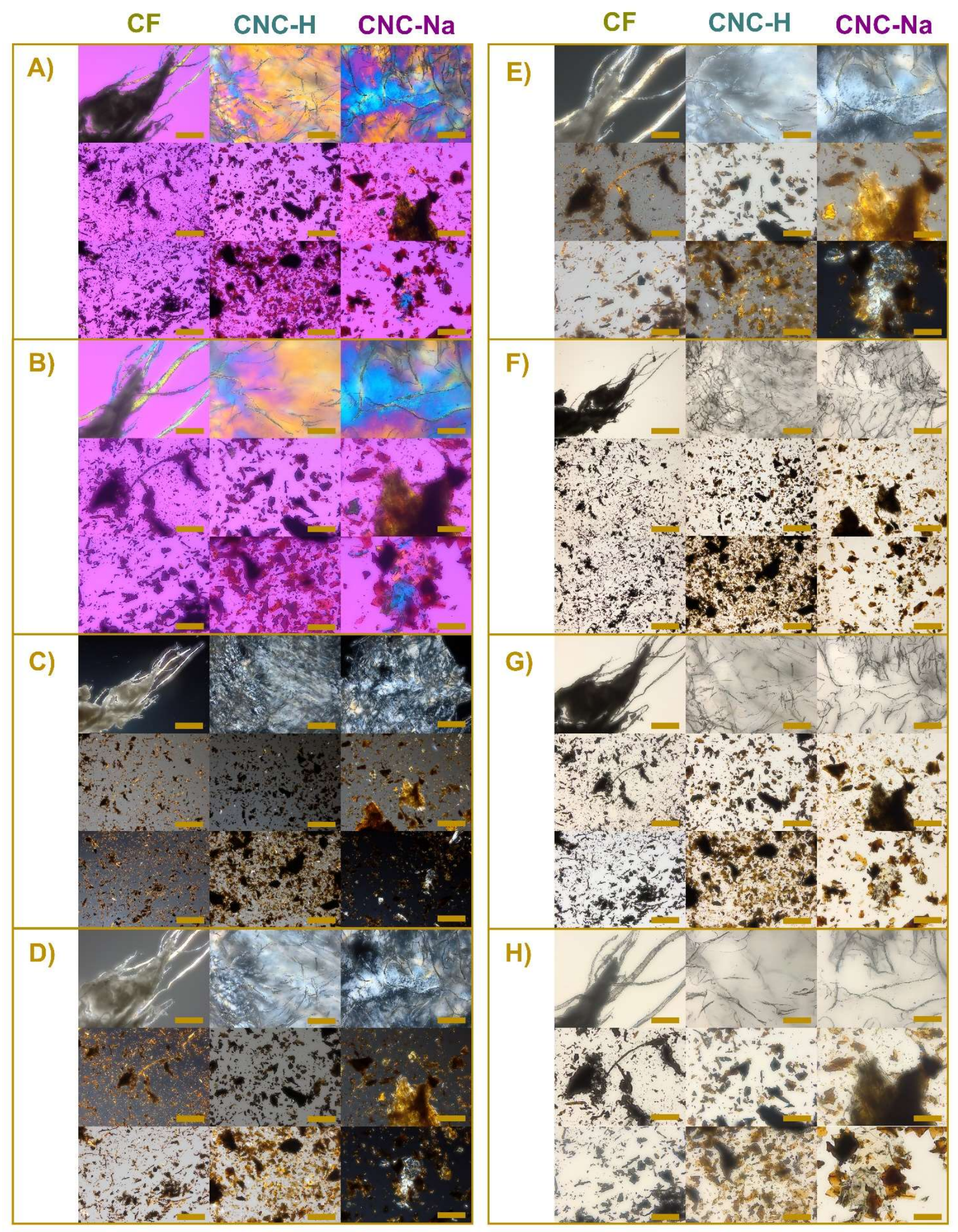

Figure S32. POM images of the pristine surface of CFs, CNC-H, and CNC-Na (top row), and char of the 
same materials at the primary pyrolysis stage using a heating rate of $10^{\circ} \mathrm{C} / \mathrm{min}$ under air (second row) and $\mathrm{N}_{2}$ atmospheres (third row). The images were taken $(\mathrm{A}, \mathrm{B})$ between crossed polarizers with a lambda plate at (A) 10x, and (B) 20x magnifications; (C-E) between crossed polarizers without a lambda plate at (C) 5x, (D) 10x, and (E) 20x magnifications; (F-H) without polarizers at (F) 5x, (G) 10x, and (H) 20x magnifications. Scale bars: (C,F) $200 \mu \mathrm{m},(\mathrm{A}, \mathrm{D}, \mathrm{G}) 100 \mu \mathrm{m},(\mathrm{B}, \mathrm{E}, \mathrm{H}) 50 \mu \mathrm{m}$. 


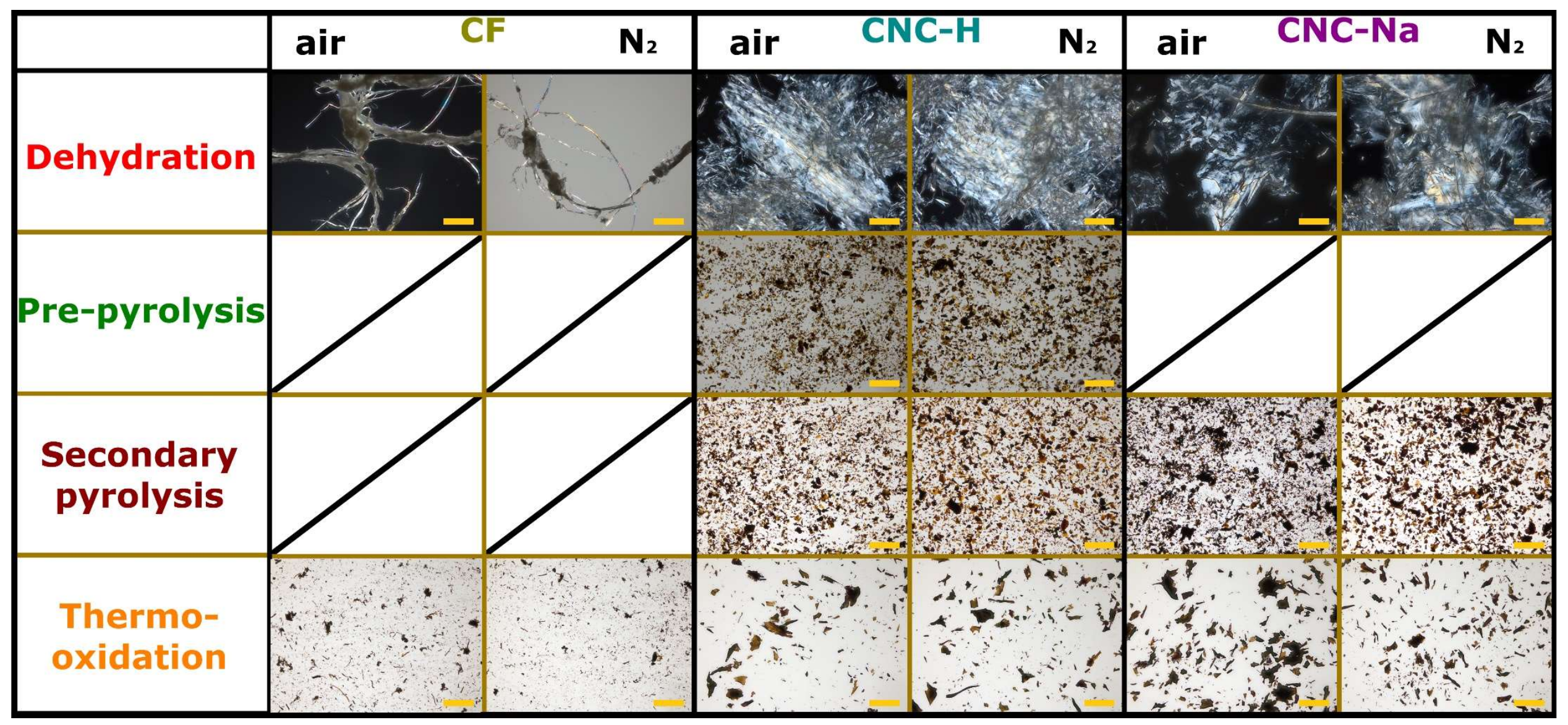

Figure S33. POM images (between crossed polarizers) of the pristine birefringent surface of CF, CNC-H, and CNC-Na and debris of the same materials at dehydration, pre-pyrolysis, secondary pyrolysis, and thermo-oxidation stages using a heating rate of $10{ }^{\circ} \mathrm{C} / \mathrm{min}$ under air and $\mathrm{N}_{2}$ atmospheres. Crossed boxes represent degradation stages that do not take place. Scale bar: $200 \mu \mathrm{m}$. 


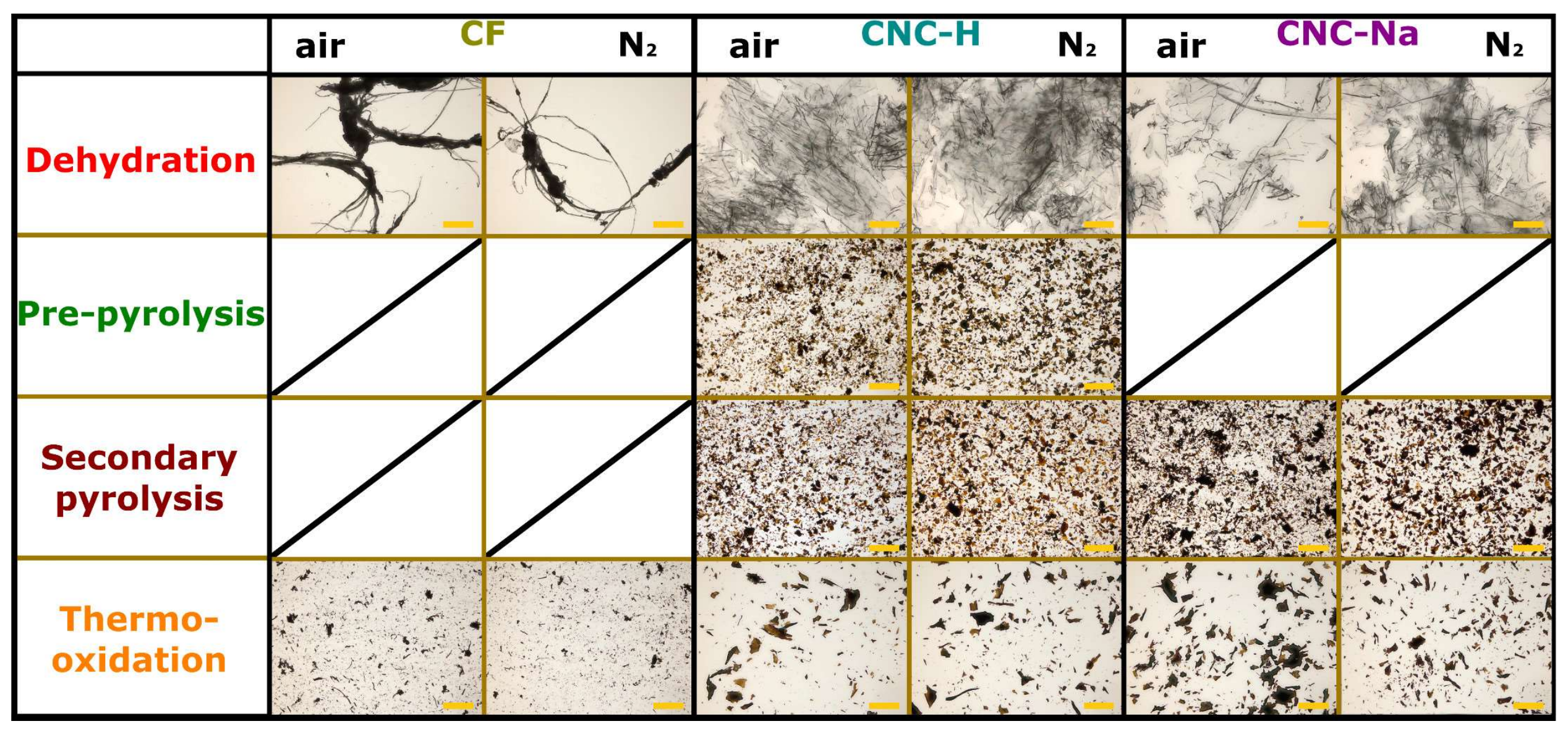

Figure S34. POM images (without polarizers) of the pristine birefringent surface of $\mathrm{CF}, \mathrm{CNC}-\mathrm{H}$, and $\mathrm{CNC}-\mathrm{Na}$ and debris of the same materials at dehydration, pre-pyrolysis, secondary pyrolysis, and thermo-oxidation stages using a heating rate of $10{ }^{\circ} \mathrm{C} / \mathrm{min}$ under air and $\mathrm{N}_{2}$ atmospheres. Crossed boxes represent degradation stages that do not take place. Scale bar: $200 \mu \mathrm{m}$. 


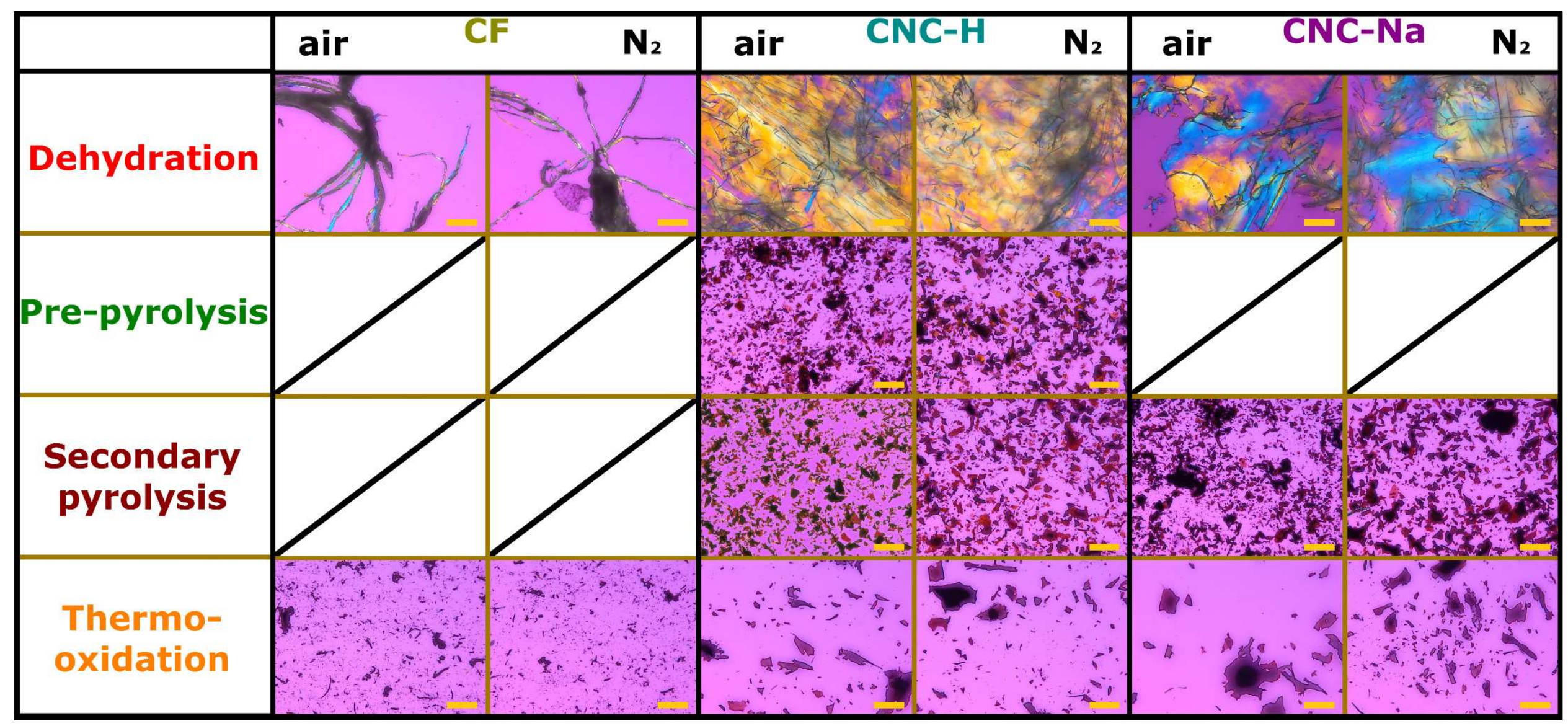

Figure S35. POM images (between crossed polarizers with a lambda plate) of the pristine birefringent surface of CF, CNC-H, and CNC-Na and debris of the same materials at dehydration, pre-pyrolysis, secondary pyrolysis, and thermo-oxidation stages using a heating rate of $10^{\circ} \mathrm{C} / \mathrm{min}$ under air and $\mathrm{N}_{2}$ atmospheres. Crossed boxes represent degradation stages that do not take place. Scale bar: $100 \mu \mathrm{m}$. 


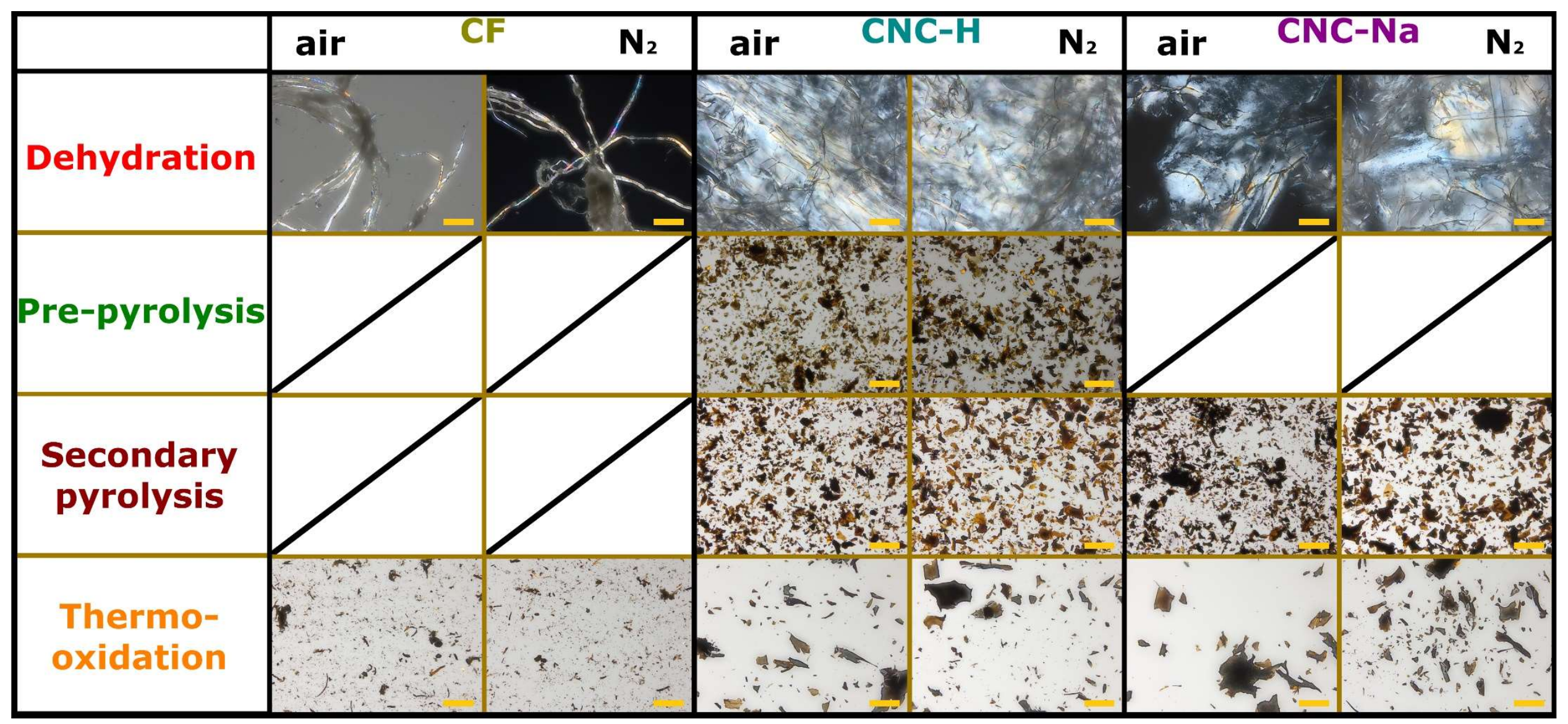

Figure S36. POM images (between crossed polarizers) of the pristine birefringent surface of CF, CNC-H, and CNC-Na and debris of the same materials at dehydration, pre-pyrolysis, secondary pyrolysis, and thermo-oxidation stages using a heating rate of $10^{\circ} \mathrm{C} / \mathrm{min}$ under air and $\mathrm{N}_{2}$ atmospheres. Crossed boxes represent degradation stages that do not take place. Scale bar: $100 \mu \mathrm{m}$. 


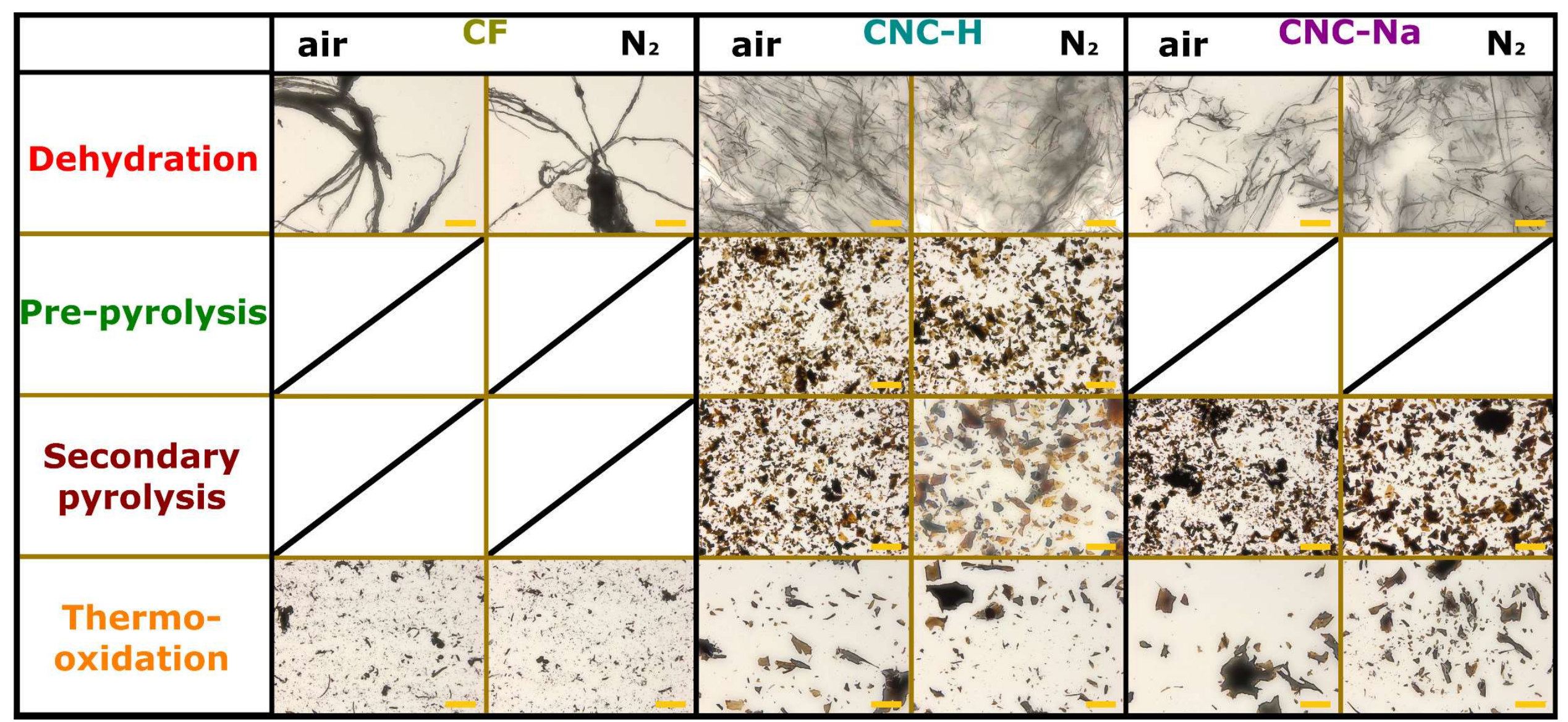

Figure S37. POM images (without polarizers) of the pristine birefringent surface of $\mathrm{CF}, \mathrm{CNC}-\mathrm{H}$, and $\mathrm{CNC}-\mathrm{Na}$ and debris of the same materials at dehydration, pre-pyrolysis, secondary pyrolysis, and thermo-oxidation stages using a heating rate of $10{ }^{\circ} \mathrm{C} / \mathrm{min}$ under air and $\mathrm{N}_{2}$ atmospheres. Crossed boxes represent degradation stages that do not take place. Scale bar: $100 \mu \mathrm{m}$. 


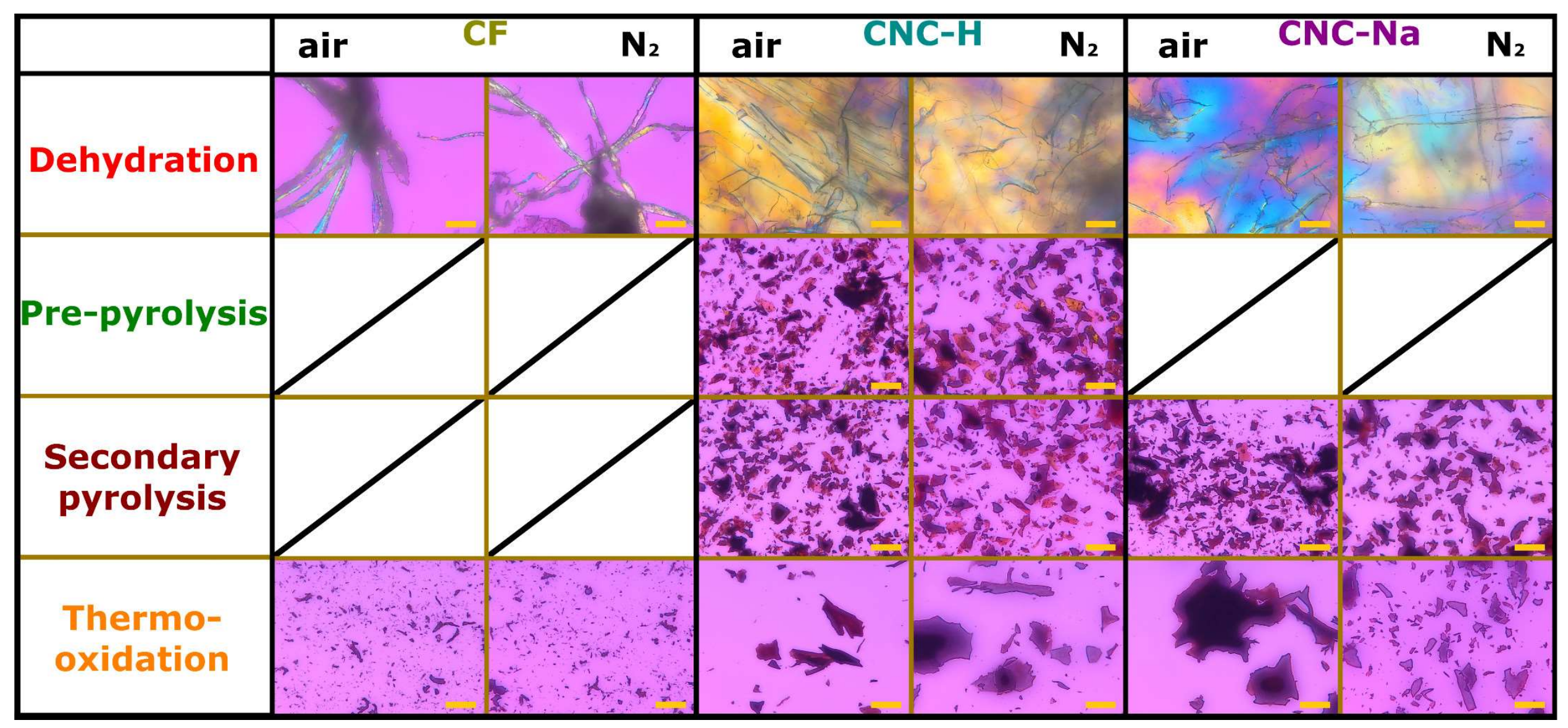

Figure S38. POM images (between crossed polarizers with a lambda plate) of the pristine birefringent surface of CF, CNC-H, and CNC-Na and debris of the same materials at dehydration, pre-pyrolysis, secondary pyrolysis, and thermo-oxidation stages using a heating rate of $10^{\circ} \mathrm{C} / \mathrm{min}$ under air and $\mathrm{N}_{2}$ atmospheres. Crossed boxes represent degradation stages that do not take place. Scale bar: $50 \mu \mathrm{m}$. 


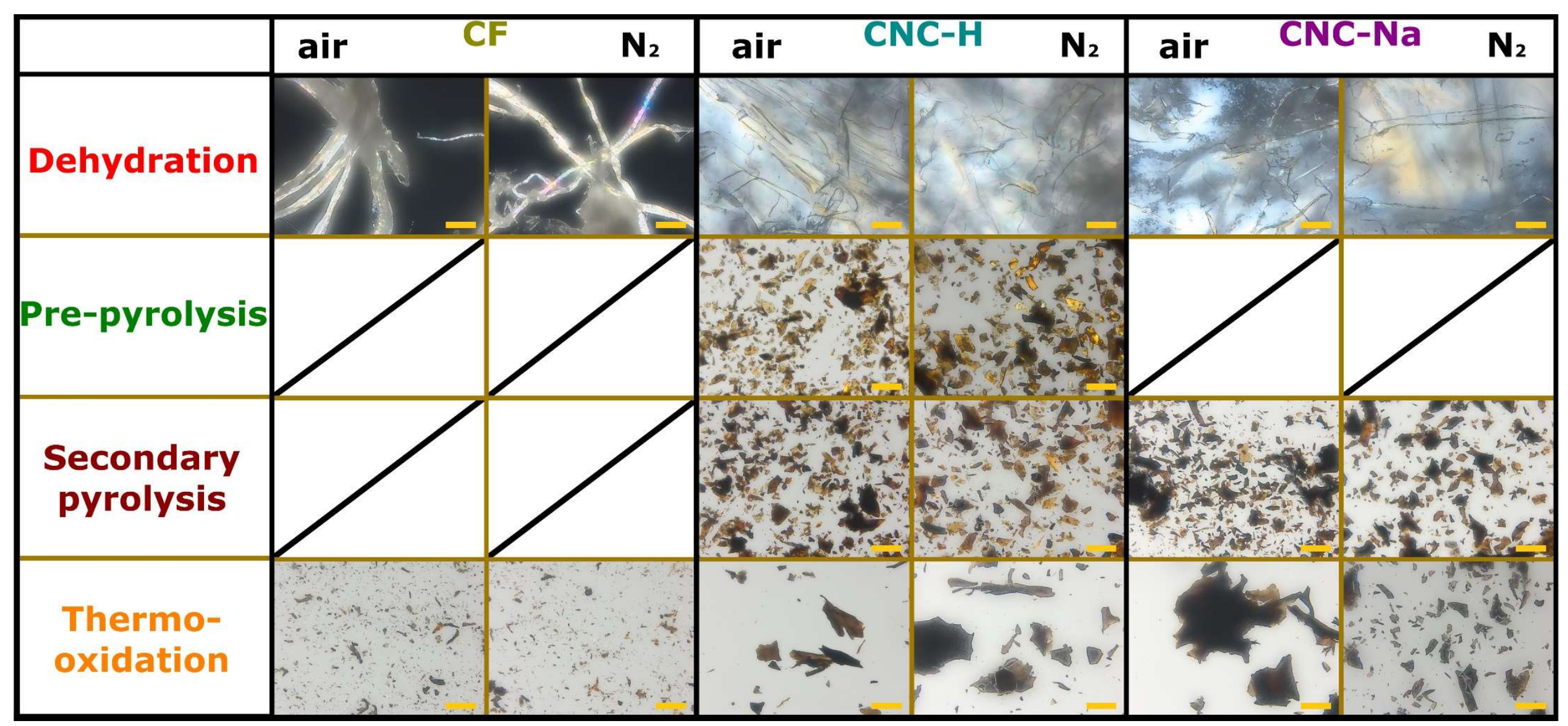

Figure S39. POM images (between crossed polarizers) of the pristine birefringent surface of CF, CNC-H, and CNC-Na and debris of the same materials at dehydration, pre-pyrolysis, secondary pyrolysis, and thermo-oxidation stages using a heating rate of $10^{\circ} \mathrm{C} / \mathrm{min}$ under air and $\mathrm{N}_{2}$ atmospheres. Crossed boxes represent degradation stages that do not take place. Scale bar: $50 \mu \mathrm{m}$. 


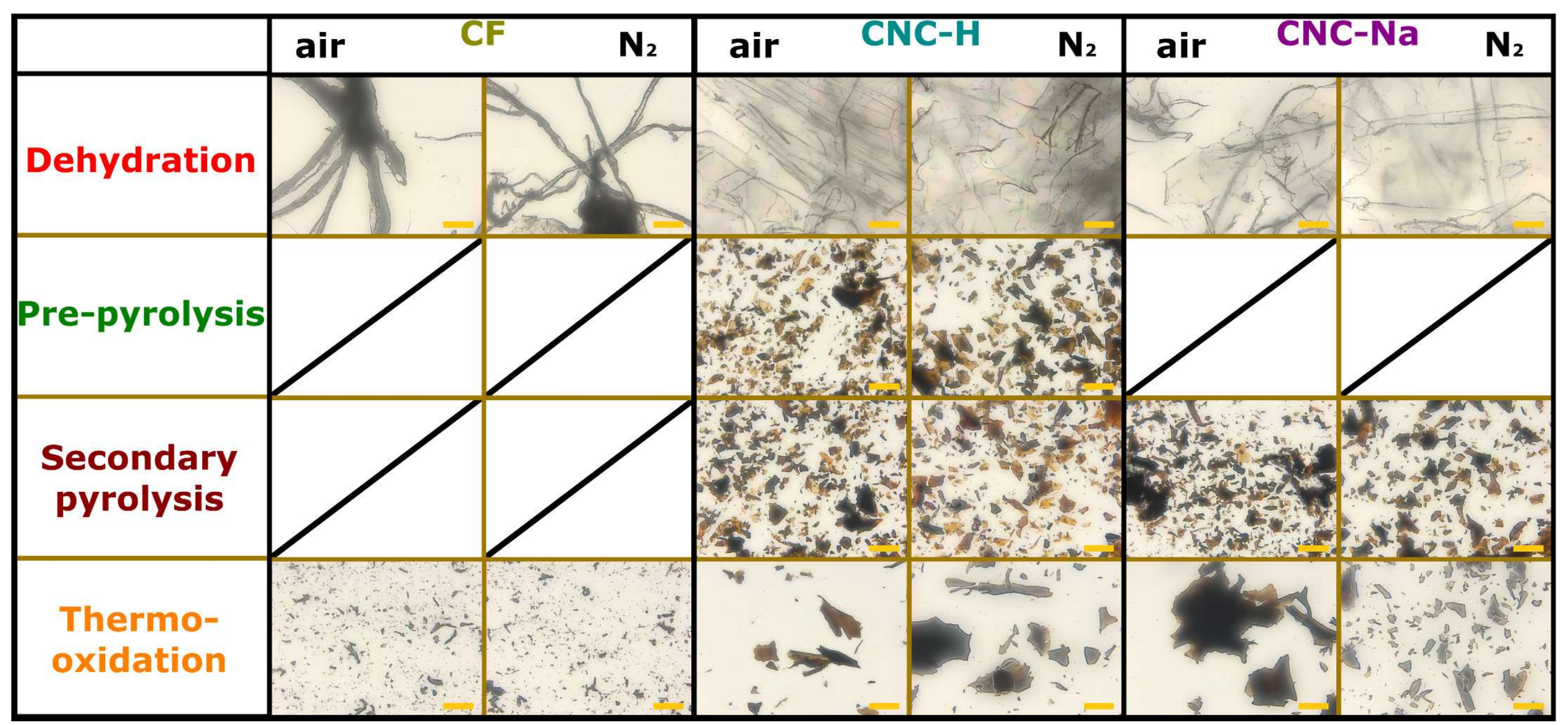

Figure S40. POM images (without polarizers) of the pristine birefringent surface of $\mathrm{CF}, \mathrm{CNC}-\mathrm{H}$, and $\mathrm{CNC}-\mathrm{Na}$ and debris of the same materials at dehydration, pre-pyrolysis, secondary pyrolysis, and thermo-oxidation stages using a heating rate of $10{ }^{\circ} \mathrm{C} / \mathrm{min}$ under air and $\mathrm{N}_{2}$ atmospheres. Crossed boxes represent degradation stages that do not take place. Scale bar: $50 \mu \mathrm{m}$. 


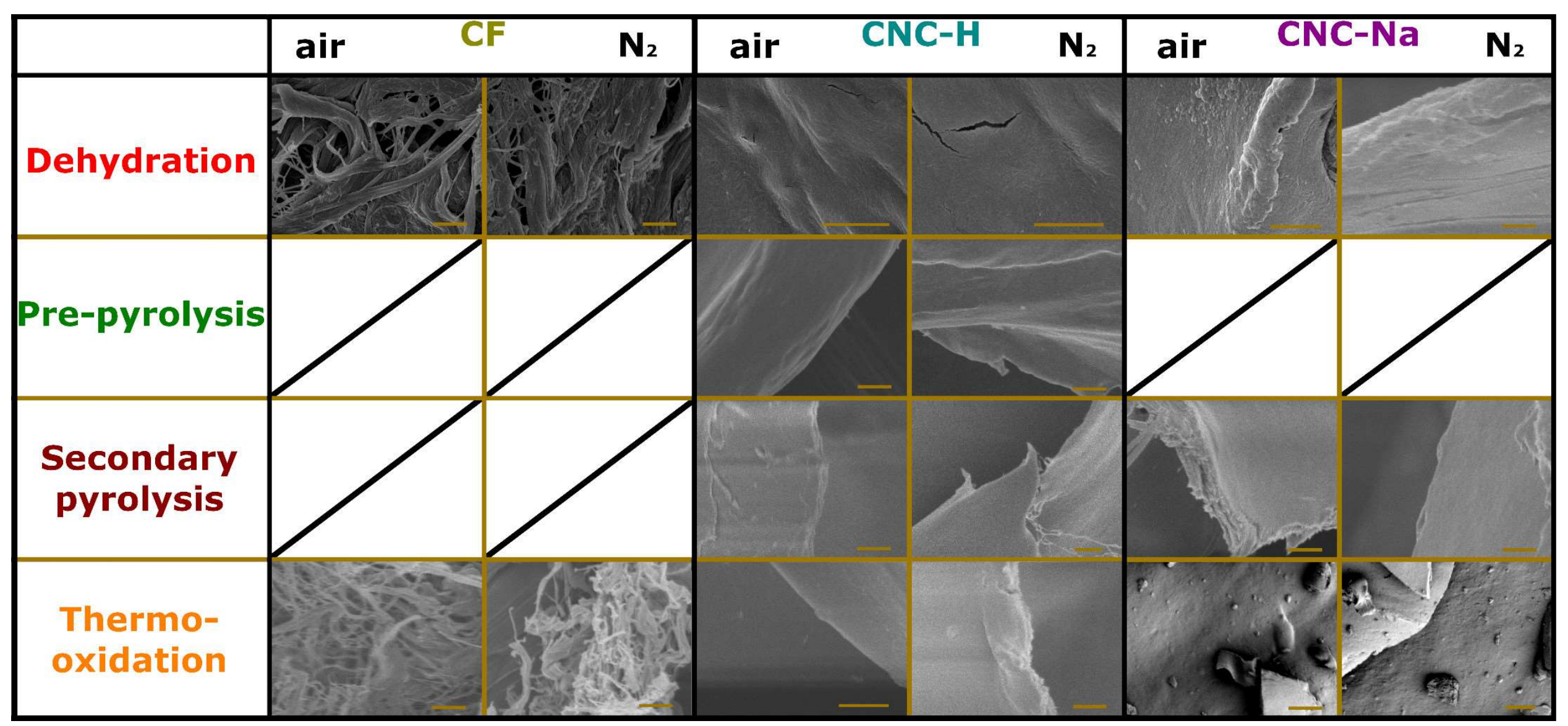

Figure S41. SEM images of the surface of CF, CNC-H, and CNC-Na at dehydration, pre-pyrolysis, secondary pyrolysis, and thermo-oxidation stages using a heating rate of $10^{\circ} \mathrm{C} / \mathrm{min}$ under air and $\mathrm{N}_{2}$ atmospheres. Crossed boxes represent degradation stages that do not take place. Scale bar: $1 \mu \mathrm{m}$. 


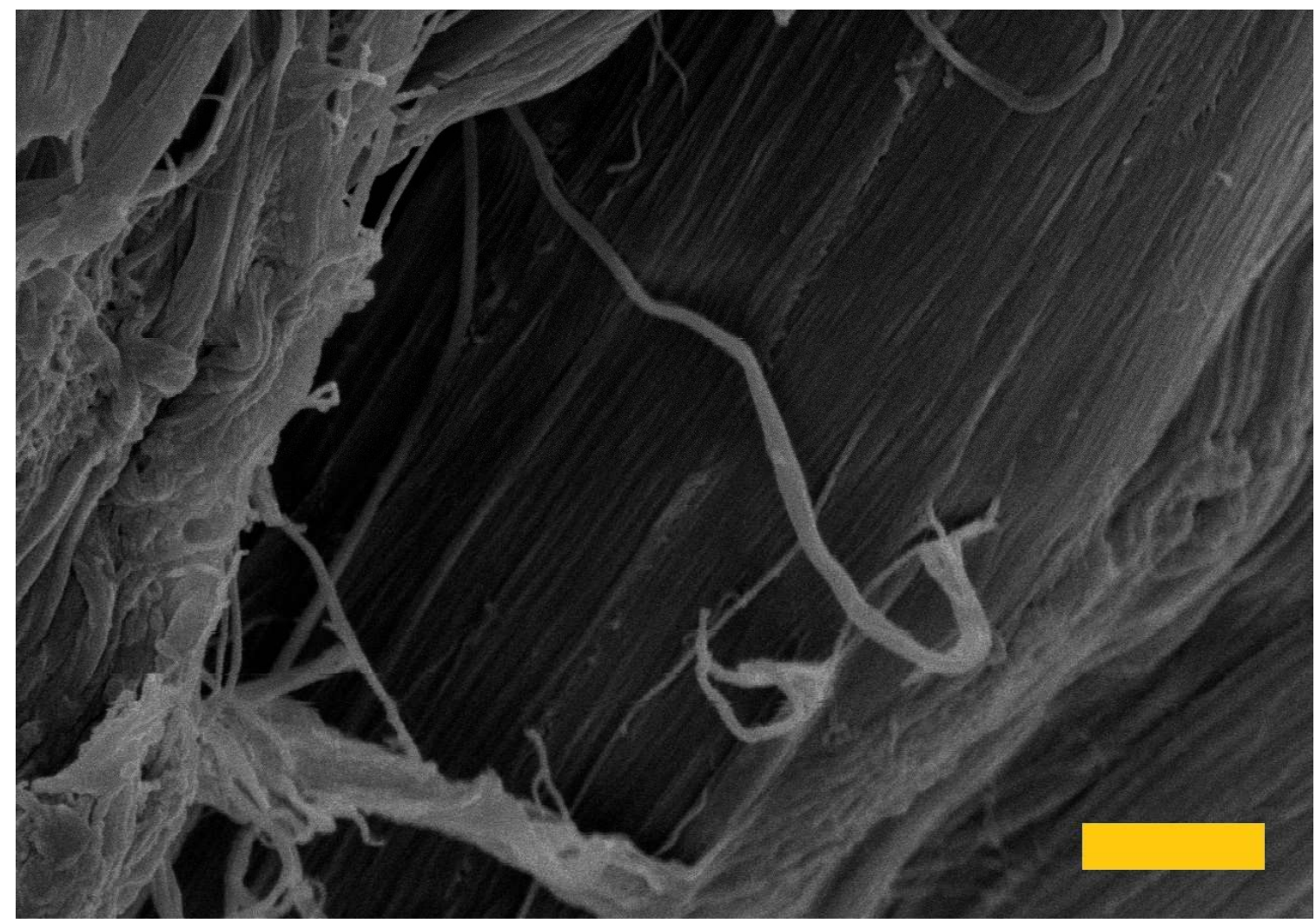

Figure S42. SEM image of the pristine surface of CF. Scale bar: $1 \mu \mathrm{m}$.

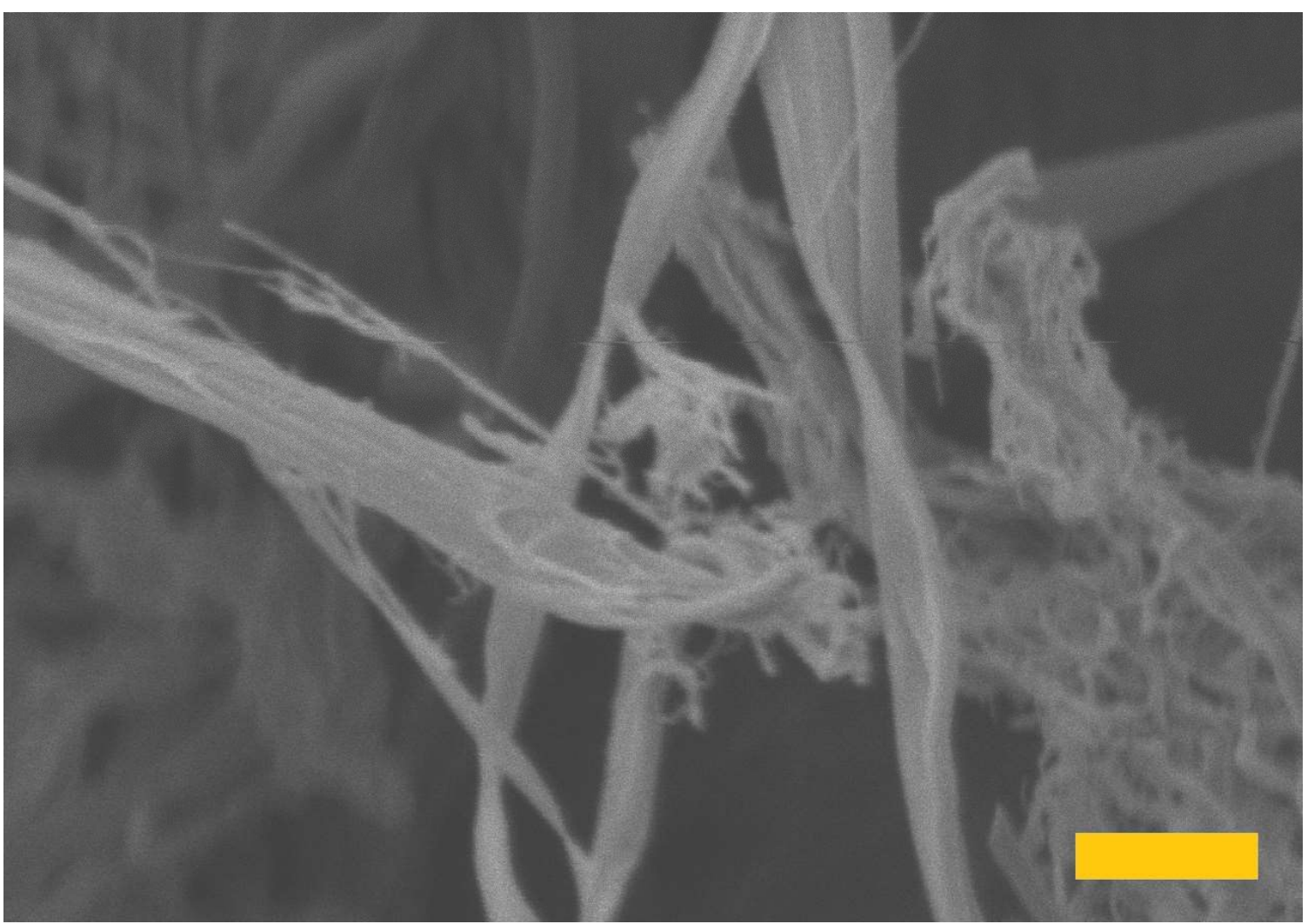

Figure S43. SEM image of the surface of CF at the pyrolysis stage under air atmosphere. Scale bar: 1 $\mu \mathrm{m}$. 


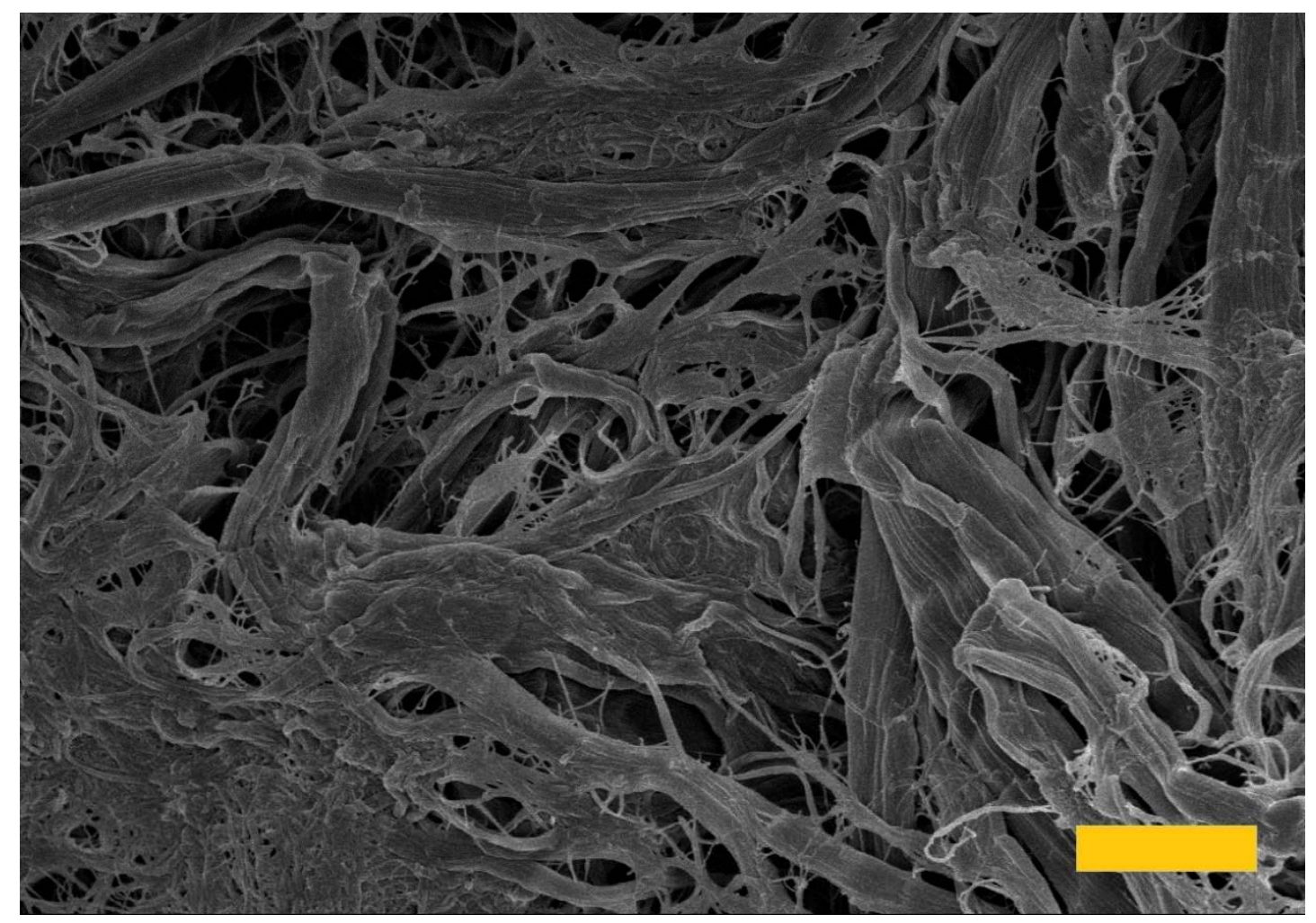

Figure S44. SEM image of the surface of CF at the pyrolysis stage under $\mathrm{N}_{2}$ atmosphere. Scale bar: 1 $\mu \mathrm{m}$.

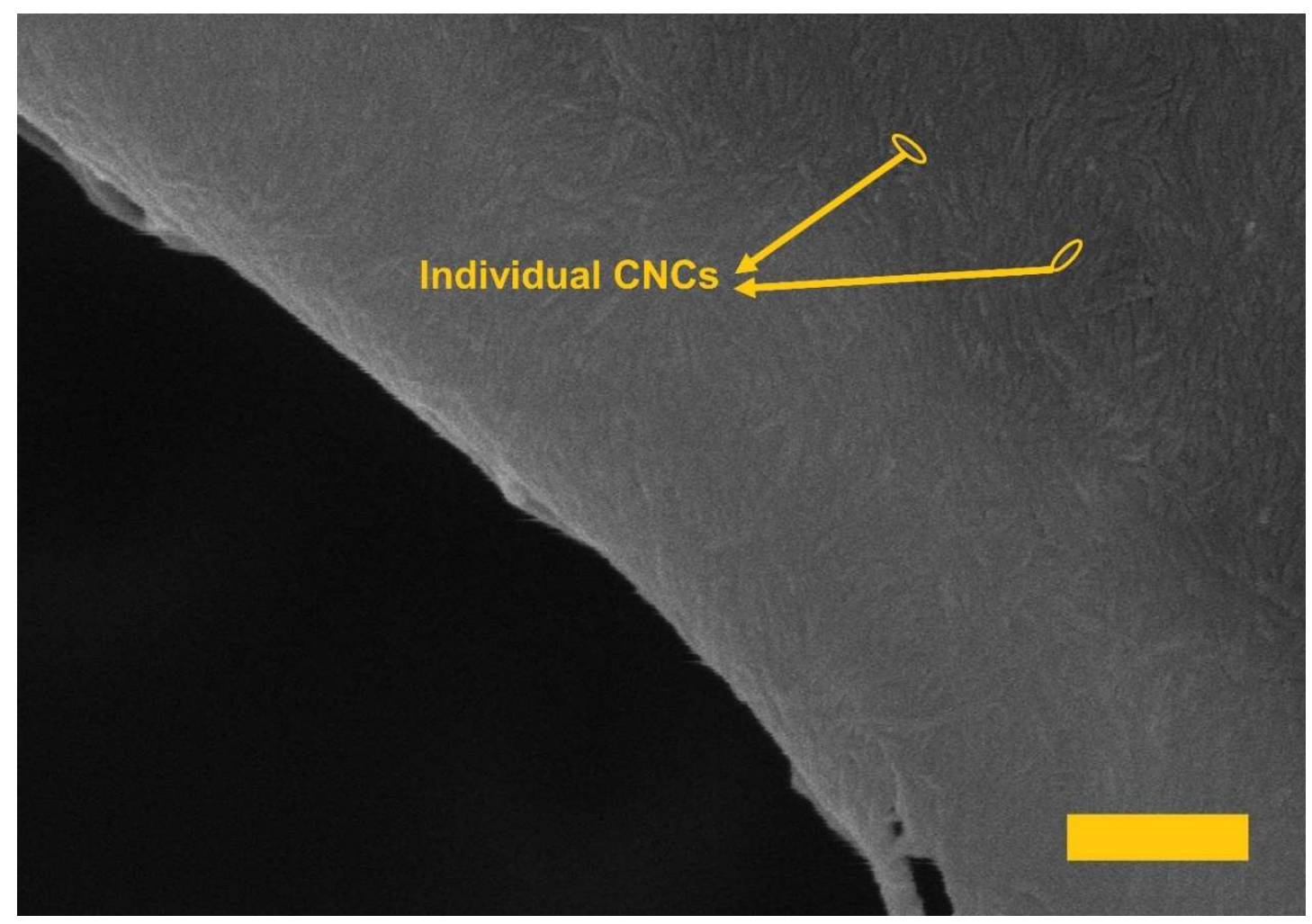

Figure S45. SEM image of the pristine surface of CNC-H (grey) close to an edge (black). Scale bar: 1 $\mu \mathrm{m}$. 


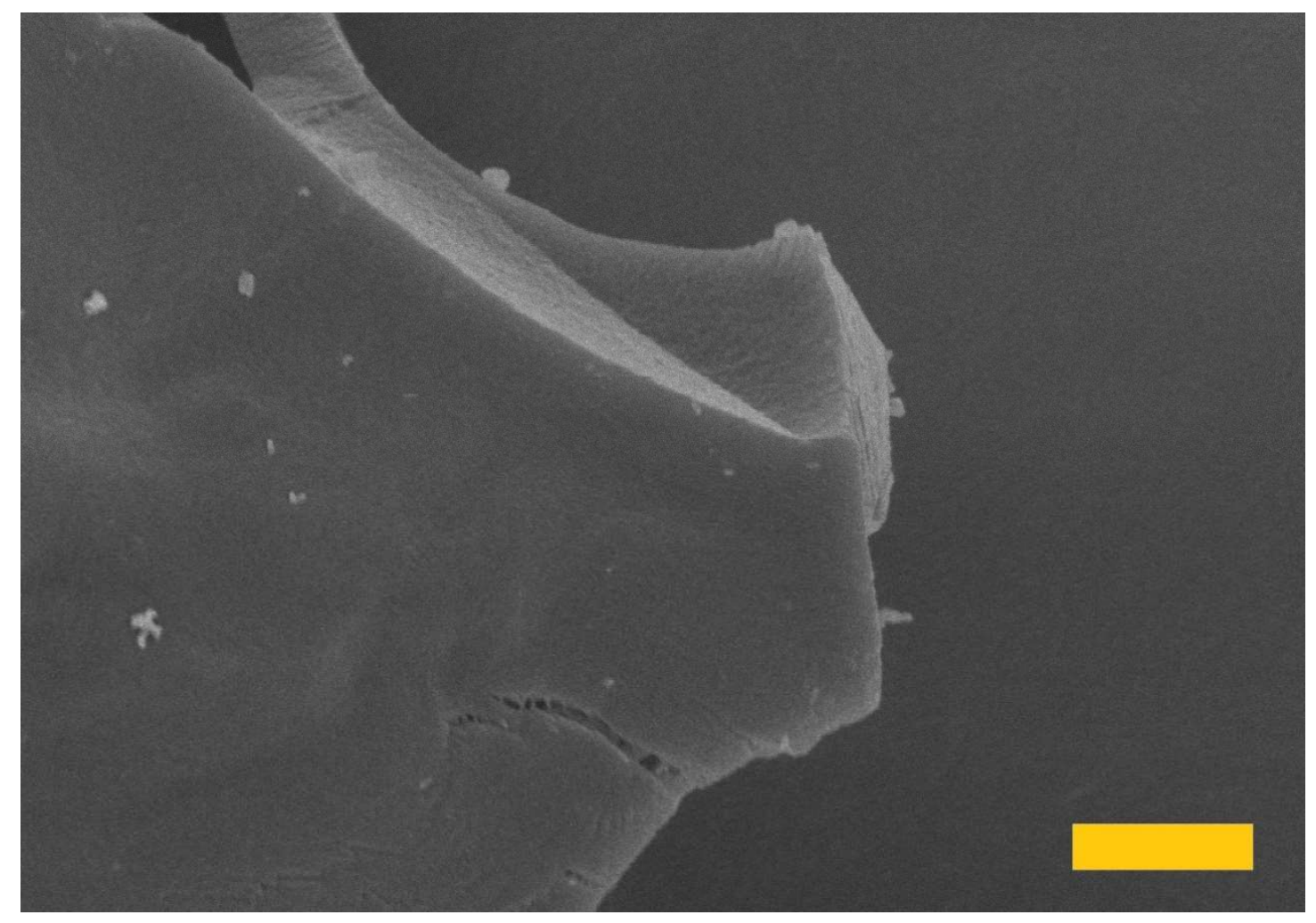

Figure S46. SEM image of the surface of CNC-H at the primary pyrolysis stage under air atmosphere.

Scale bar: $1 \mu \mathrm{m}$.

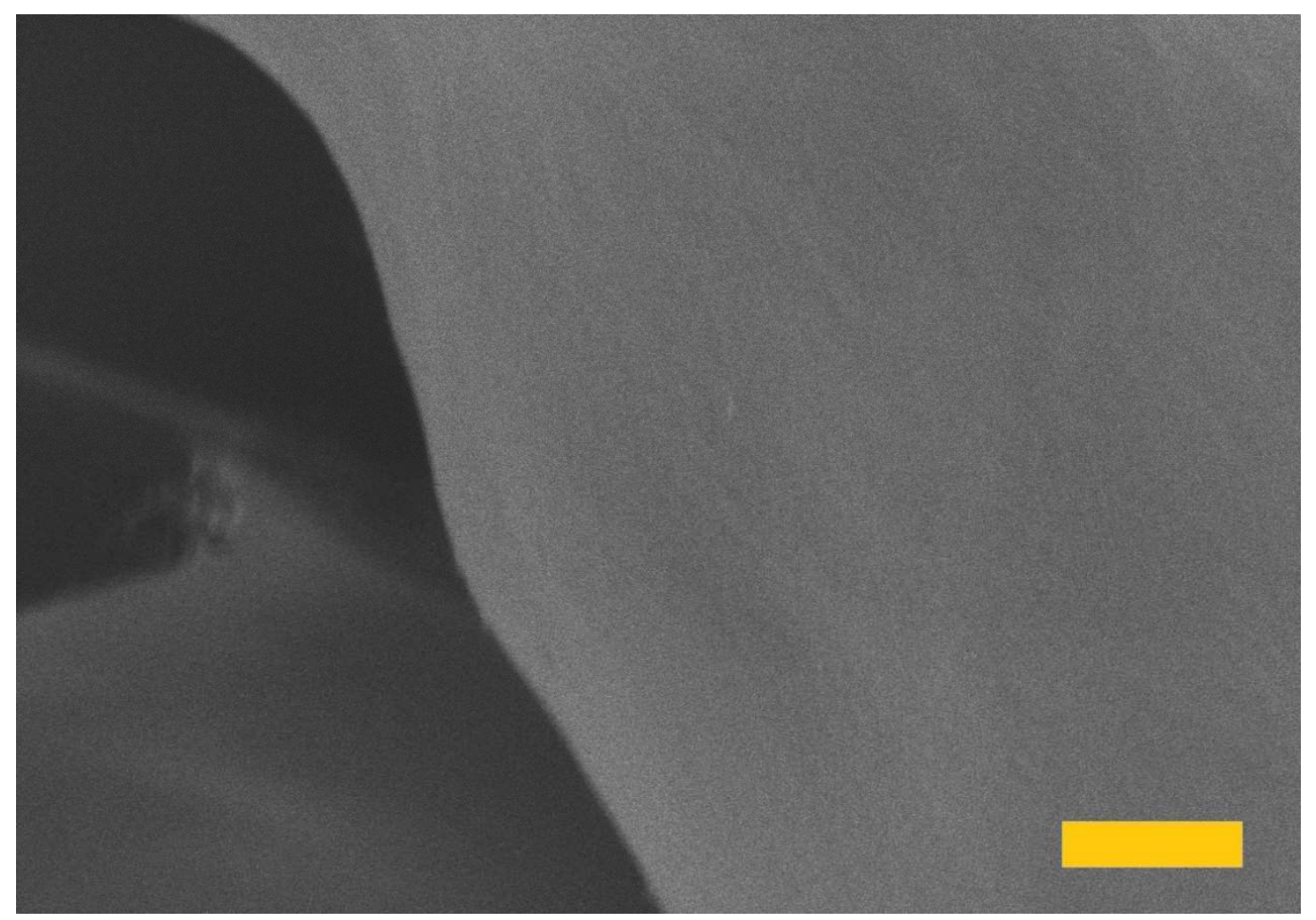

Figure S47. SEM image of the surface of $\mathrm{CNC}-\mathrm{H}$ at the primary pyrolysis stage under $\mathrm{N}_{2}$ atmosphere. Scale bar: $1 \mu \mathrm{m}$. 


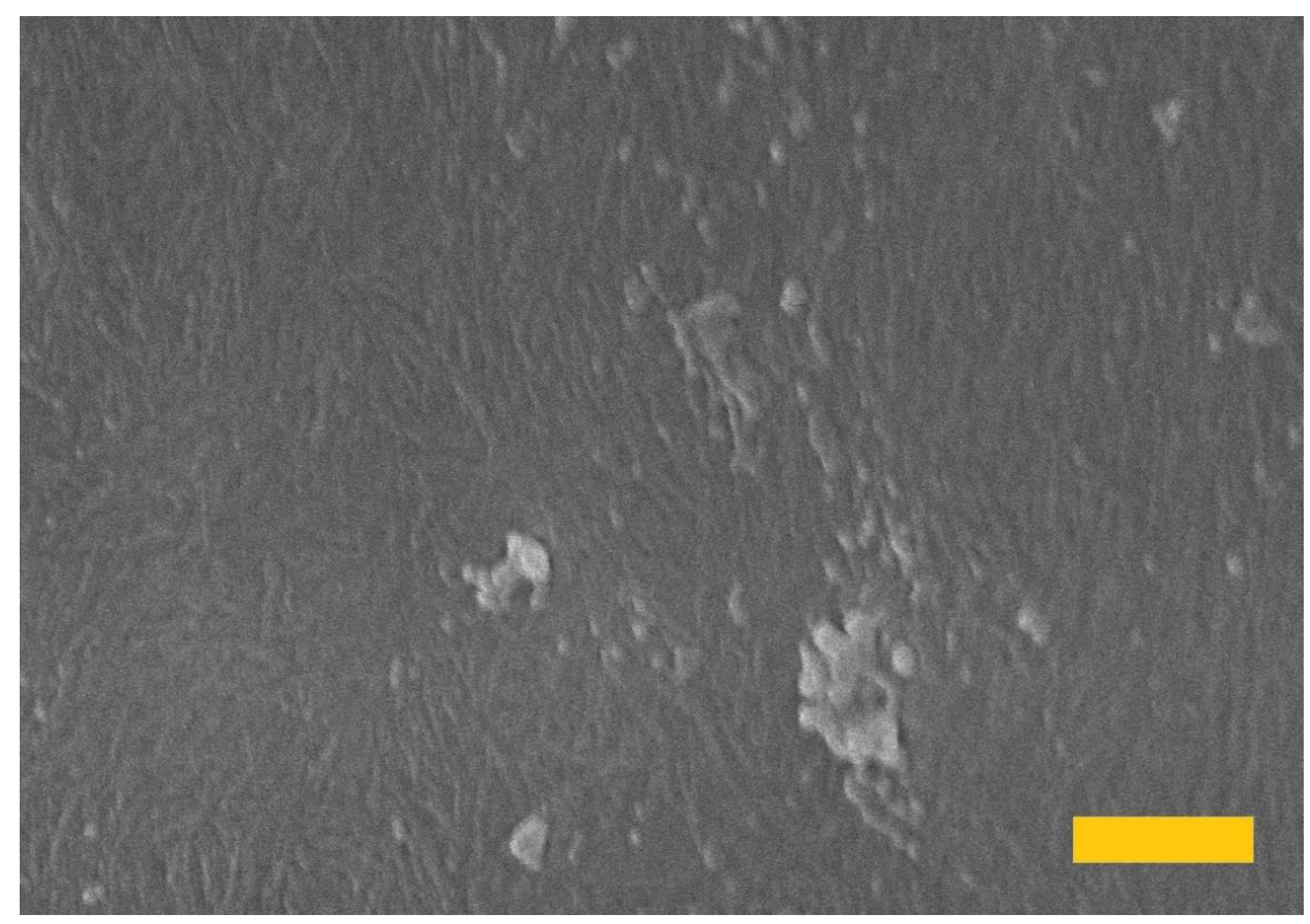

Figure S48. SEM image of the pristine surface of CNC-Na. Scale bar: $1 \mu \mathrm{m}$.

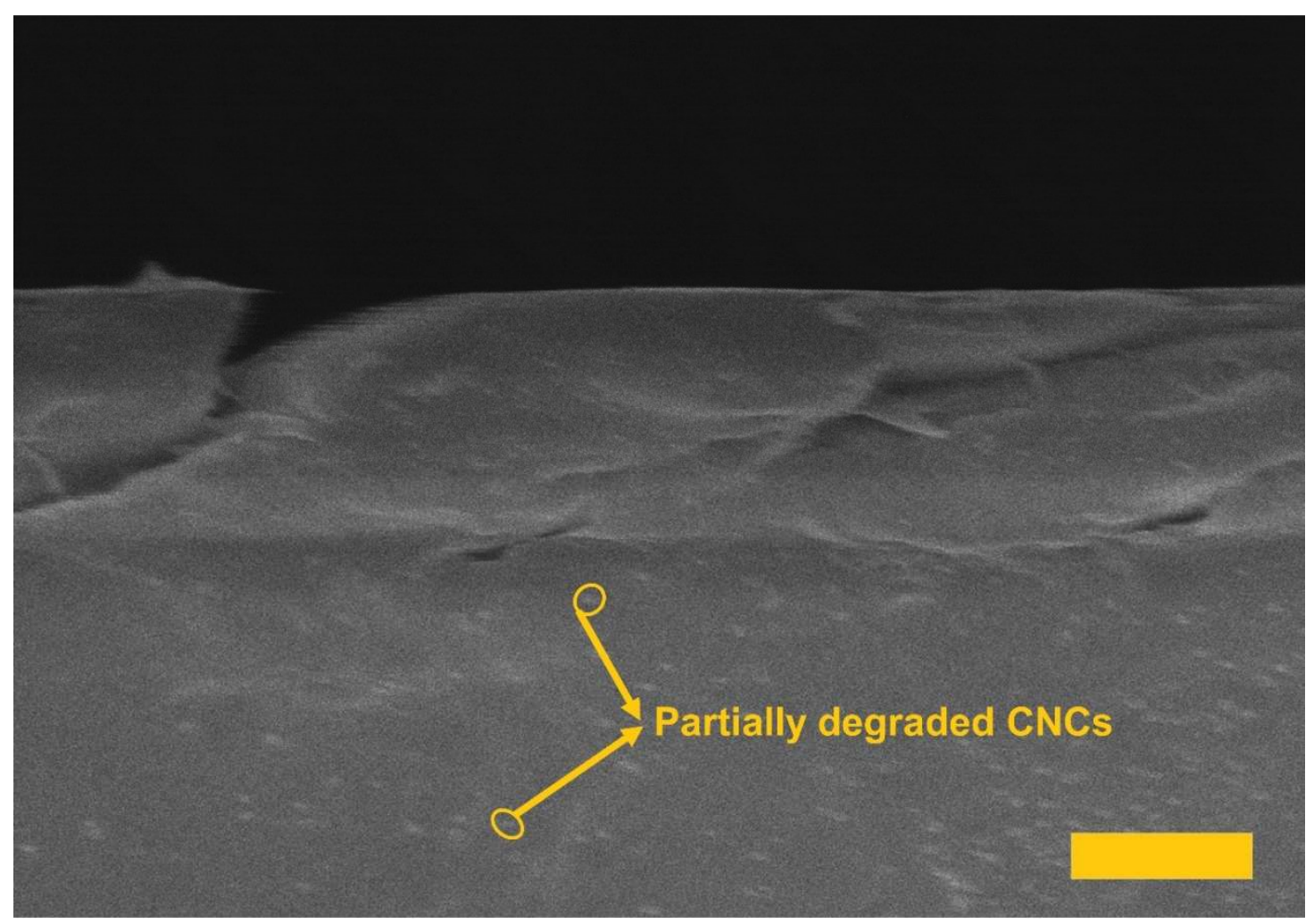

Figure S49. SEM image of the surface of CNC-Na at the primary pyrolysis stage under air atmosphere.

Scale bar: $1 \mu \mathrm{m}$. 


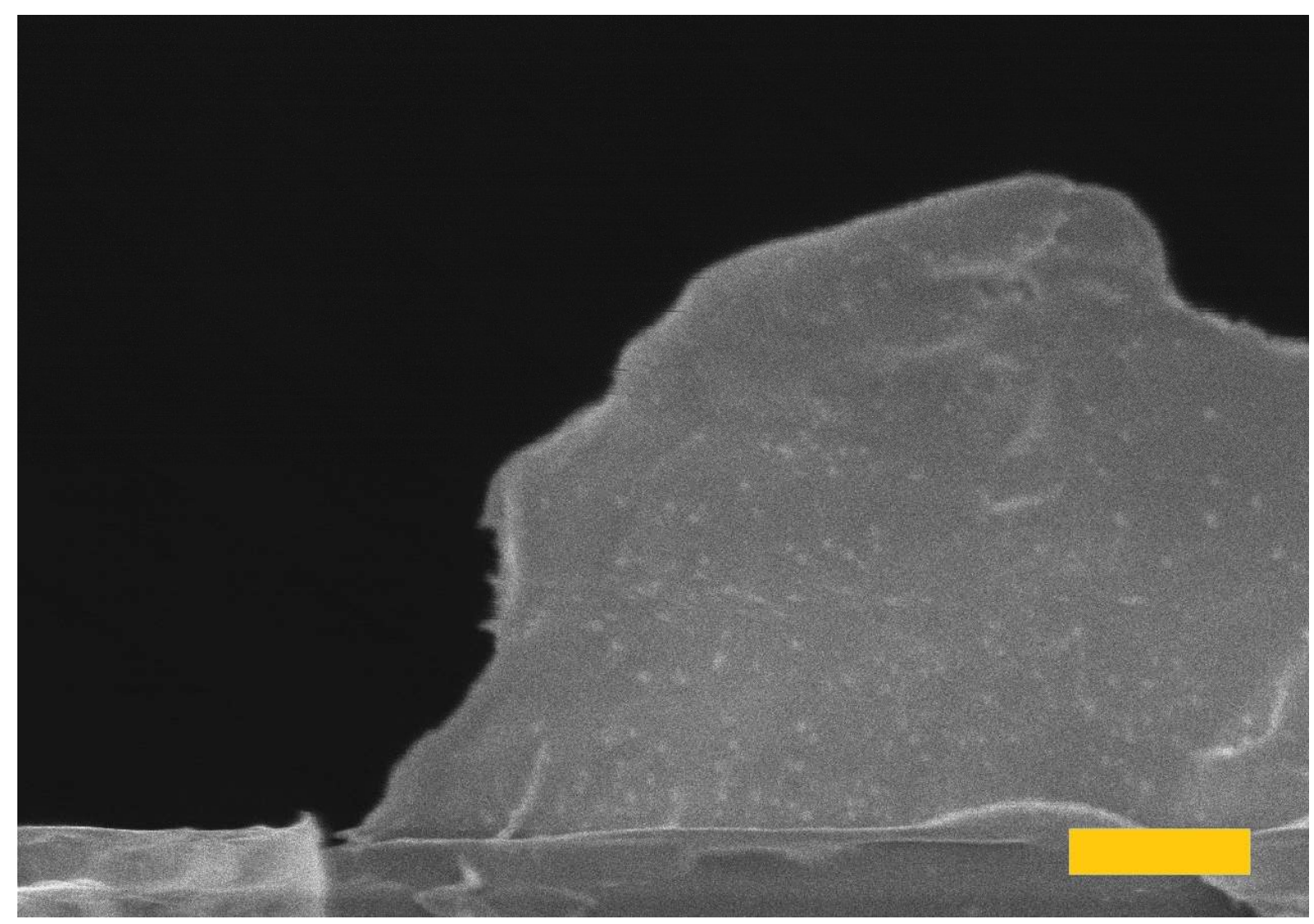

Figure S50. SEM image of the surface of $\mathrm{CNC}-\mathrm{Na}$ at the primary pyrolysis stage under $\mathrm{N}_{2}$ atmosphere. Scale bar: $1 \mu \mathrm{m}$.
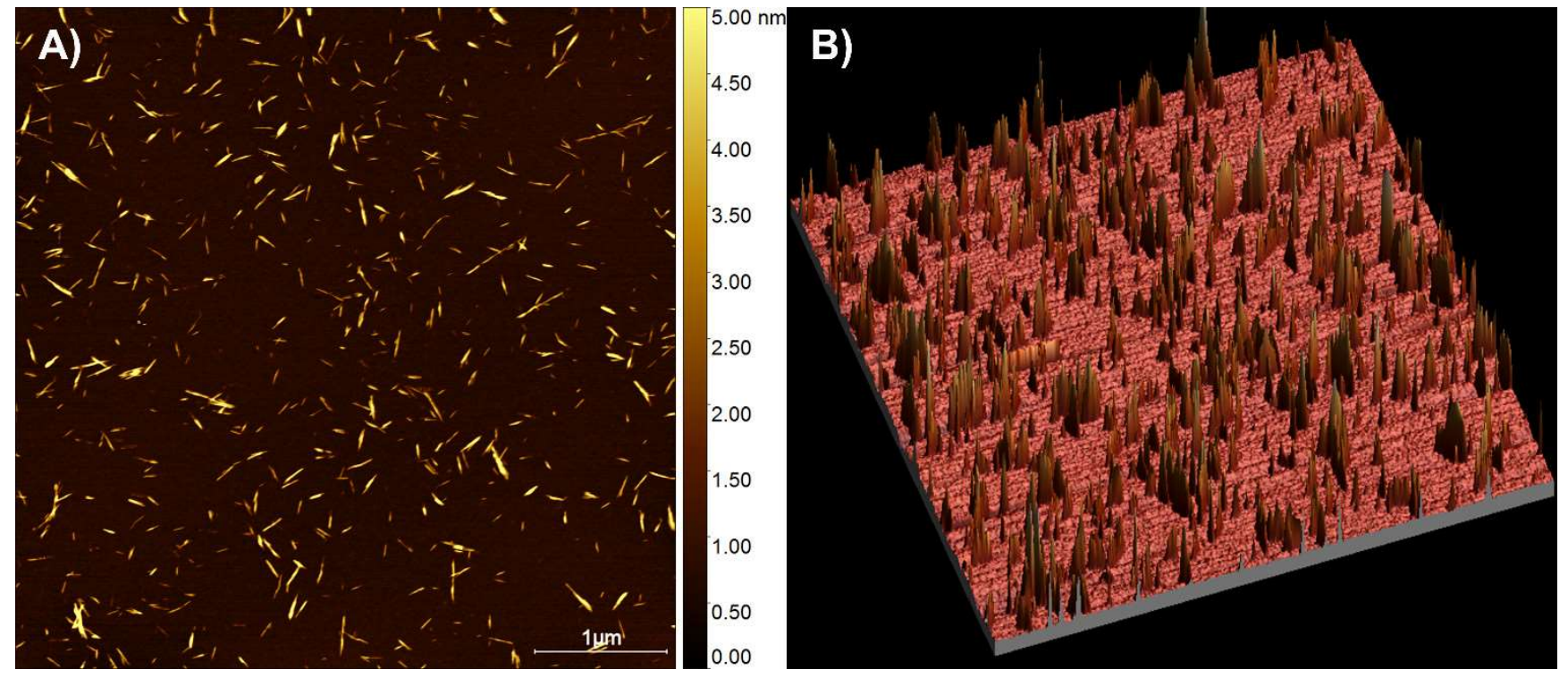

Figure S51. AFM image of the surface of suspended CNC-Na in (A) 2D, and (B) 3D representations. 


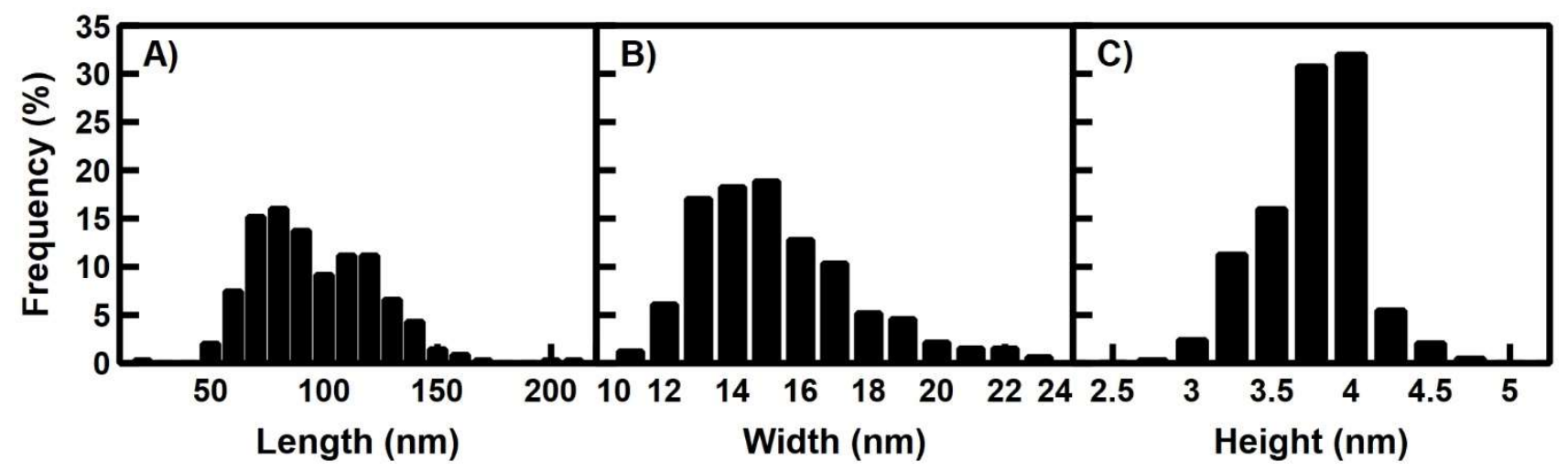

Figure S52. Size statistics for (A) length, (B) width, and (C) height from AFM images for CNC-Na.

Table S7. Geometrical dimensions from the results of AFM ( $>500$ individual CNCs), crystalline dimensions of 101 and 10-1 planes, content of surface hydroxyl groups $(-\mathrm{OH})$, sulfate groups $\left(-\mathrm{OSO}_{3}{ }^{-}\right)$, and degree of substitution (DS) of CNC-H and CNC-Na. CNC volumes have been calculated using an ellipsoid model.

\begin{tabular}{|c|c|c|c|c|c|c|c|c|}
\hline Samples & $\begin{array}{c}\text { Length } \\
\text { (nm) }\end{array}$ & $\begin{array}{l}\text { Width } \\
\text { (nm) }\end{array}$ & $\begin{array}{c}\text { Height } \\
\text { (nm) }\end{array}$ & $\begin{array}{l}\mathrm{B}_{101} \\
(\mathrm{~nm})\end{array}$ & $\begin{array}{l}B_{10-1} \\
(n m)\end{array}$ & $\begin{array}{c}\text { Surface -OH } \\
\left(\mathrm{mmol} \mathrm{g}^{-1}\right)\end{array}$ & $\begin{array}{c}\text { Surface } \\
-\mathrm{OSO}_{3}^{-} \\
\left(\mathrm{mmol} \mathrm{g}^{-1}\right)\end{array}$ & $\begin{array}{c}\text { DS-OSO3- } \\
(\%)\end{array}$ \\
\hline CNC-H & $\begin{array}{c}101.4 \pm \\
25.6\end{array}$ & $\begin{array}{c}15.7 \pm \\
2.3\end{array}$ & $\begin{array}{c}3.9 \pm \\
1.0\end{array}$ & $\begin{array}{c}4.6 \pm \\
0.1\end{array}$ & $\begin{array}{c}3.6 \pm \\
0.1\end{array}$ & 0.8626 & 0.0968 & 11.2 \\
\hline $\mathrm{CNC}-\mathrm{Na}$ & $\begin{array}{c}101.4 \pm \\
25.6\end{array}$ & $\begin{array}{c}15.7 \pm \\
2.3\end{array}$ & $\begin{array}{c}3.9 \pm \\
1.0\end{array}$ & $\begin{array}{c}3.1 \pm \\
0.2\end{array}$ & $\begin{array}{c}3.1 \pm \\
0.4\end{array}$ & 1.124 & 0.0802 & 7.14 \\
\hline
\end{tabular}




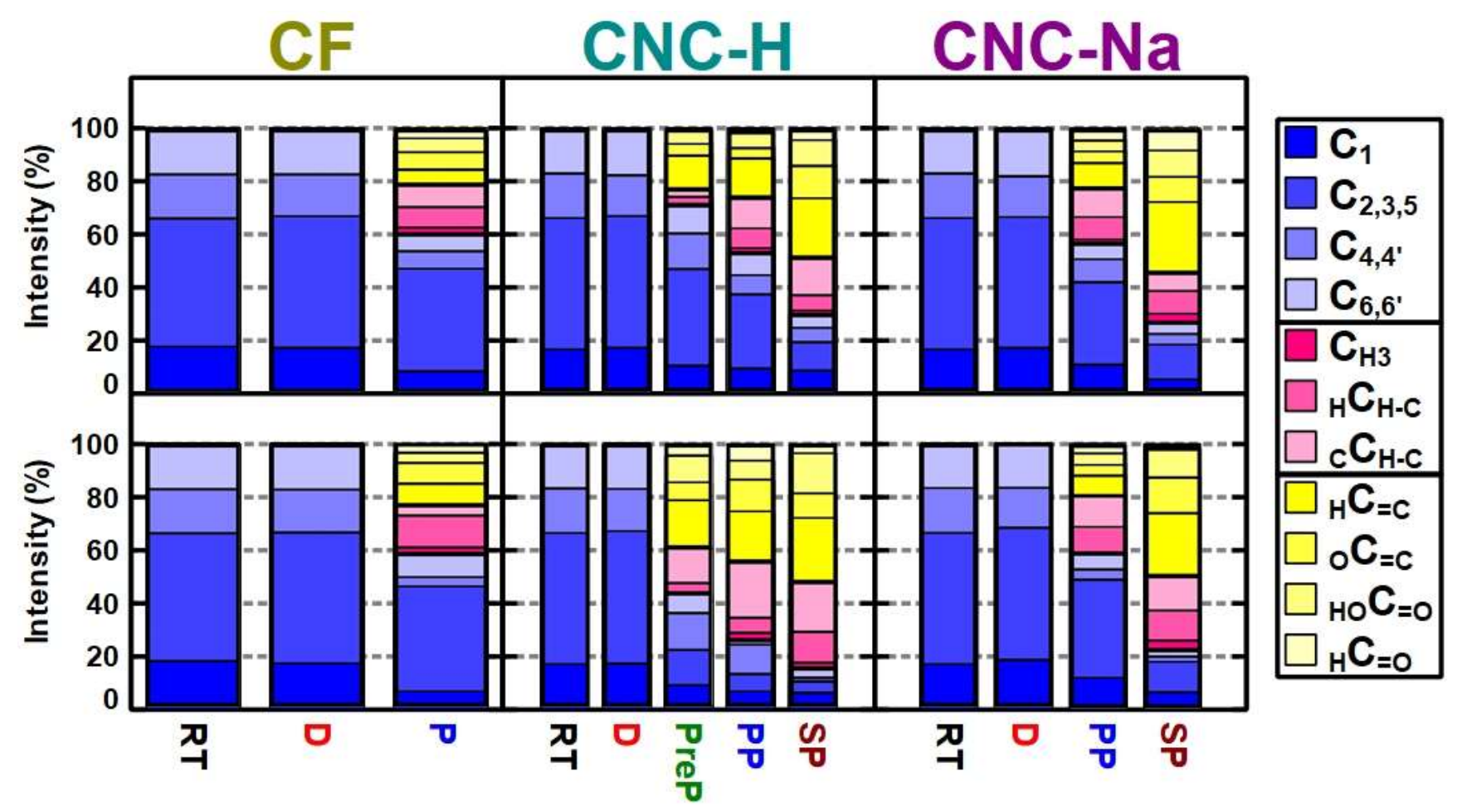

Figure S53. Contribution of different functional groups to the total carbon distribution in solid-state ${ }^{1} \mathrm{H}$ ${ }^{13} \mathrm{C} \mathrm{CP} / \mathrm{MAS} \mathrm{NMR}$ data of $\mathrm{CF}, \mathrm{CNC}-\mathrm{H}$, and $\mathrm{CNC}-\mathrm{Na}$ at increasing degradation stages under air (top row) and nitrogen (bottom row) atmospheres.

Discussion S4: Interpretation of thermochemical conversion reactions from solid-state NMR (ssNMR) spectra.

Comparing the relative intensities of the rigid carbon sites of the glycopyranosic units $\left(\mathrm{C}_{2,3,5}\right)$ and the aromatic site $\left({ }_{\mathrm{H}} \mathrm{C}=\mathrm{C}\right)$, we noticed a strong correlation between the decrease of the former and the increase of the latter (Figure S53). This is consistent with the expected yield of two main bio-oil products, 5-hydroxymethylfurane $(5-H M F)(4),(12) \rightarrow(18)$ (the numbers refer to the reactions shown in Scheme $\mathrm{S} 1, \mathrm{~S} 2)$ and furfural $(\mathrm{FF})(\mathbf{1 2}) \rightarrow(\mathbf{1 8}) \rightarrow(\mathbf{2 8}) .{ }^{25}$ Their formation is described as a post-ring-opening creation of double bonds in $\mathrm{C}_{2}, \mathrm{C}_{3}$ and $\mathrm{C}_{5}$ through dehydration of the corresponding hydroxyl groups followed by the acetal reaction of the hydroxyl groups on $\mathrm{C}_{2}$ and $\mathrm{C}_{5}$ to form 5 -HMF (direct conversion). FF is the product of the secondary reaction of 5-HMF, leading the creation of formaldehyde through the dehydroxymethylation reaction of the side chain of the furan-ring. These pathways are manifested for CF and 
$\mathrm{CNC}-\mathrm{Na}$ in the high temperature region $\left(>300^{\circ} \mathrm{C}\right)$, while for $\mathrm{CNC}-\mathrm{H}$ they take place extensively already at low temperatures $\left(\sim 200^{\circ} \mathrm{C}\right)$ due to their low thermal stability. Condensation reactions of these cyclic species triggers the formation of decomposition products, known as humins.

Continuing to compare calculated NMR spectrum intensities, we hypothesized another plausible transformation from the bulk/crystalline and surface/amorphous sites $\mathrm{C}_{4,4}$, to the aldehydic group, ${ }_{\mathrm{H}} \mathrm{C}_{=\mathrm{O}}$. This rearrangement yields the emergence of oxygenated products, such as glyceraldehyde (GA), and pyrulvaldehyde (PA) (11) $\rightarrow$ (15), (12) $\rightarrow(\mathbf{1 7}),(\mathbf{1 2}) \rightarrow(\mathbf{1 7}) \rightarrow(\mathbf{2 1})$, derived from secondary decomposition of cellulose. The amount of products formed at the end of these pathways depends on the cellulose material, the degradation stage, and the atmosphere. Due to the charred polymeric layer formed on the surface of the nanocrystals, the reactivity is attenuated at the primary pyrolysis stage when degraded under air. However, the effect of oxidative and inert atmospheres is switched at the secondary pyrolysis stage, due to parallel catalyzing oxidation reactions. Such differences are not observed for CF, as they do not contain acidic groups on the surface and do not show a secondary pyrolysis stage.

Additional quantitative analysis suggests that the anomeric carbon $\mathrm{C}_{1}$ transforms into carboxylic acid, $\mathrm{HO}_{\mathrm{O}}=\mathrm{O}$. In fact, the rearrangement is consistent with the high-temperature rehydration of 5-HMF to produce levulinic acid (LA) and formic acid (FAc) (4) $\rightarrow(7)$, kinetically favored by the fast pyrolysis conditions, as well as acidic catalysts. ${ }^{25}$ The trend is similar to the $\mathrm{C}_{4,4}{ }^{\prime}-{ }_{\mathrm{H}} \mathrm{C}=\mathrm{O}$ conversion, even though the intensity of the transformation is slightly reduced. Moreover, the rapid decrease of $\mathrm{C}_{6}$, and $\mathrm{C}_{6}$ ' intensities at the pyrolysis stage is linked with the formation of levoglucosan (LG) (1). This degradation pathway involves the cleavage of the 1,4-glycosidic bond by the acetal reaction between $\mathrm{C}_{1}$ and $\mathrm{C}_{6}$, evolving the hydroxyl radical from $\mathrm{C}_{6}$. The free radical then coalesces with the disrupted glycosidic bond on $\mathrm{C}_{4}$ to form levoglucosan. The trend of conversion is very similar to that of the previous two sites. However, the working conditions do not seem to be relevant and the conversion occurs at a much faster rate in $\mathrm{CNC}$ Na. In fact, while surface $\mathrm{C}_{4}$ ' sites are bonded to hydroxyl groups, the surface $\mathrm{C}_{6}$ 'sites are bonded to a sodium sulfate group, which catalyze the conversion. LG is essential to activate any type of secondary 
reaction, since its hydrated form, the glucopyranose (GP) unit, is the starting reagent in all pathways (10-

29). ${ }^{26}$
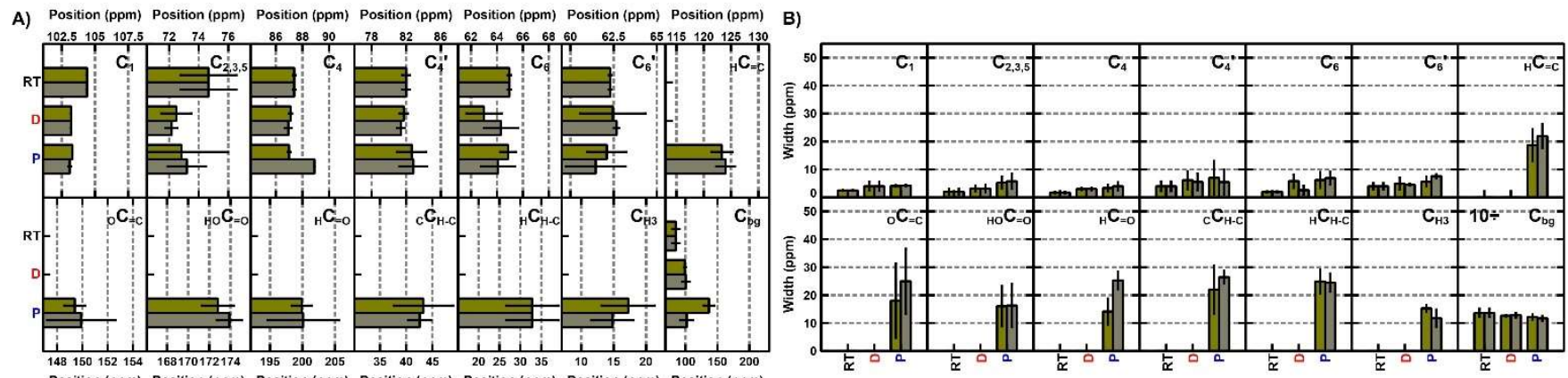

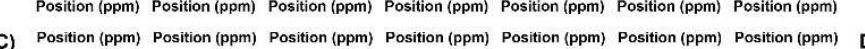
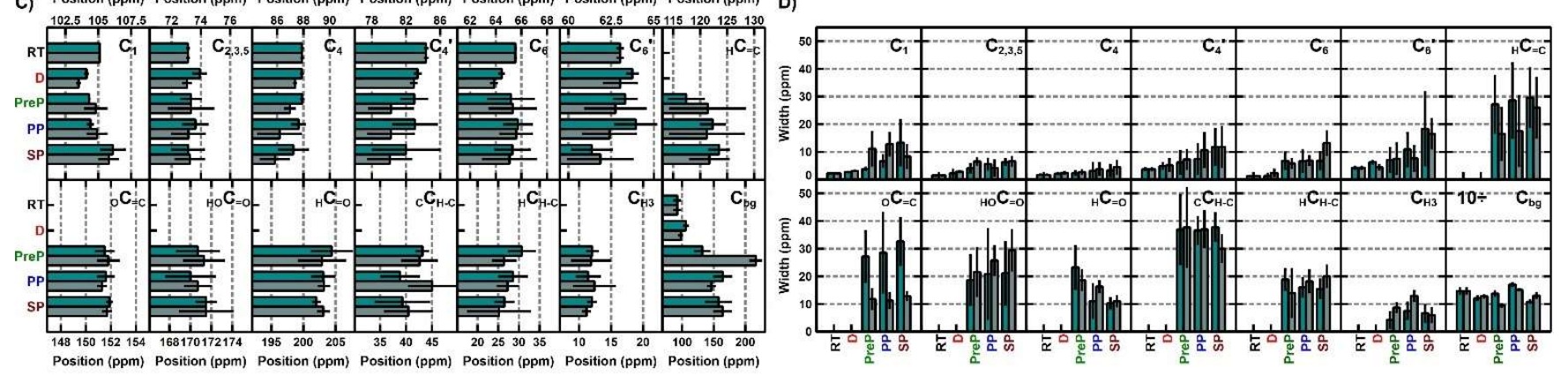

E) Position (ppm) Position (ppm) Position (ppm) Position (ppm) Position (ppm) Position (ppm) Position (ppm) F
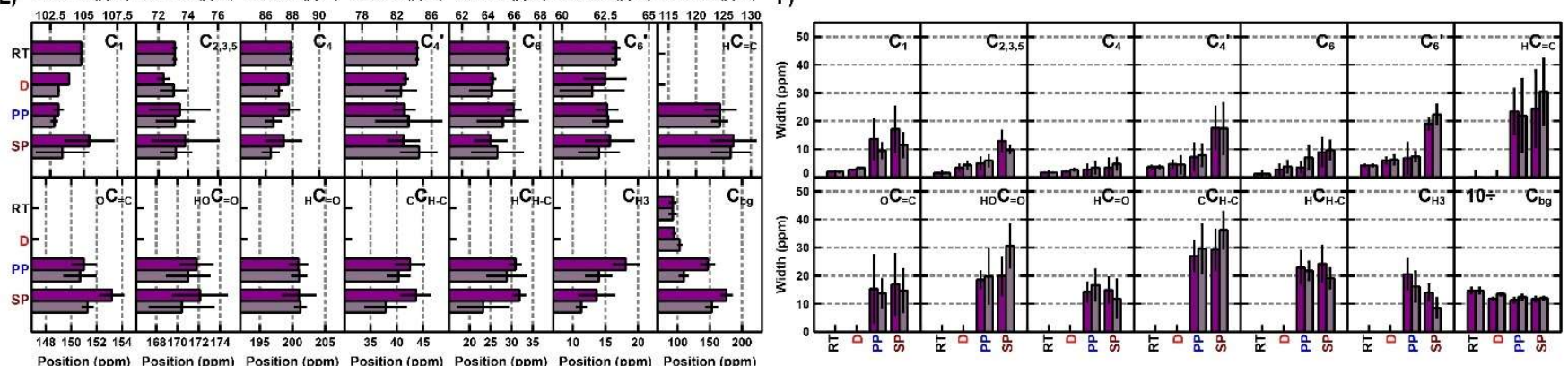

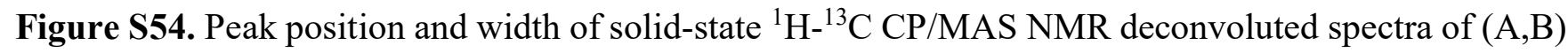

$\mathrm{CF},(\mathrm{C}, \mathrm{D}) \mathrm{CNC}-\mathrm{H}$, and (E,F) CNC-Na at increasing degradation stages under air (bright tones) and nitrogen (opaque tones) atmospheres. The data for $\mathrm{C}_{2,3,5}$ refers to the values obtained from the average of $\mathrm{C}_{2}$, $\mathrm{C}_{3}$, and $\mathrm{C}_{5} . \mathrm{C}_{\mathrm{bg}}$ refers to the spectrum background, whose width has been scaled down by 10 times. 


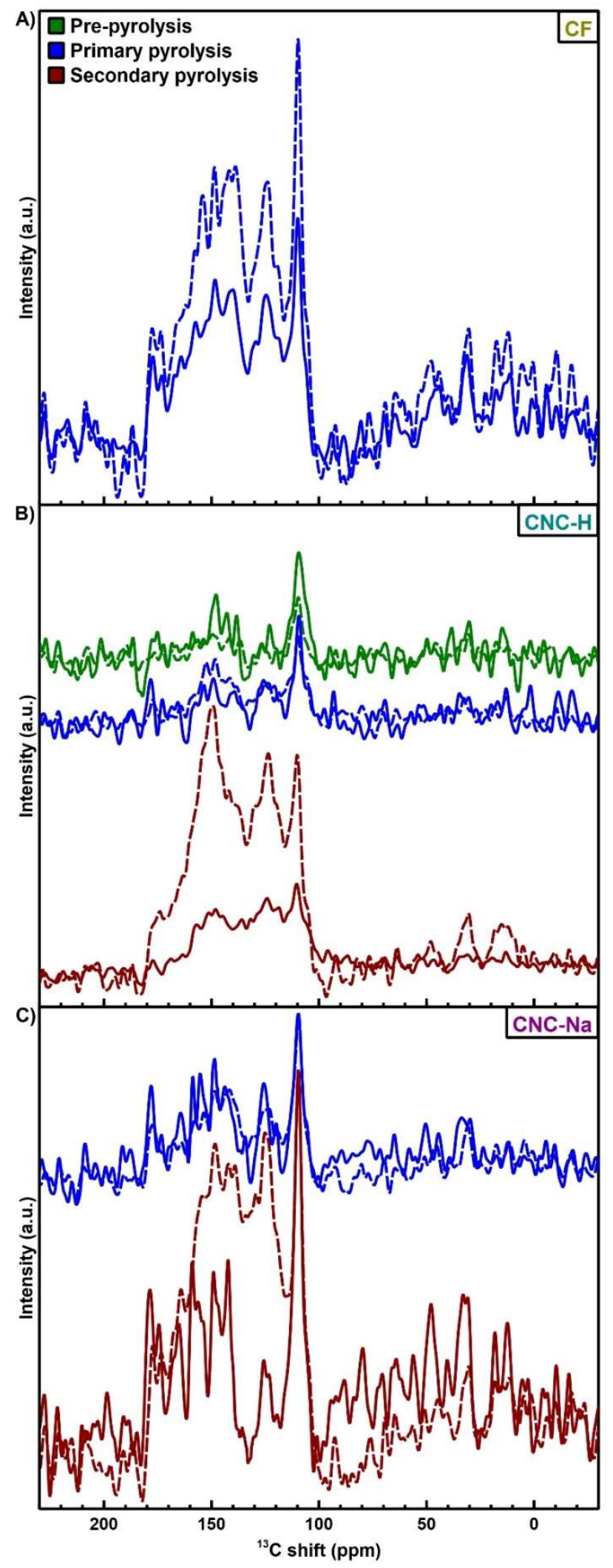

Figure S55. ${ }^{13} \mathrm{C}$ MAS TOSS spectra of (A) CF, (B) CNC-H, and (C) CNC-Na chars under air (solid) and $\mathrm{N}_{2}$ (dashed) atmospheres at the maximum of each degradation stage. Spectra have been normalized by their mass and the number of transients. 
Table S8. Aromaticity and minimum number of carbons per aromatic cluster in $\mathrm{CF}, \mathrm{CNC}-\mathrm{H}$, and $\mathrm{CNC}$ Na. The geometry of condensation, for example, linear (primary catenation) versus clustered (e.g., circular catenation), can be assessed considering the upper limit of the edge fraction of aromatic rings, $\chi_{\text {edge, } \max }=$ $\chi_{\text {edge,min }}+\chi_{\text {alkyl }}+\chi_{\mathrm{C}=\mathrm{O}}=\chi_{\mathrm{C}-\mathrm{H}}+\chi_{\mathrm{C}-\mathrm{O}}+\chi_{\text {alkyl }}+\chi_{\mathrm{C}=\mathrm{O}} \cdot \chi_{\text {edge }}>0.5$ is typical of linearly condensed systems, and therefore $\chi_{\text {edge,max }}<0.5$ rules out this type of geometry. In general, the number of carbons, $\mathrm{n}_{\mathrm{C}}$, in a cluster relates to the edge fraction by $3 /\left(\chi_{\text {edge }}-0.5\right) \geq n_{C}>=6 / \chi_{\text {edge }}{ }^{2} \geq 6 / \chi_{\text {edge,max }}{ }^{2}$ with the upper limit for linear and the lower for circular condensation.

\begin{tabular}{|c|c|c|c|c|}
\hline Char & Stage & Atm. & $\begin{array}{c}\text { Arom. } \\
\text { (\%) }\end{array}$ & $\mathbf{n}_{\mathbf{C}, \min }$ \\
\hline \multirow{3}{*}{$\mathrm{CF}$} & \multirow{3}{*}{ Primary pyrolysis } & air & $85(2)$ & $>15 \mathrm{C}$ \\
\hline & & & & \\
\hline & & $\mathrm{N}_{2}$ & $87(2)$ & $>16 \mathrm{C}$ \\
\hline \multirow{8}{*}{$\mathrm{CNC}-\mathrm{H}$} & \multirow{3}{*}{ Pre-pyrolysis } & Air & $82(4)$ & $>6 \mathrm{C}$ \\
\hline & & & & \\
\hline & & $\mathrm{N}_{2}$ & $78(5)$ & $>4 \mathrm{C}$ \\
\hline & \multirow{3}{*}{ Primary pyrolysis } & air & $89(3)$ & $>7 \mathrm{C}$ \\
\hline & & & & \\
\hline & & $\mathrm{N}_{2}$ & $77(3)$ & $>10 \mathrm{C}$ \\
\hline & \multirow{2}{*}{ Secondary pyrolysis } & air & $83(1)$ & $>16 \mathrm{C}$ \\
\hline & & $\mathrm{N}_{2}$ & $86(2)$ & $>18 \mathrm{C}$ \\
\hline \multirow{6}{*}{$\mathrm{CNC}-\mathrm{Na}$} & \multirow{3}{*}{ Primary pyrolysis } & air & $57(4)$ & $>8 \mathrm{C}$ \\
\hline & & $\mathrm{N}_{2}$ & $50(4)$ & $>11 \mathrm{C}$ \\
\hline & & & & \\
\hline & \multirow{3}{*}{ Secondary pyrolysis } & air & $77(3)$ & $>13 \mathrm{C}$ \\
\hline & & & & \\
\hline & & $\mathrm{N}_{2}$ & $89(2)$ & $>19 \mathrm{C}$ \\
\hline
\end{tabular}




\section{Discussion S5: ${ }^{1} \mathrm{H}$ wide-line and ${ }^{1} \mathrm{H}$ and ${ }^{13} \mathrm{C} \mathrm{T}_{1}$ relaxation ss-NMR experiments}

We carried out ${ }^{1} \mathrm{H}$ wide-line experiments to verify the behavior of protons as temperature increases (Figure S56). Proton spectra can display a signature of water in the local structure of the materials. A broad component and a narrow component are visible in all spectra. The background-subtracted broad component is attributed to rigid cellulose molecules, while the narrow component is assigned to relatively mobile absorbed water. ${ }^{27}$

With increasing temperature, the intensity of the narrow component gradually decreases, denoting physical dehydrating reactions across the entire thermal degradation. Similarly, the ${ }^{1} \mathrm{H}$ line shape of the broad component narrows significantly upon degradation. Such a gradual shrinking can be interpreted as a decrease in the magnitude of ${ }^{1} \mathrm{H}-{ }^{1} \mathrm{H}$ dipole-dipole coupling arising from more separated ${ }^{1} \mathrm{H}$ nuclei or an increased ability of water to reorient rapidly. This consideration confirms the gradual intra- and interchain deprotonation of cellulose molecules induced by thermal degradation, leading to more stable compounds.

${ }^{1} \mathrm{H}$ and ${ }^{13} \mathrm{C} \mathrm{T}_{1}$ relaxation experiments as functions of temperature probe the local environment around proton and carbon nuclei, respectively, during thermal degradation. Proton $\mathrm{T}_{1}$ relaxation timescales are on the order of a few seconds (Figure S57, top-right insets). The ${ }^{1} \mathrm{H} \mathrm{T}_{1}$ of CF is relatively short (1.7 s) because of the large fraction of amorphous regions, while highly crystalline pristine CNCs in both forms have relaxation times $\sim 30 \%$ longer. ${ }^{1} \mathrm{H} \mathrm{T}_{1}$ of water-desorbed materials are generally slightly longer, as mobile water is a source of relaxation. Relaxation times decrease upon thermal degradation due to the loss of crystallinity and the appearance of radicals. In $\mathrm{CF}$ and $\mathrm{CNC}-\mathrm{H}$ the ${ }^{1} \mathrm{H} \mathrm{T}_{1} \mathrm{~s}$ (olive and teal lines) and the degree of order of all the sites decreases gradually with increasing temperature, while in CNC-Na the ${ }^{1} \mathrm{H} \mathrm{T}_{1} \mathrm{~s}$ (purple lines) drop dramatically at the secondary pyrolysis stage due to the extensive structural dehydration. Materials degraded under inert atmosphere have lower relaxation times due to the disordering effect of amorphization. 
The integrated intensities in ${ }^{13} \mathrm{C} \mathrm{T}_{1}$ relaxation measurements can be satisfactorily described by stretched exponential functions with $\beta$ factors between 0.4 and $0.7 .^{28}$ Their trend is very similar to the proton relaxation experiments. Due to the presence of surrounding protons, saturated carbons are more mobile and have lower relaxation times. The stretch parameter $\beta$ varies in the 0.4-0.7 range without a clear temperature dependence (Figure S57, top-left inset), but signifies a broad distribution of relaxation times. We calculated deviations from the constant exponent value and large error bars are in cases of small signal detection. 


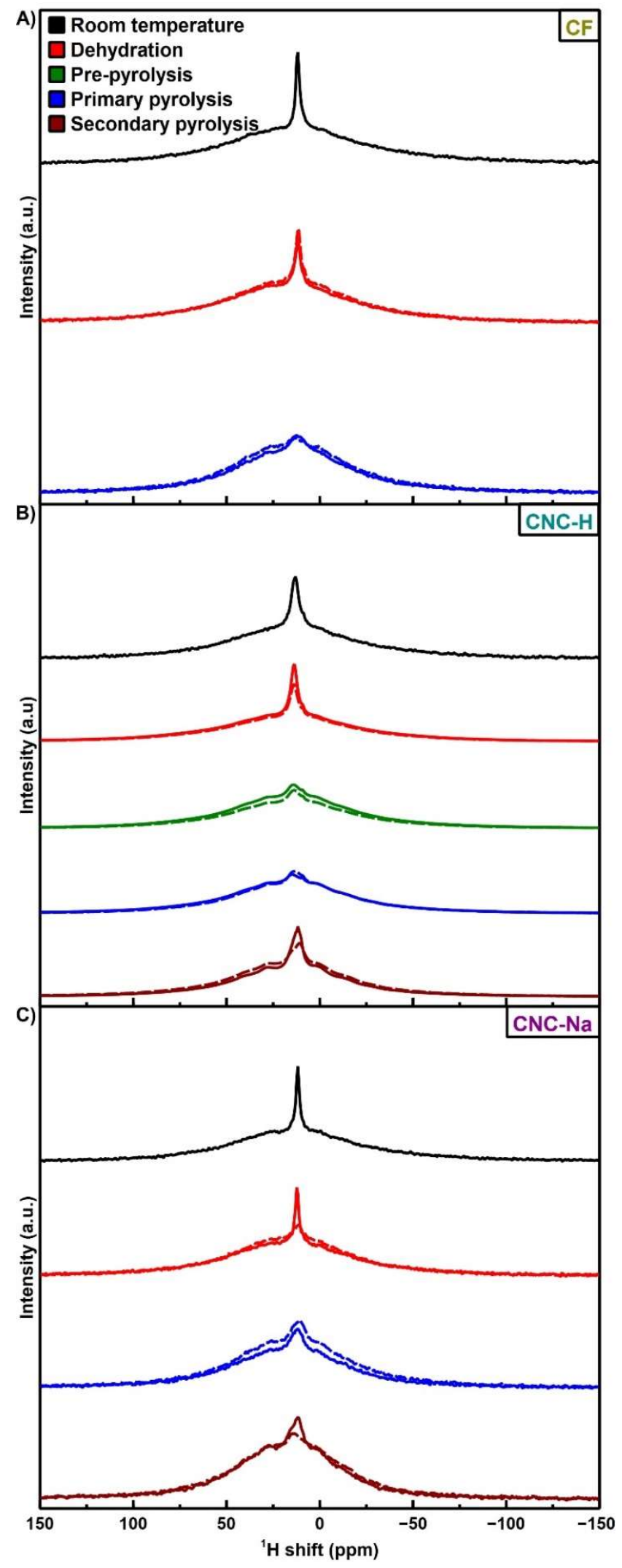

Figure S56. ${ }^{1} \mathrm{H}$ MAS spectra of (A) CF, (B) CNC-H, and (C) CNC-Na under air (solid) and $\mathrm{N}_{2}$ (dashed) atmospheres at the maximum of each degradation stage. Spectra have been normalized by their mass and the number of transients. 


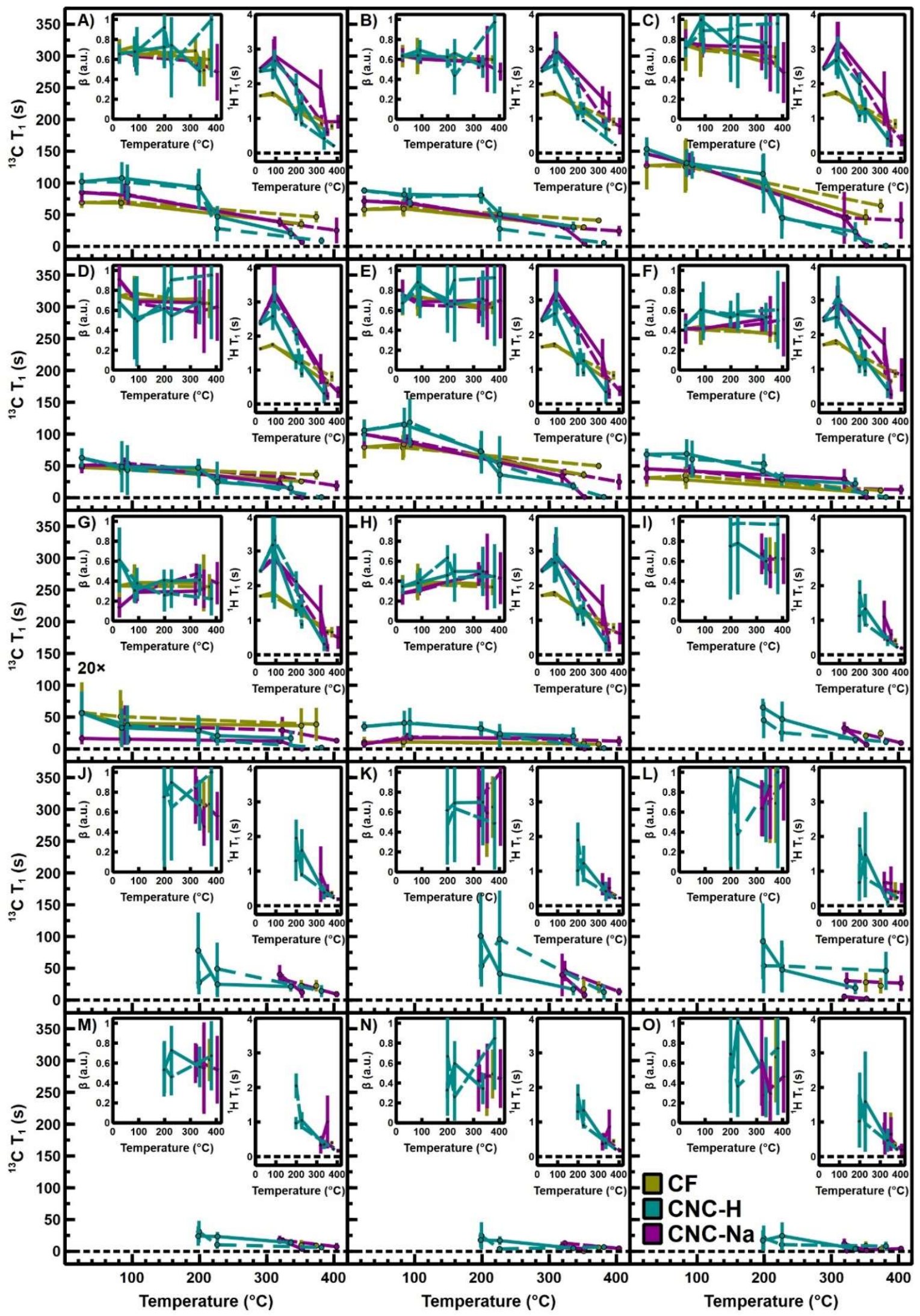

Figure S57. ${ }^{13} \mathrm{C}_{1}$ relaxation times of $(\mathrm{A}) \mathrm{C}_{1},(\mathrm{~B}) \mathrm{C}_{2,3,5},(\mathrm{C}) \mathrm{C}_{4},(\mathrm{D}) \mathrm{C}_{4}{ }^{\prime},(\mathrm{E}) \mathrm{C}_{4,4}{ }^{\prime},(\mathrm{F}) \mathrm{C}_{6},(\mathrm{G}) \mathrm{C}_{6}{ }^{\prime}$ (scaled up by 20), (H) $\mathrm{C}_{6,6}$, (I) ${ }_{\mathrm{H}}=\mathrm{C},(\mathrm{J}){ }_{\mathrm{o}} \mathrm{C}=\mathrm{C},(\mathrm{K}){ }_{\mathrm{HO}} \mathrm{C}=\mathrm{O}$, (L) ${ }_{\mathrm{H}} \mathrm{C}=\mathrm{O},(\mathrm{M}){ }_{\mathrm{C}} \mathrm{C}_{\mathrm{H}-\mathrm{C}},(\mathrm{N}){ }_{\mathrm{H}} \mathrm{C}_{\mathrm{H}-\mathrm{C}}$, and (O) $\mathrm{C}_{\mathrm{H} 3}$ as a 
function of the degradation temperature of $\mathrm{CF}, \mathrm{CNC}-\mathrm{H}$, and $\mathrm{CNC}-\mathrm{Na}$. Top-left inset: stretching factor $\beta$ of ${ }^{13} \mathrm{C} \mathrm{T}_{1}$ relaxation one-term exponentials as a function of the degradation temperature of $\mathrm{CF}, \mathrm{CNC}-\mathrm{H}$, and CNC-Na. Top-right inset: ${ }^{1} \mathrm{H} \mathrm{T}_{1}$ relaxation times as a function of the degradation temperature of $\mathrm{CF}$, CNC-H, and CNC-Na.

\section{Discussion S6: Analysis of X-ray photoelectron spectroscopy (XPS) high-resolution C 1s and O 1s spectra of CNC-Na}

In Figure S58, we show the XPS high-resolution $\mathrm{C}$ 1s and $\mathrm{O}$ 1s spectra of CNC-Na and their chars obtained at the primary pyrolysis stage after degradation under air and nitrogen atmospheres. The highresolution spectra of the $1 \mathrm{~s}$ orbital of carbon (Figure S58A) display common peaks at $284.6 \mathrm{eV}$, assigned to carbon-carbon bonds (both aliphatic and aromatic), at $286.4 \mathrm{eV}$, assigned to the bond between carbon and oxygen (mainly representative of the bonds with hydroxyl groups), and at $287.9 \mathrm{eV}$, assigned to the oxygen-carbon-oxygen bond (typical of the anomeric carbon $\mathrm{C}_{1}$ ) and the carbonyl group. Upon degradation, the spectra of the chars exhibit an additional component (Figure S58A, blue lines). ${ }^{29}$ A new peak emerges at $288.6 \mathrm{eV}$ and it is assigned to the carboxylic bond, which is not present in cellulose but that is typical of bio-oil and char molecular structures. The distribution of the components is in good agreement with the analyses carried out by ss-NMR, EA, and FT-IR.

We report here also the high-resolution spectra carried out for oxygen $(\mathrm{O}$ 1s) for $\mathrm{CNC}-\mathrm{Na}$ and their chars (Figure S58B). The spectrum of neutralized cellulose nanocrystals at room temperature shows a single peak at $532.0 \mathrm{eV}$, assigned to single-bonded oxygen with carbon. In contrast, the spectra of the CNC-Na chars (Figure S58B, blue lines) include two other contributions to their fitting: the dominant double-bonded oxygen-carbon peak centered at $533.0 \mathrm{eV}$, and the minor water peak at $535.8 \mathrm{eV}$, caused by the unavoidable partial rehydration of charred materials in the XPS spectrometer. ${ }^{29}$ The peak distribution correlates well with the XPS high-resolution C 1s spectra, as well as the results from ss-NMR, EA, and FT-IR. 
It is worth noticing that the XPS high-resolution $\mathrm{C} 1 \mathrm{~s}$ and $\mathrm{O} 1 \mathrm{~s}$ spectra do not exhibit features that can be associated with carbon- or oxygen-containing sodium compounds, such as sodium carbonate, ruling out the possibility of their formation in parallel with hydrated sodium hydroxide in the thermal degradation mechanism of $\mathrm{CNC}-\mathrm{Na}{ }^{30}$

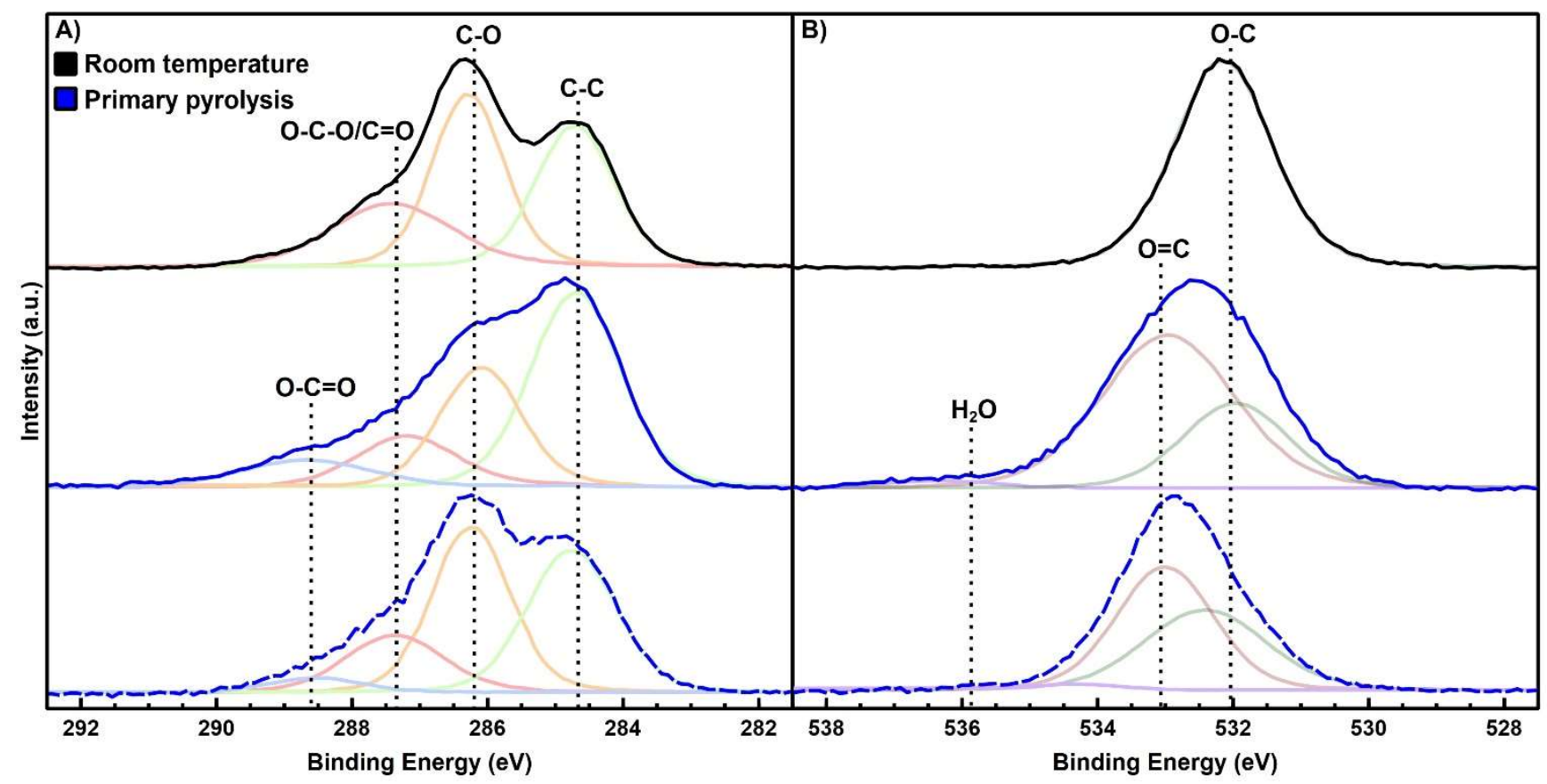

Figure S58. XPS high-resolution (A) C 1s and (B) O 1s spectra of CNC-Na prepared at the maximum of primary pyrolysis under air (solid) or $\mathrm{N}_{2}$ (dashed) atmospheres. Vertical lines indicate the location of carbon and oxygen sites.

\section{Discussion S7: Analysis of Fourier-transform infrared (FT-IR) spectra of CF, CNC-H, and CNC-} Na

We show the FT-IR spectra of CF, CNC-H, and CNC-Na in Figure S59. The intensity of the OH band at different stages can be used to estimate the modification of the H-bond network as a function of temperature. Quantitative measurements of normalized intensities of $\mathrm{OH}$ bands suggest that more crystalline materials, such as CNCs, retain a larger fraction of the original H-bond network at high T compared to CF owing to the stronger intermolecular forces. The spectrum of the char resulting from the pre-pyrolysis step (Figure S59B, green lines) of CNC-H shows first indications of dehydration. This is revealed by 
the lower intensity of the $\mathrm{O}-\mathrm{H}$ stretching band $\left(3600-3100 \mathrm{~cm}^{-1}\right)$, also representative of the hydrogenbond network, and the decreased signal at $1059 \mathrm{~cm}^{-1}$, corresponding to C-O skeletal vibrations of secondary alcohols. The spectrum displays two new bands, at 1620 and $1700 \mathrm{~cm}^{-1}$, assigned to $\mathrm{C}=\mathrm{C}$ and $\mathrm{C}=\mathrm{O}$ stretching, respectively, signatures of thermal cracking, carbonization and esterification. These processes are also consistent with the (4), (12) $\rightarrow(\mathbf{1 8}),(\mathbf{1 2}) \rightarrow(\mathbf{1 8}) \rightarrow(\mathbf{2 8}),(\mathbf{1 1}) \rightarrow(\mathbf{1 5}),(\mathbf{1 2}) \rightarrow(\mathbf{1 7}),(\mathbf{1 2}) \rightarrow(\mathbf{1 7}) \rightarrow(\mathbf{2 1})$ pathways.

Transmittances in the $1000-800 \mathrm{~cm}^{-1}$ region, i.e. aromatic out-of-plane bending, and in the 1500 $1000 \mathrm{~cm}^{-1}$ region, i.e. aromatic $\mathrm{C}=\mathrm{C}$ skeletal vibrations and $\mathrm{C}-\mathrm{H}$ deformation modes in alkenes, imply the presence of aromatic species in the structure. However, the pyranose structures of cellulose are mostly preserved, such as the $\mathrm{C}-\mathrm{O}$ stretching in pyranose rings at $1200 \mathrm{~cm}^{-1}$ and the $\mathrm{C}-\mathrm{O}-\mathrm{C}$ skeletal vibrations at $1080 \mathrm{~cm}^{-1}$.

In the following stage, primary pyrolysis (blue lines), dehydration and aromatization severely affect the structure of all cellulose materials, even though a large fraction of the original cellulose character is still maintained. The $\mathrm{C}=\mathrm{C}$ and $\mathrm{C}=\mathrm{O}$ stretching bands are greatly enhanced and the ratios of their intensities change, indicating an increased loss of structural oxygen. ${ }^{31}$ At this stage under air atmosphere (solid lines), the spectra of the cellulose materials show no clear difference from each other, suggesting a similar chemistry of chars. Observed profiles of chars degraded under nitrogen atmosphere are dissimilar from each other and denote one more time a more extensive degree of aromatization with respect to the airdegraded materials. CNC-H is the material with the most abundant presence of aromatic species, followed by $\mathrm{CNC}-\mathrm{Na}$ and $\mathrm{CF}$, inversely proportional to their thermal stability. At the secondary pyrolysis stage of cellulose nanocrystals (Figure S59B,C, maroon lines), the aromatic compounds become predominant in the solid residue and the original cellulose structure is barely distinguishable. The $\mathrm{C}=\mathrm{C}$ stretching band becomes more intense than $\mathrm{C}=\mathrm{O}$, due to the further volatilization of small oxygen-containing molecules, and the $\mathrm{O}-\mathrm{H}$ stretching band is much reduced, highlighting the highest levels of dehydration. Similar to 
the CP/MAS NMR results, the cellulose bands of CNC-H chars are more intense than CNC-Na due to the surface layer made of swollen sulfuric acid protecting the bulk.

The temperature dependence of inter- and intramolecular H-bonding in cellulose materials can be estimated through spectra analysis (Table S10). Materials with lower crystallinity and a less stable intermolecular H-bond network, i.e., CF, are less affected by temperature with respect to the nanocrystals. Thermal degradation under air has a larger impact than nitrogen on H-bonds breaking at the initial stages, due to the catalytic role of oxygen in the depolymerization of cellulose. However, at more advanced stages the level of H-bond disruption is similar between samples degraded under air and nitrogen. 


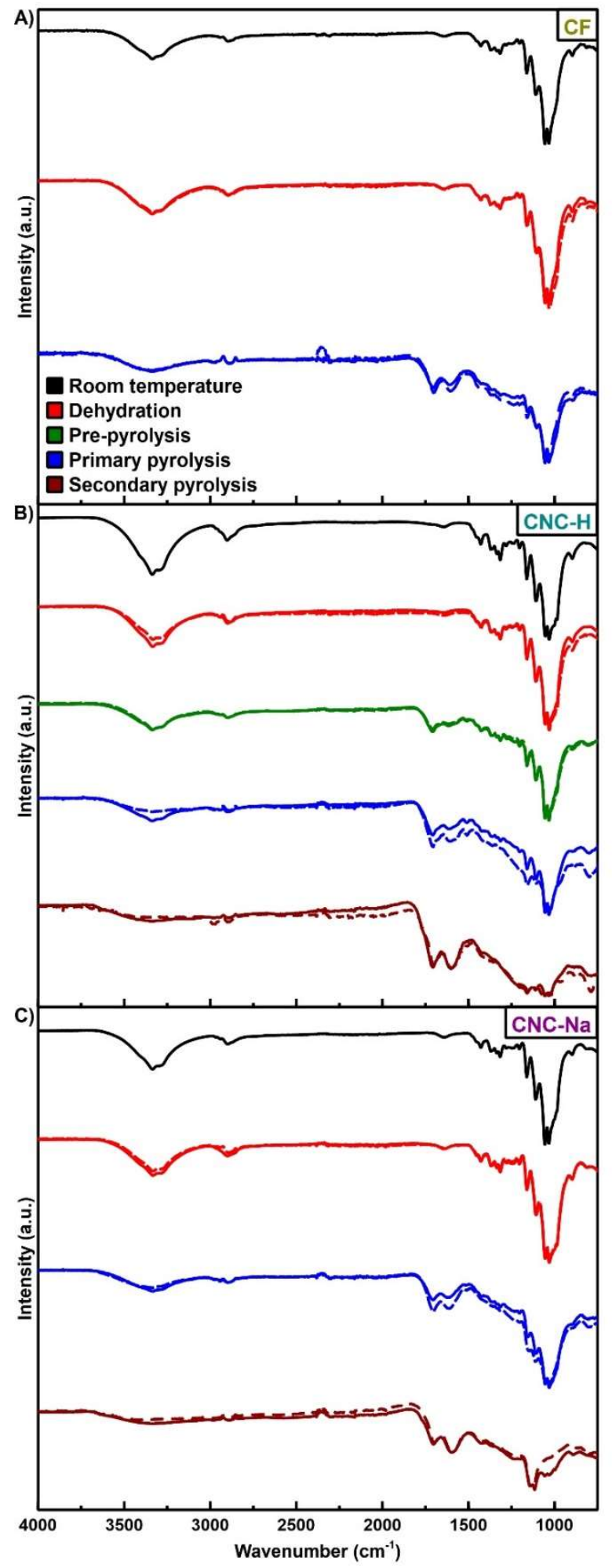

Figure S59. FTIR spectra of (A) CF, (B) CNC-H, and (C) CNC-Na under air (solid) and $\mathrm{N}_{2}$ (dashed) atmospheres at the maximum of each degradation stage. Spectra have been normalized to the same intensity of the $\mathrm{C}_{3}-\mathrm{O}_{3} \mathrm{H}$ stretching vibration at $1059 \mathrm{~cm}^{-1}$. 
Table S9. Bands in the FTIR spectra of cellulose materials and their assignments.

\begin{tabular}{|c|c|}
\hline Region $\left(\mathrm{cm}^{-1}\right)$ & Assigned to \\
\hline $3100-3600$ & O-H stretching \\
\hline $2800-3000$ & C-H stretching \\
\hline 1700 & $\mathrm{C}=\mathrm{O}$ stretching \\
\hline 1620 & $\mathrm{C}=\mathrm{C}$ stretching \\
\hline 1410 & H-C-H bending \\
\hline $1310-1360$ & C-C and C-O skeletal vibrations \\
\hline 1360 & O-H bending \\
\hline 1200 & $\mathrm{C}-\mathrm{O}$ stretching in pyranose ring \\
\hline 1170 & $\mathrm{C}-\mathrm{O}$ antisymmetric bridge stretching \\
\hline 1110 & C-OH skeletal vibrations \\
\hline 1080 & C-O-C pyranose ring skeletal vibrations \\
\hline 1059 & C-O secondary alcohols skeletal vibrations \\
\hline 1030 & C-O skeletal vibrations \\
\hline
\end{tabular}


Table S10. Level of hydrogen-bonding network in $\mathrm{CF}, \mathrm{CNC}-\mathrm{H}$, and $\mathrm{CNC}-\mathrm{Na}$ (after structural dehydration) with increasing temperature. The values are obtained by numerical integration of the region in the FT-IR spectrum assigned to H-bonds $\left(3100-3600 \mathrm{~cm}^{-1}\right)$.

\begin{tabular}{|c|c|c|c|c|c|c|}
\hline \multirow{3}{*}{ Stage } & \multicolumn{6}{|c|}{ H-bond level (\%) } \\
\hline & \multicolumn{2}{|c|}{$\mathbf{C F}$} & \multicolumn{2}{|c|}{ CNC-H } & \multicolumn{2}{|c|}{ CNC-Na } \\
\hline & air & $\mathbf{N}_{2}$ & air & $\mathbf{N}_{2}$ & air & $\mathbf{N}_{2}$ \\
\hline Dehydration & 100 & 100 & 100 & 100 & 100 & 100 \\
\hline Pre-pyrolysis & $\mathrm{N} / \mathrm{A}$ & N/A & $76(2)$ & $96(2)$ & $\mathrm{N} / \mathrm{A}$ & $\mathrm{N} / \mathrm{A}$ \\
\hline Primary pyrolysis & $22(3)$ & $41(1)$ & $60(3)$ & $46(2)$ & $51(1)$ & $95(2)$ \\
\hline
\end{tabular}

\begin{tabular}{|l|l|l|l|l|l|l|}
\hline Secondary pyrolysis & N/A & N/A & $42(3)$ & $29(5)$ & $48(2)$ & $50(2)$ \\
\hline
\end{tabular}


A)

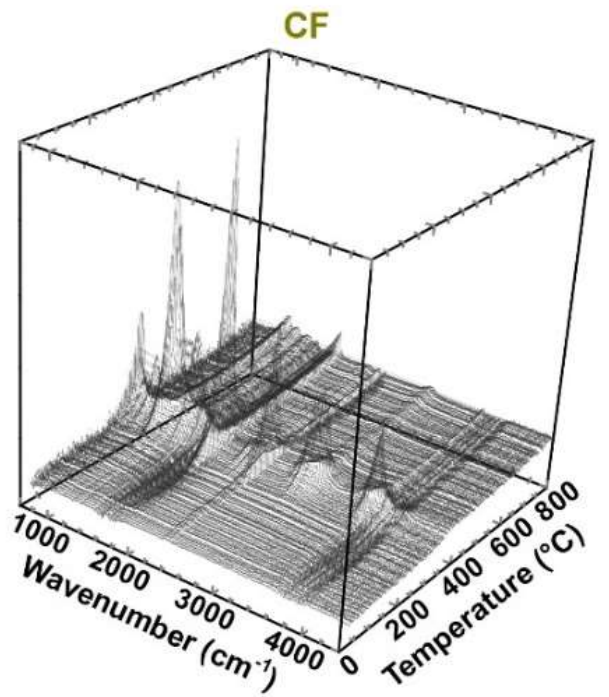

B)

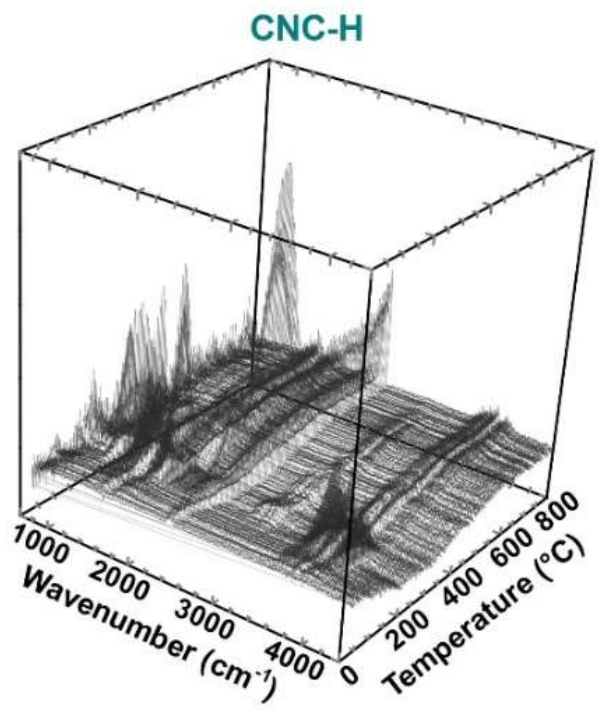

C)

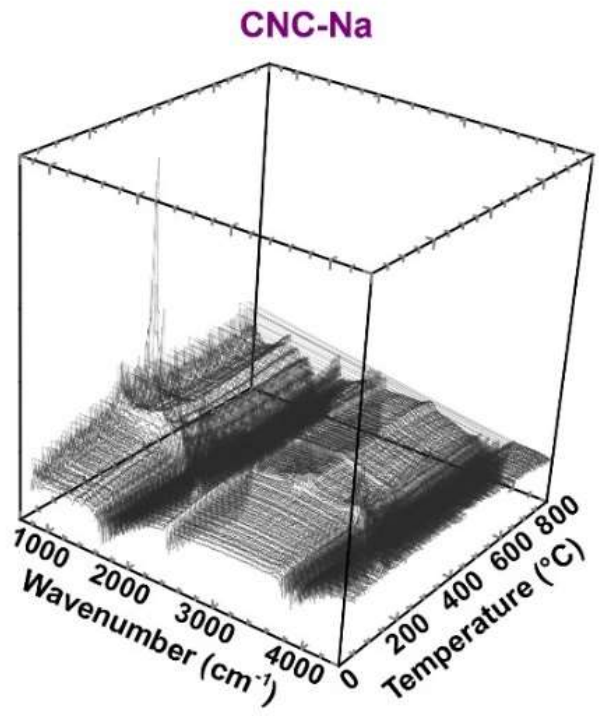

Figure S60. TGA-IR spectra of (A) CF, (B) CNC-H, and (C) $\mathrm{CNC}-\mathrm{Na}$ as they are heated under $\mathrm{N}_{2}$ atmosphere. 


\section{Discussion S8: Analysis of thermogravimetric-analysis infrared (TGA-IR) spectra of CF, CNC-H, and CNC-Na}

We show the TGA-IR spectra of CF, CNC-H, and CNC-Na in Figure S60. The spectrum of CF (Figure S60A) exhibits a major emissive event in correspondence of the pyrolysis peak, and with the onset (and offset) at the same temperatures of the corresponding DTG plot. Based on the assignments in Table $\mathrm{S} 10$, it appears evident that there is a strong release of carbon dioxide (very intense $\mathrm{C}=\mathrm{O}$ stretching band and asymmetric $\mathrm{C}=\mathrm{O}$ bending band at $2350 \mathrm{~cm}^{-1}$, not included in Table $\mathrm{S} 10$ ) followed by water vapor (intense $\mathrm{O}-\mathrm{H}$ bending band). The spectrum denotes also the low release of carbon monoxide $(\mathrm{C} \equiv \mathrm{O}$ band at $2150 \mathrm{~cm}^{-1}$, not included in Table S10) and the relevant emission of methane (intense C-H stretching band), although in a less consistent manner than $\mathrm{CO}_{2}$ and $\mathrm{H}_{2} \mathrm{O} .{ }^{32}$

The spectrum recorded for CNC-H (Figure S60B) is quite complex and reflects the complexity of the TGA diagram and their thermal degradation mechanism. The pre-pyrolysis and primary pyrolysis temperature regions display a strong release of water that is not observed in the following degradation stages. In fact, at the secondary pyrolysis of CNC-H, the IR spectra of the emitted gases are dominated by bands associated with carbon dioxide and, much less intense, carbon monoxide and methane. ${ }^{33}$

Similarly to CF and CNC-H, the TGA-IR spectra of CNC-Na (Figure S60C) reflect the line shape of their DTG plots. Due to their similarity in temperature, the emissions related to primary and secondary pyrolyses are difficult to deconvolute. However, we observe a relevant emission of water, followed by carbon dioxide and a small quantity of carbon monoxide and methane.

The results obtained by TGA-IR analyses confirm those achieved using the complementary technique TGA-MS, highlighting the simultaneous emission of carbon-based and water gases in the pyrolysis of $\mathrm{CF}$, the increased dehydration of $\mathrm{CNC}-\mathrm{H}$ at low temperatures due to sulfate groups, and the localized emission of gases at higher temperatures in $\mathrm{CNC}-\mathrm{Na}$. In addition, we observed a notable methane emission when cellulose filaments are degraded. 


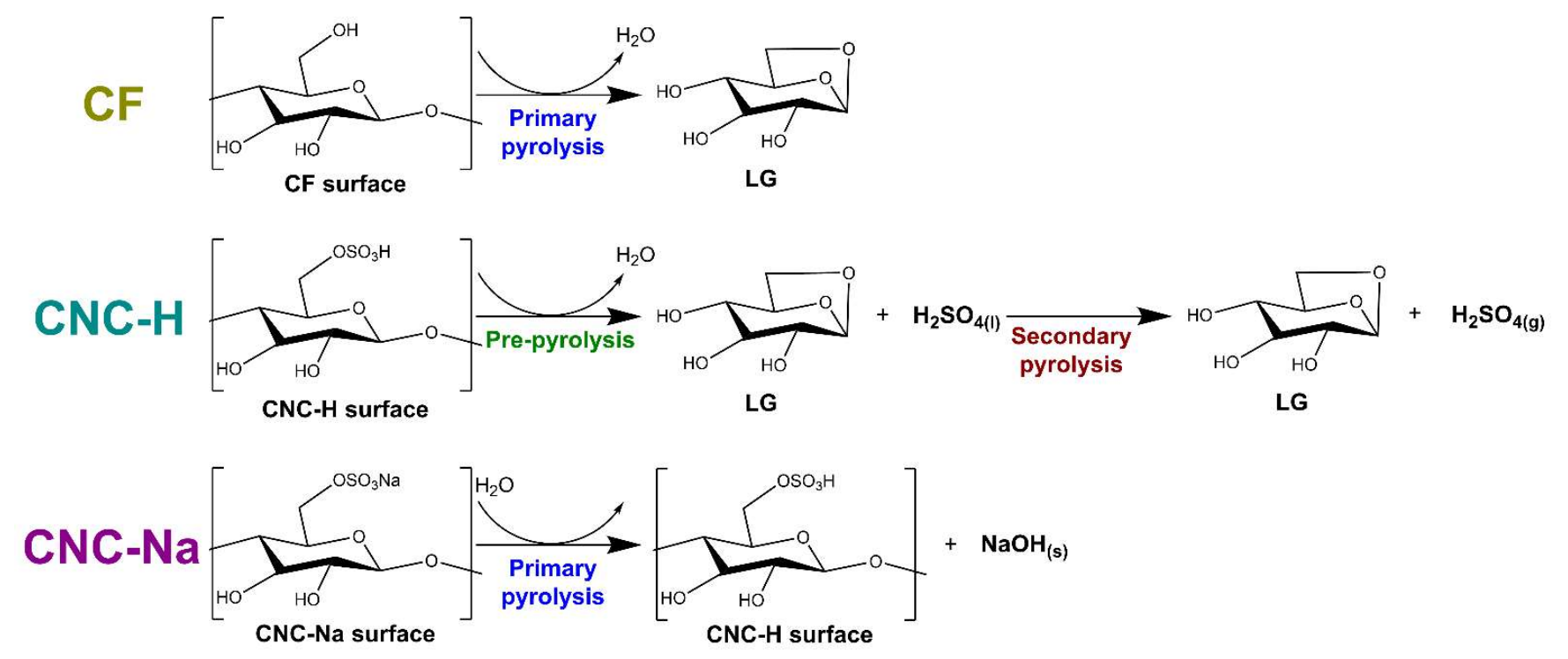

Scheme S3. Scheme of CF, CNC-H, and CNC-Na surface reactions. 
Table S11. Prevalence of the identified chemical pathways at each degradation stage, indicated by the colors used in previous figures, of CF, CNC-H, and CNC-Na under air and $\mathrm{N}_{2}$ atmospheres, based on all the characterization techniques used to identify their thermochemistry. The relevance of the reaction is expressed in grey shading, darker shading indicating increased importance of the pathway.

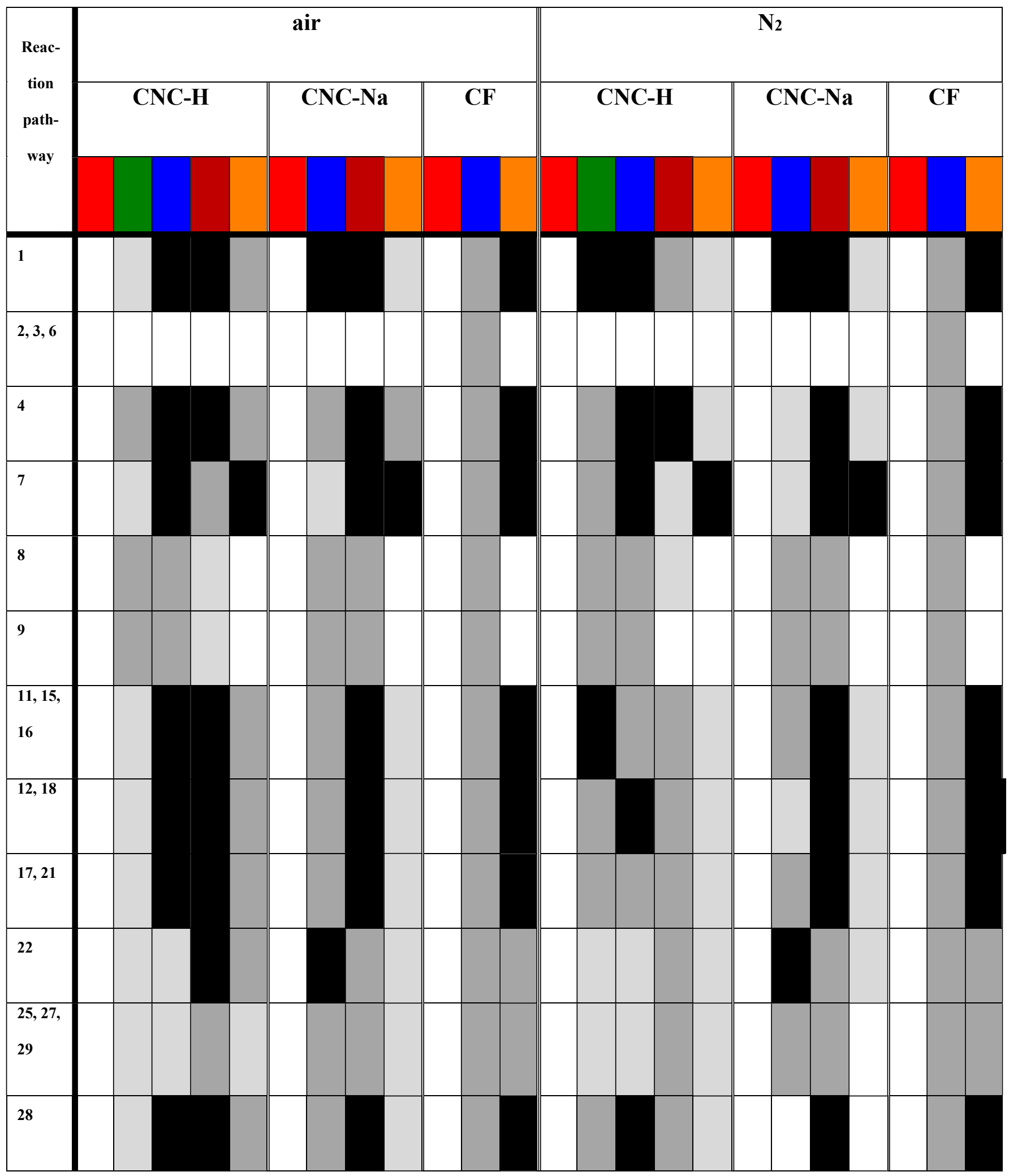




\section{References}

(1) Rowe, A.; Tajvidi, M.; Gardner, D. J. Thermal Stability of Cellulose Nanomaterials and Their Composites with Polyvinyl Alcohol (PVA). J. Therm. Anal. Calorim. 2016, 126, 1371-1386.

(2) Rietveld, H. M. Line Profiles of Neutron Powder-Diffraction Peaks for Structure Refinement. Acta Crystallogr. 1967, 22, 151-152.

(3) Rietveld, H. M. A Profile Refinement Method for Nuclear and Magnetic Structures. J. Appl. Crystal$\log$. 1969, 2, 65-71.

(4) Rodriguez-Carvajal, J. Recent Advances in Magnetic Structure Determination by Neutron Powder Diffraction. Phys. B 1993, 192, 55-69.

(5) Nishiyama, Y.; Langan, P.; Chanzy, H. Crystal Structure and Hydrogen-Bonding System in Cellulose I $\beta$ from Synchrotron X-Ray and Neutron Fiber Diffraction. J. Am. Chem. Soc. 2002, 124, 90749082.

(6) Ruland, W. X-Ray Determination of Crystallinity and Diffuse Disorder Scattering. Acta Crystallogr. 1961, 14, 1180-1185.

(7) Roman, M.; Winter, W. T. Effect of Sulfate Groups from Sulfuric Acid Hydrolysis on the Thermal Degradation Behavior of Bacterial Cellulose. Biomacromolecules 2004, 5, 1671-1677.

(8) Scheirs, J.; Carnino, G.; Tumiatti, W. Overview of Water Evolution During the Thermal Degradation of Cellulose. Eur. Polym J. 2001, 37, 933-942. 
(9) Peng, Y.; Gardner, D. J.; Han, Y.; Kiziltas, A.; Cai, Z.; Tshabalala, M. A. Influence of Drying Method on the Material Properties of Nanocellulose I: Thermostability and Crystallinity. Cellulose 2013, 20, 2379-2392.

(10) Julien, S.; Chornet, E.; Overend, R. P. Influence of Acid Pretreatment $\left(\mathrm{H}_{2} \mathrm{SO}_{4}, \mathrm{HCl}, \mathrm{HNO}_{3}\right)$ on $\mathrm{Re}-$ action Selectivity in the Vacuum Pyrolysis of Cellulose J. Anal. Appl. Pyrolysis 1993, 27, 25.

(11) Wang, N.; Ding, E.; Cheng, R. Thermal Degradation Behaviors of Spherical Cellulose Nanocrystals with Sulfate Groups. Polymer 2007, 48, 3486-3493.

(12) Shafizadeh, F.; Bradbury A. G. W. Thermal Degradation of Cellulose Under Air and Nitrogen at Low Temperatures. J. Appl. Polym. Sci. 1979, 23, 1431-1442.

(13) Varhegy; G, Antal, M. J. J.; Szekely, T; Till, F.; Jakab, E. Simultaneous Thermogravimetric-Mass Spectrometric Studies of the Thermal Decomposition of Biopolymers - Avicel Cellulose in the Presence and Absence of Catalysts. Energy Fuels 1988, 2, 267-272.

(14) Piskorz, J.; Radlein, D.; Scott, D. S.; Czernik, S. Pretreatment of Wood and Cellulose for Production of Sugars by Fast Pyrolysis. J. Anal. Appl. Pyrolysis 1989, 16, 127-142.

(15) Wielage, B.; Lampke, T.; Marx, G.; Nestler, K.; Starke, D. Thermogravimetric and Differential Scanning Calorimetric Analysis of Natural Fibres and Polypropylene. Thermochim. Acta 1999, 337, 169-177.

(16) Flynn, J. H. The Isoconversional Method for Determination of Energy of Activation at Constant Heating Rates. J. Therm. Anal. 1983, 27, 95-102.

(17) Friedman, H. L. Kinetics of Thermal Degradation of Char-Forming Plastics from Thermogravimetry - Application to a Phenolic Plastic. J. Polym. Sci. C 1963, 6, 183-195.

(18) Broido, A. A Simple, Sensitive Graphical Method of Treating Thermogravimetric Analysis Data. J. Polym. Sci. B 1969, 7, 1761-1773. 
(19) Bradbury, A. G. W.; Sakai, Y; Shafizadeh, F. A Kinetic Model for Pyrolysis of Cellulose. J. Appl. Polym. Sci. 1979, 23, 3271-3280.

(20) George, J.; Ramana, K. V.; Bawa, A. S.; Siddaramaiah. Bacterial Cellulose Nanocrystals Exhibiting High Thermal Stability and Their Polymer Nanocomposites. Int. J. Biol. Macromol. 2011, 48, 50-57.

(21) Henrique, M. A.; Flauzino Neto, W. P.; Silvério, H. A.; Martins, D. F.; Gurgel, L. V. A.; da Silva Barud, H.; de Morais, L. C.; Pasquini, D. Kinetic Study of the Thermal Decomposition of Cellulose Nanocrystals with Different Polymorphs, Cellulose I and II, Extracted from Different Sources and Using Different Types of Acids. Ind. Crops. Prod. 2015, 76, 128-140.

(22) Cho, J.; Davis, J. M.; Huber, G. W. The Intrinsic Kinetics and Heats of Reactions for Cellulose Pyrolysis and Char Formation. ChemSusChem 2010, 3, 1162-1165.

(23) Ball, R.; McIntosh, A. C.; Brindley, J. Feedback Processes in Cellulose Thermal Decomposition: Implications for Fire-Retarding Strategies and Treatments. Combust. Theor. Model 2004, 8, 281-291.

(24) Yang, H.; Yan, R.; Cehn, H.; Lee, D.H.; Zheng, C. Characteristics of Hemicellulose, Cellulose and Lignin Pyrolysis. Fuel 2007, 86, 1781-1788.

(25) Shen, D. K.; Gu, S. The Mechanism for Thermal Decomposition of Cellulose and Its Main Products. Bioresour. Technol. 2010, 100, 6496-6504.

(26) Weingarten, R.; Conner, Jr., W. C.; Huber, G. W. Production of Levulinic Acid from Cellulose by Hydrothermal Decomposition Combined with Aqueous Phase Dehydration with a Solid Acid Catalyst. Energy Environ. Sci. 2012, 5, 7559-7574.

(27) Soares, S; Ricardo, N. M. P. S.; Jones, S.; Heatley, F. High Temperature Thermal Degradation of Cellulose under air Studied Using FTIR and ${ }^{1} \mathrm{H}$ and ${ }^{13} \mathrm{C}$ Solid-State NMR. Eur. Polym. J. 2001, 37, 737745. 
(28) Lindsey, C. P.; Patterson, G. D. Detailed Comparison of the William-Watts and Cole-Davidson Functions. J. Chem. Phys. 1980, 73, 3348-3356.

(29) Lawrinenko, M.; Jing, D.; Banik, C.; Laird, D. A. Aluminum and Iron Biomass Pretreatment Impacts on Biochar Anion Exchange Capacity. Carbon 2017, 118, 422-430.

(30) Wagner, C. D.; Muilenberg, G. E. Handbook of X-Ray Photoelectron Spectroscopy: A Reference Book of Standard Data for Use in X-Ray Photoelectron Spectroscopy. Perkin-Elmer Corporation 1979.

(31) Pastorova, I.; Botto, R. E.; Arisz, P. W.; Boon, J. J. Cellulose Char Structure: A Combined Analytical Py-GC-MS, FTIR, and NMR Study. Carbohydr. Res. 1994, 262, 27-47.

(32) Yang, X.; Zhang, Y.; Li, R.; Wu, Y.; Yang, M. A Modified Kinetic Analysis Method of Cellulose Pyrolysis Based on TG-FTIR Technique. Thermochim. Acta 2018, 665, 20-27.

(33) Monika; Dhar, P., Katiyar, V. Thermal Degradation Kinetics of Polylactic Acid/Acid Fabricated Cellulose Nanocrystal Based Bionanocomposites. Int. J. Biol. Macromol. 2017, 104, 827-836. 